OECD Health Working Papers No. 59

\title{
A Comparative Analysis of Health Forecasting Methods
}

\author{
Roberto Astolfi, \\ Luca Lorenzoni, \\ Jillian Oderkirk
}


Organisation de Coopération et de Développement Économiques

Organisation for Economic Co-operation and Development

31-Oct-2012

DIRECTORATE FOR EMPLOYMENT, LABOUR AND SOCIAL AFFAIRS

English text only

HEALTH COMMITTEE

\section{Health Working Papers}

OECD Health Working Paper No. 59

A COMPARATIVE ANALYSIS OF HEALTH FORECASTING METHODS

Roberto Astolfi, Luca Lorenzoni and Jillian Oderkirk

JEL Classification: H51, I12, J11

All Health Working Papers are now available through the OECD's Internet Website at http://www.oecd.org/health/workingpapers

JT03329920

Complete document available on OLIS in its original format

This document and any map included herein are without prejudice to the status of or sovereignty over any territory, to the delimitation of international frontiers and boundaries and to the name of any territory, city or area. 


\title{
DIRECTORATE FOR EMPLOYMENT, LABOUR AND SOCIAL AFFAIRS
}

\author{
www.oecd.org/els
}

\section{OECD HEALTH WORKING PAPERS}

\section{http://www.oecd.org/health/workingpapers}

This series is designed to make available to a wider readership health studies prepared for use within the OECD. Authorship is usually collective, but principal writers are named. The papers are generally available only in their original language - English or French - with a summary in the other.

Comment on the series is welcome, and should be sent to the Directorate for Employment, Labour and Social Affairs, 2, rue André-Pascal, 75775 PARIS CEDEX 16, France.

The opinions expressed and arguments employed here are the responsibility of the author(s) and do not necessarily reflect those of the OECD.

\author{
Applications for permission to reproduce or translate \\ all or part of this material should be made to: \\ Head of Publications Service \\ OECD \\ 2, rue André-Pascal \\ 75775 Paris, CEDEX 16 \\ France \\ Copyright OECD 2012
}




\section{ACKNOWLEDGEMENTS}

The OECD would like to acknowledge the contributions of the following experts in the field of health expenditure forecasting who provided a peer review of this report:

- Dr. Louise Anderson, Research Associate, Healthpartners Research Foundation, United States

- Dr. Vincenzo Atella, Associate Professor of Economics, University of Rome, Italy

- Dr. Ravindra P. Rannan-Eliya, Executive Director and Fellow, Institute for Health Policy (IHP), Sri Lanka

- Dr. Michael Wolfson, Canada Research Chair in Population Health Modelling/Populomics, Institute of Population Health and Faculty of Medicine, University of Ottawa

The OECD would also like to thank the leaders of the health models included in this report for reviewing the summary description of their models; and members of the OECD Secretariat who reviewed the report, particularly Mark Pearson and Franco Sassi. 


\section{TABLE OF CONTENTS}

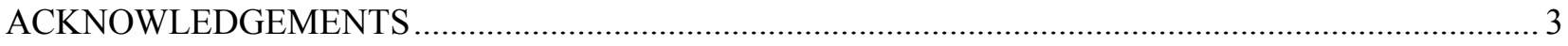

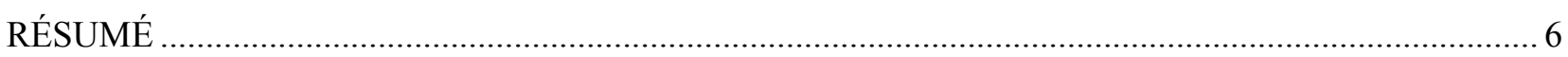

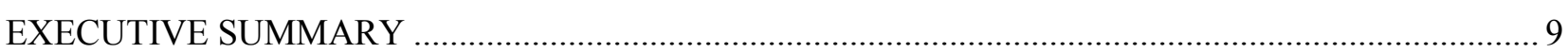

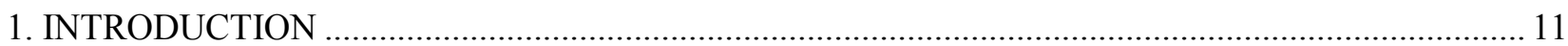

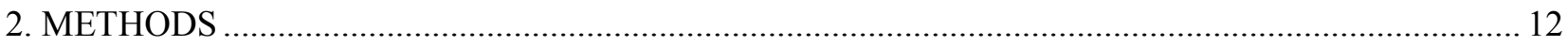

3. POLICY QUESTIONS FORECASTING MODELS HAVE HELPED TO ADDRESS ........................ 13

3.1 What may be future health expenditures if no action is taken?.................................................. 13

3.2 In which sector of the health care system are costs rising the most? ................................................ 14

3.3 What may happen if we put a brake on growth in public health expenditure? ................................. 15

3.4 What are the main drivers of rising expenditures? ...................................................................... 15

3.5 What will be the potential impact on health care expenditures if different medical technologies or innovations which experts view as being on the horizon are actually introduced?.................................. 16 3.6 Are rising health expenditures good for the economy? And, conversely, will economic forces ever

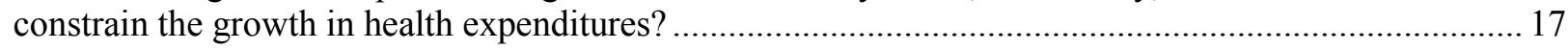

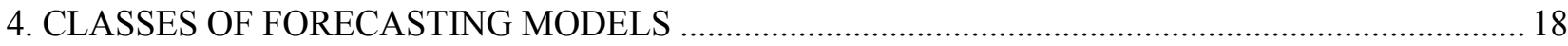

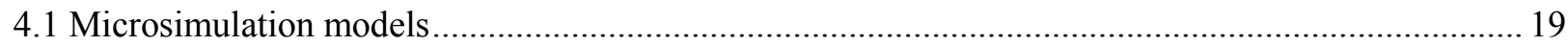

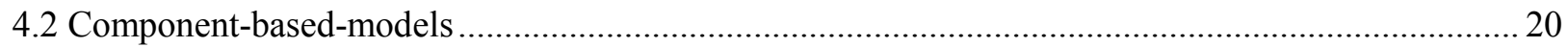

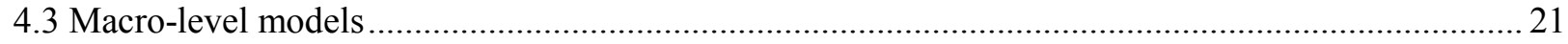

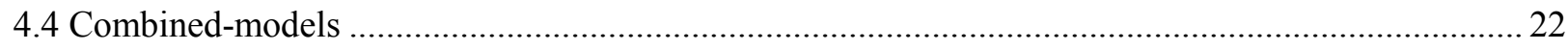

5. PROJECTED VARIABLES AND MEASUREMENT UNITS ..............................................................2 24

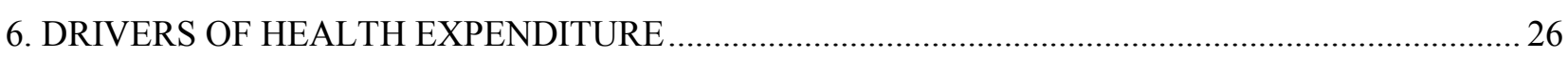

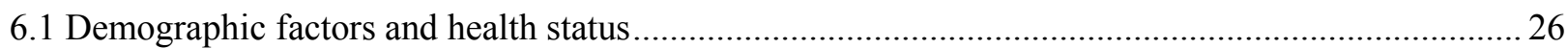

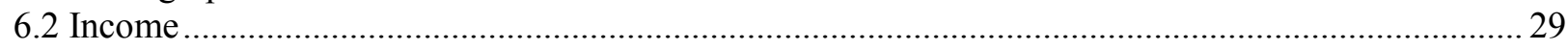

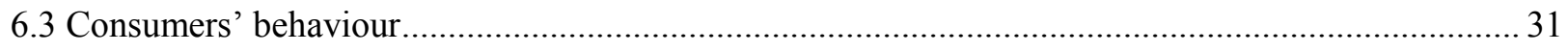

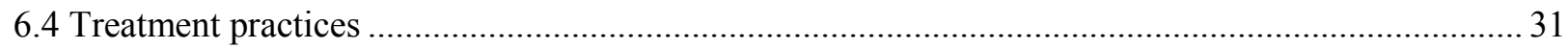

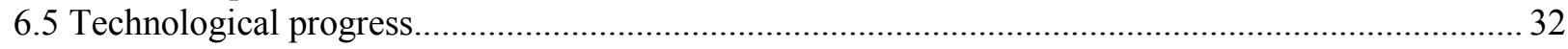

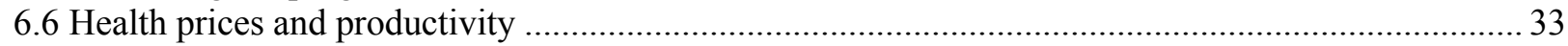

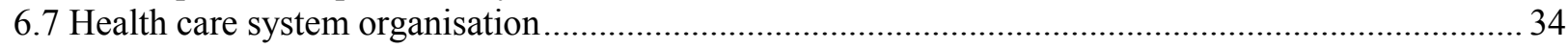

7. CRITERIA TO ASSESS THE PERFORMANCE OF FORECASTING METHODS.............................. 36

7.1 Techniques to assess the influence of assumptions on the outcome of forecasting models................ 37

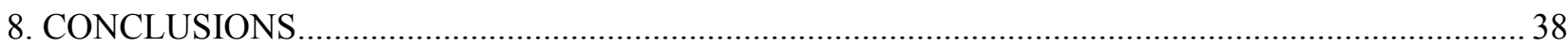

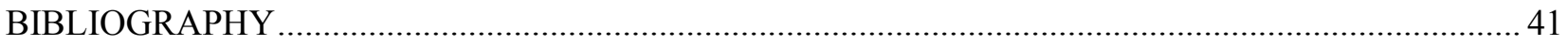

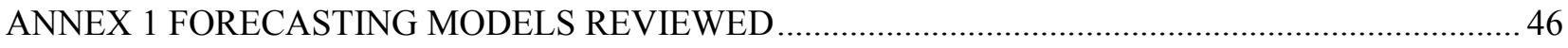

Annex 1.1 Australia - Australian Institute for Health and Welfare (AIHW) ........................................ 46 Annex 1.2 Australia - National Centre for Social and Economic Modelling (NATSEM) Micro-Macro. 48 
Annex 1.3 Australia - Australian Government Productivity Commission ............................................ 52

Annex 1.4 Australia - Australian Government, The Treasury.............................................................. 54

Annex 1.5 Canada - Canadian Institute for Health Information (CIHI) .................................................. 56

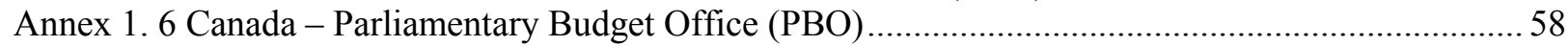

Annex 1.7 Canada - Statistics Canada/Population Health Model (POHEM) .......................................... 61

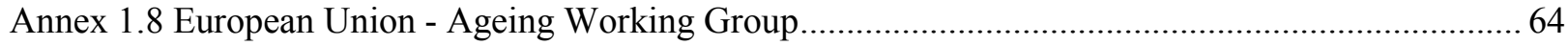

Annex 1.9 France - Direction de la recherché, de l'évaluation et des etudes statistiques (DRESS) ......... 67

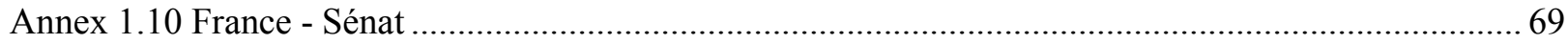

Annex 1.11 Italy - Ministry of Health/Università di Roma Tor Vergata ................................................ 73

Annex 1.12 Italy - Ragioneria Generale dello Stato ............................................................................. 75

Annex 1.13 Netherlands - Bureau for Economic Policy Analysis (CPB) …….................................... 78

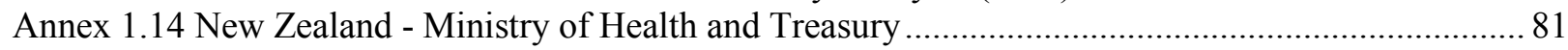

Annex 1.15 OECD - Directorate for Social Affairs, Manpower and Education ....................................... 83

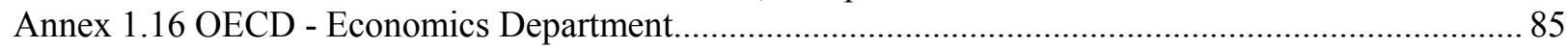

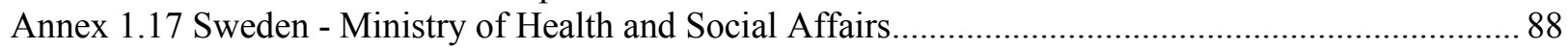

Annex 1.18 UK - HM Treasury/Office for Budgetary Responsibility (OBR) ....................................... 92

Annex 1.19 UK - National Heart Forum Microsimulation Model (Foresight).......................................96

Annex 1.20 USA - Centers for Medicare \& Medicaid Services (Component)......................................... 98

Annex 1.21 USA - Centers for Medicare \& Medicaid Services (GE) ................................................... 101

Annex 1.22 USA - Congressional Budget Office (CBOLT) ........................................................ 104

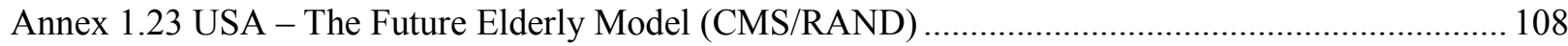

Annex 1.24 USA - U.S. Department of Veterans Affairs.................................................................. 112

Annex 1.25 USA - Comprehensive Assessment of Reform Efforts (COMPARE)

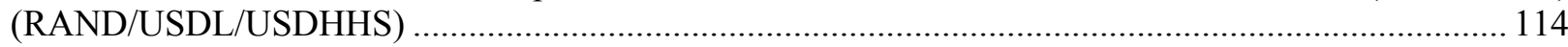

\section{Tables}

Table 1. Health expenditure forecasting models reviewed................................................................... 23

Table 2 Impact of Selected Medical Technologies on Spending and Life Years in the United States ..... 33

\section{Figures}

Figure 1: Forecasts of public health expenditure growth if no action is taken...................................... 14

Figure 2 Total Australian government health expenditure with and without non-demographic growth (in

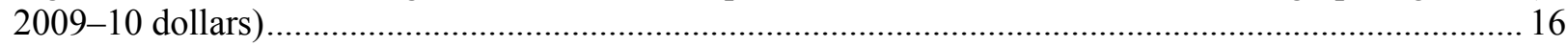

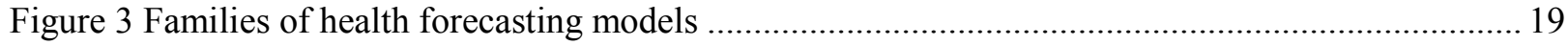

Figure 4 Relationship between life expectancy and morbidity .........................................................2 27

Figure 5 Projected growth in health and elderly care expenditures as a share of GDP in Sweden under

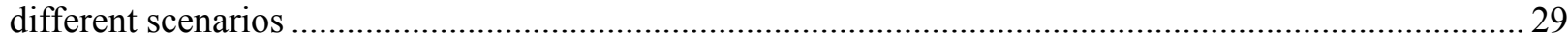

Figure 6 CBO Projected Health Expenditure under the Excess Cost Growth Assumption ...................... 31

Figure 7 Intensity of care may be the most important driver of projected growth in health expenditures in

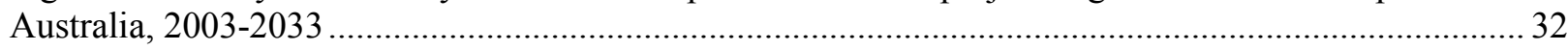

Figure 8 Utilisation and excess health prices account for a large share of projected growth for the United

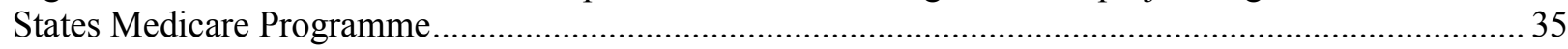

Figure 9 AIHW Projections of health and residential aged care expenditure under different scenarios, 2002-03 to 2032-33, (\$ billion in 2006-07 dollars). 


\section{RÉSUMÉ}

1. Les préoccupations concernant la croissance des dépenses de santé et leur soutenabilité à long terme ont suscité le développement de modèles de prévision des dépenses de santé dans de nombreux pays de l'OCDE. La présente étude comparative porte sur 25 modèles qui ont été élaborés ou utilisés par des pays membres de l'OCDE ou par d'autres organisations internationales pour l'analyse des politiques.

2. L'intérêt des prévisions à court terme réside dans leur exactitude prédictive parce que, comme en météorologie, elles sont destinées à prédire des événements auxquels il y a peu de moyens de changer quelque chose. Les projections à moyen ou long terme, quant à elles, doivent être appréciées pour l'aide qu'elles sont susceptibles d'apporter à la planification des politiques et à la prise de décision. Ces modèles montrent dans quelle direction une société peut se diriger si les tendances se maintiennent et ils donnent aux responsables publics une possibilité d'agir pour modifier le cours des événements. En conséquence, il ne faut pas juger les modèles destinés à assister l'action gouvernementale à l'aune de l'exactitude de leurs projections.

3. Les questions qui se posent aux autorités publiques doivent orienter le choix du modèle de prévision et la spécification de ce modèle. Les limitations des données et autres éléments disponibles influeront aussi sur la mise au point du modèle et souvent il faudra trouver un compromis entre l'idéal et le possible.

4. Les modèles de prévision peuvent viser à répondre à diverses questions : estimer la croissance des dépenses dans le cadre d'action présent; identifier les secteurs où les dépenses augmentent le plus ; tester l'impact d'un freinage de la croissance des dépenses publiques; déterminer les facteurs de la croissance des dépenses; tester des scénarios sur les changements de politique possibles; ou encore examiner l'impact de la croissance des dépenses sur le reste de l'économie.

5. On distingue trois grandes catégories de modèles de prévision pour les dépenses de santé.

6. Les modèles micro simulent des populations entières et offrent la faculté de tester un ensemble de scénarios de simulation de politiques concernant la prévention, le traitement ou l'organisation et le financement des soins et d'examiner les résultats de la prévision suivant différentes caractéristiques incluses dans le modèle, telles que les maladies, les catégories d'âge, les fournisseurs de soins ou les traitements.

7. Les modèles à composantes prévoient les dépenses de santé selon différentes composantes telles que les agents de financement ou les fournisseurs de soins. Les modèles à cohortes ou actuariels, où les prévisions sont habituellement estimées par catégorie d'âge, font partie de cette famille.

8. Les modèles macro s'attachent à prévoir les dépenses totales de santé, avec une analyse des séries chronologiques et des coupes transversales d'indicateurs agrégés. Cette catégorie de modèles comprend aussi les modèles d'équilibre général calculable (EGC) qui tentent de relier la croissance des dépenses de santé à leur impact sur l'ensemble de l'économie et de tenir compte des réactions des consommateurs et des producteurs à la hausse des dépenses de santé et aux changements des prix relatifs. 
9. Les modèles à composantes constituent la catégorie dominante, avec plus de la moitié des modèles de prévision considérés dans la présente étude. Une des raisons de leur prolifération est l'attention portée aux facteurs démographiques de la croissance des dépenses de santé. Les modèles à composantes sont aussi moins exigeants en données et moins complexes que les modèles de micro-simulation. Les modèles de micro-simulation, quant à eux, sont plus aptes à répondre à une plus grande variété de questions difficiles pour l'action gouvernementale. Les modèles macro sont les moins exigeants du point de vue des données requises et ils peuvent être assez faciles à mettre en œuvre. Toutefois, ils conviennent le mieux aux projections à court terme étant donné qu'ils s'appuient sur des tendances claires et stables. Les modèles d'équilibre général calculable (EGC) constituent une catégorie particulière de modèles macro. Ces modèles sont complexes et nécessitent des hypothèses fortes sur le comportement des personnes, des entreprises et des gouvernements.

10. Les modèles tentent d'estimer l'impact relatif de facteurs potentiels sur la croissance des dépenses de santé. Pratiquement tous les modèles tiennent compte des évolutions démographiques de la population et certains considèrent en particulier des scénarios concernant l'état de santé potentiel des personnes âgées à l'avenir. Toutefois, les modèles considérés ici désignent l'innovation dans les soins comme le facteur le plus important de la croissance des dépenses de santé. L'innovation peut consister en des technologies et traitements médicaux nouveaux, de nouvelles utilisations de technologies anciennes, des changements dans l'intensité des traitements, de nouveaux modes de délivrance des services ou de nouveaux modes de financement. L'innovation peut influer sur l'intensité des soins dispensés aux patients, ainsi que sur les prix des soins de santé.

11. L'innovation technologique et le rôle des changements du comportement de recherche de santé et des normes sociétales sous-jacentes concernant la santé et la maladie sont deux éléments importants qui influent sur la croissance des dépenses de santé mais qui sont parmi les moins bien compris. Sur ces facteurs il existe peu de résultats empiriques qui pourraient servir de base au développement des modèles.

12. Pour inspirer les décisions gouvernementales, les modèles de prévision doivent être crédibles. Les hypothèses sous-jacentes aux différents modèles ont souvent une forte influence sur les résultats. La transparence des méthodes et des hypothèses est une condition nécessaire pour la qualité des modèles, comme l'est aussi une stratégie de validation des résultats.

13. Il faut aussi prêter attention à l'impact des hypothèses quand on commence à spécifier les modèles. L'hypothèse suivant laquelle les taux de croissance des dépenses de santé seront toujours supérieurs à la croissance du PIB produit des prévisions où les dépenses de santé consomment finalement 100 pour cent du PIB. Cette hypothèse n'est sans doute pas contraignante pour une prévision à court terme mais elle est très restrictive pour une prévision à long terme. D'autres possibilités consistent à inclure une contrainte sur la croissance des dépenses ou à utiliser une autre approche de modélisation. L'idée que les projections de la croissance de la population et du vieillissement peuvent être un indicateur approché de la santé future des populations implique une hypothèse très négative et improbable sur l'état de santé des futures personnes âgées. Cela implique en effet que tous les gains d'espérance de vie représentent des années supplémentaires vécues en mauvaise santé. Il existe d'autres approches de modélisation qui permettent de tester des hypothèses différentes sur la santé des futures personnes âgées, ou bien qui prédisent directement l'état de santé futur de la population. L'hypothèse suivant laquelle l'inflation générale peut servir d'indicateur pour la hausse des prix de la santé ignore les preuves empiriques que les prix de la santé augmentent plus vite que l'inflation générale. D'autres possibilités consistent à utiliser un indice des prix de la santé ou à corriger un indice général des prix du supplément d'inflation du secteur de la santé, comme on le voit dans certains travaux publiés.

14. Les progrès de l'informatique et des données de santé détaillées ouvrent de nouvelles possibilités pour la création de précieux outils d'aide à la décision. L'examen réalisé dans le présent document met en 
lumière l'apparition de systèmes de modèles où différentes approches de modélisation sont conçues pour interfonctionner de manière cohérente. On amalgame ainsi des techniques présentant des avantages différents, ce qui permet d'explorer un plus large éventail de questions pour l'action gouvernementale. On peut mentionner, par exemple, le système de modèles mis au point par le Congressional Budget Office des États-Unis et celui de l’Université de Canberra et de l'Université Monash en Australie.

15. Le paysage des modèles de prévision en santé est dynamique et évolutif. Par la voie de l'OCDE, les pays ont la possibilité d'exploiter les enseignements tirés de la comparaison de leurs méthodes de prévision pour élaborer et mettre en œuvre une plate-forme d'aide à la décision internationale. Celle-ci présenterait les avantages suivants: comparabilité internationale des prévisions de dépenses, par la standardisation de la structure des modèles, des hypothèses et des données ; possibilité de tester et de comparer les résultats potentiels des réformes; et la capacité d'aborder les questions qui commencent à se poser au niveau mondial concernant les mouvements internationaux de patients, de personnel, de services et de capitaux. 


\section{EXECUTIVE SUMMARY}

16. Concerns about health expenditure growth and its long-term sustainability have stimulated the development of health expenditure forecasting models in many OECD countries. This comparative analysis reviewed 25 models that were developed by, or used for, policy analysis by OECD member countries and other international organisations.

17. Short-term forecasts may be valued for their predictive accuracy because, similar to a weather forecast, they aim to predict events where there is little action that may be taken to change the outcome. Medium-to-long term projections, on the other hand, should be valued for their ability to support policyplanning and decision-making. Such models identify where a society may be heading if future trends continue and give policy makers an opportunity to act to modify the course of events. As a result, policysupport models should not be judged against the benchmark of making accurate future projections.

18. The policy questions that need to be addressed should drive the choice of forecasting model and the model's specification. Limitations in available data and evidence will also have a bearing on model development and often compromises will be stuck between what is 'ideal' and what is 'feasible'.

19. Policy questions addressed by forecasting models range from estimating the growth in expenditures in the current policy setting; to identifying the sectors where expenditures are rising the most; to testing the impact of slowing growth in public expenditures; to understanding what factors are driving expenditure growth; to testing scenarios about potential policy changes; and to examining the impact of expenditure growth on the rest of the economy.

20. There are three main classes of forecasting models for health spending.

21. Micro models simulate entire populations and offer flexibility to test a range of "what if" policy scenarios related to prevention, treatment and the organisation and financing of care; and to examine forecasted results by different characteristics included in the model, such as by diseases, age-groups, providers or treatments.

22. Component-based models forecast health expenditure by component, such as by financing agents or providers of care. Within this family are cohort or actuarial models, where forecasts are usually estimated by age group.

23. Macro models focus on forecasting total health expenditure and include analysis of time-series and cross-sections of aggregate indicators. This class of models also includes computable general equilibrium models (CGE) which attempt to connect health expenditure growth to its impact on the overall economy and to account for reactions from consumers and industry to rising health expenditures and changing relative prices.

24. Component-based models are the dominant class, accounting for more than half of all forecasting models surveyed in this study. One reason for their proliferation is a focus on demographic drivers of health expenditure growth. Component-based models are also less data intensive and less complex than microsimulation models. Microsimulation models, on the other hand, are more capable of answering a greater variety of challenging policy questions. Macro models are the least demanding in terms of data 
requirements and can be fairly straightforward to implement. They are most appropriate for short-term projections, however, as they depend on clear and undisturbed trends. A special category of macro models are computable general equilibrium models or CGE. These models are complex and require strong assumptions about the behaviour of individuals, firms and governments.

25. Models attempt to estimate the relative impact on health expenditure growth of potential drivers. Virtually all models account for demographic shifts in the population and some focus specifically on scenarios about the potential future health status of older people. The models reviewed here, however, point to innovation in health care as the more important driver of health expenditure growth. Innovation can include new medical technologies and treatments, new uses of old technologies, changes in the intensity of treatments, new modes of service delivery and new financing alternatives. Innovation can influence the intensity of care provided to patients, as well as health care prices.

26. Two important influences on health expenditure growth that are the least understood include technological innovation and the role played by changes in health-seeking behaviour and underlying societal norms about health and illness. There is little empirical evidence on these factors upon which models may be developed.

27. To influence policy decisions, forecasting models must be credible. The assumptions underlying different models often have a strong influence on results. Transparency of methods and assumptions is a prerequisite for model quality, as is a strategy to validate results.

28. The impact of assumptions should also be considered when models are first specified. The assumption that health expenditure growth rates will always exceed growth in the GDP produces forecasts where 100 percent of GDP is eventually consumed by health expenditure. This assumption may not be strong for a short-term forecast but it is very strong for a long-term forecast. Alternatives include the introduction of a constraint on expenditure growth or the use of an alternative modelling approach. The assumption that projections of population growth and aging can proxy the future health of populations makes a very negative and unlikely assumption about the health status of the future elderly. This is because it implies that all gains in life expectancy result in increased years lived in ill-health. Alternatives include modelling approaches that allow the testing of alternative assumptions about the health of the future elderly or that directly forecast the future health status of the population. The assumption that general inflation is a proxy for health price inflation ignores empirical evidence of health prices rising faster than overall inflation. Alternatives include using a health price index or adjusting a general price index for excess health-price inflation as reported in the literature.

29. Advances in computing and in detailed health data are opening up new possibilities for the generation of helpful decision-support tools. The review of models in this paper highlights emerging systems of models where different modelling approaches are designed to work together coherently. In this way, techniques with different strengths are amalgamated and a broader range of policy questions may be explored. Examples include the system of models developed by the U.S. Congressional Budget Office and by the University of Canberra and Monash University in Australia.

30. The landscape for health forecasting models is dynamic and evolving. Through the OECD, there is an opportunity for countries to benefit from the lessons learned from comparing forecasting methods across countries to develop and implement an international decision-support platform. Advantages include international comparability of expenditure forecast, through the standardisation of model structure, assumptions, and data; the ability to test and compare the potential results of policy reforms; and the ability to address emerging global issues related to international movement of patients, personnel, services and capital. 


\section{INTRODUCTION}

31. Concerns about health care expenditure growth and its long-term sustainability have risen to the top of the policy agenda in many OECD countries. As continued growth in spending places pressure on government budgets ${ }^{1}$, health services provision and patients' personal finances, policy makers in OECD countries have launched forecasting projects to support policy planning.

32. This study presents a comparative analysis of health expenditure forecasting methods through examination of leading methods that have been used by health policy makers. Methods reviewed were selected on the basis of demonstrated institutional or governmental participation in the model development and/or policy applications of the model.

33. The study aims to identify good practices in the development of health-spending forecasting models that can be shared among OECD countries. In so doing, it has the potential to enhance transparency and support improvement in future health expenditure modelling exercises.

34. Section two of this paper describes the criteria for model selection and evaluation, and the review process. Section three discusses the policy questions that have been explored with forecasting models and provides an overview of some of the answers. More specific information on the classes of forecasting methods available to address these policy questions and their relative strengths and weaknesses is provided in Section four. Section five reviews the projected variables, and the time horizon of projections. The drivers of health spending growth that have been included in forecasting models and the assumptions associated with these drivers are discussed in Section six. This is followed by a discussion in Section seven of the criteria to assess the performance of forecasting methods. The conclusions point to next steps in the development of decision-support forecasting tools.

1 The public sector is the main source of health financing in the OECD, accounting for $72 \%$ of health expenditure consistently over the past twenty years. So the burden of health expenditure growth is largely born by tax payers (OECD, 2011). 


\section{METHODS}

35. A search for health expenditure forecasting models developed in OECD member states was carried out using a selection of search engines and including accredited academic journals and grey literature. Results were then restricted to models where the methodology was described in one of the two official OECD languages, English or French. Health expenditure forecasting methods were then selected on the basis of demonstrated institutional or governmental participation in the model development and/or policy applications of the model, guided by the OECD Health Committee. Twenty-five models were selected for inclusion in the study.

36. Two-page summaries of each model were prepared following a standard format and were provided for review to the main authors of each of the models to ensure a fair and accurate portrayal of their work. Telephone conference calls with model developers were conducted, as required. Model summaries and conclusions drawn from the work were presented in an overview report that was guided by a team of international model development experts. The preliminary report was then presented and discussed with country delegates at the OECD Health Committee meeting in December 2011. 


\section{POLICY QUESTIONS FORECASTING MODELS HAVE HELPED TO ADDRESS}

37. The choice of forecasting model to be developed, including the parameters and the time horizon of the projection, should be guided by the policy questions to be addressed. Of course, the availability of empirical evidence may place constraints on model development and compromises between an "ideal" and a "feasible" approach are often necessary. This section highlights policy questions that have been addressed by forecasting models included in this review and summarizes some of the answers that have been provided.

38. Short-term forecasting models help with immediate budgeting and fiscal planning decisions. Similar to a weather forecast, their value is in their predictive accuracy. The weather in the next day or two cannot be changed, but you can react to it. Similarly, there is little room for policy intervention to change health expenditures in the very near term. An example of this approach is the "nowcast" projections of the Canadian Institute for Health Information (Ballinger, 2006).

39. Medium to long-term forecasting models, on the other hand, identify where a society may be heading in the future, if current trends continue, and give policy makers an opportunity to act to modify the course of events. Many of these forecasting models clarify factors that are driving health expenditures, and thus make clearer the potential policy options available. They also provide a more complete picture, so that the benefits of health spending in terms of health and well-being, labour supply and economic growth are not overlooked. Some offer the opportunity to test "what if scenarios" to see how the future course of events may be altered through the introduction of new policies, new programmes and new innovations in treatment, financing and organisation of care.

40. In essence, they are like a map for policy development. A good map will tell you how to get from point $\mathrm{A}$ to point $\mathrm{B}$, including the different routes you might take and which would be the most efficient. Should you not wish to go to point B, it will also show you alternative pathways so that you can change course to a different future destination. Still, a map is an abstraction of reality and cannot include all eventualities, like road construction, traffic jams or a storm. Similarly, medium to long-term forecasting models are useful but certainly imperfect abstractions of reality that point the way to a set of possible alternative future outcomes. The value of forecasting models does not lie in their ability to "predict" the future - a task that no medium-to-long term model could realistically accomplish. Indeed if models based on current trends accurately predicted the future, it could signal a lack of innovation or policy development. As a recent report from the Swedish Ministry of Health and Social Affairs states, "Effective forecasts change the future, which means that they prove - and have to prove - wrong" (Ministry of Health and Social Affairs, 2010).

41. The most basic question inspiring forecasting models is simply:

\subsection{What may be future health expenditures if no action is taken?}

42. As an example, the Congressional Budget Office of the United States generates 75-year projections of expenditure on federal programmes, such as Medicare and Medicaid, and total health expenditures to support long-term fiscal planning decisions. CBO projected that without significant changes in law or policy, spending on health care in the United States could reach over 31 percent of GDP by 2035 and could increase further to 49 percent by 2082 (Congressional Budget Office, 2008). Using a 
similar approach, the Canadian Parliamentary Budget Office has projected that provincial-territorial governmental spending on health may reach 9.5 percent of GDP by 2035, with the federal governmental expenditure also rising, but at various degrees depending on policy decisions (Askari et al., 2010).

43. Figure 1 presents public expenditure growth forecasts from models in five countries if no policy action is taken. Results are not necessary comparable, however, as the model classes, structures and specifications are not the same. Further, modelling teams often present several different forecasts in their publications, and this figure presents only one baseline forecast from each model. Results are illustrative, however, of the range of expenditure growth forecasts available among OECD countries.

44. A final example is the forecast of health expenditures among EU member states prepared by the European Commission. Assuming no changes in laws or policies, the EU average health expenditure as a share of GDP is estimated to rise from $6.7 \%$ in 2007 to $8.2 \%$ in 2060 . Across countries, increases range from less than 1\% of GDP to more than 3\% (European Commission, 2009).

Figure 1: Forecasts of public health expenditure growth if no action is taken

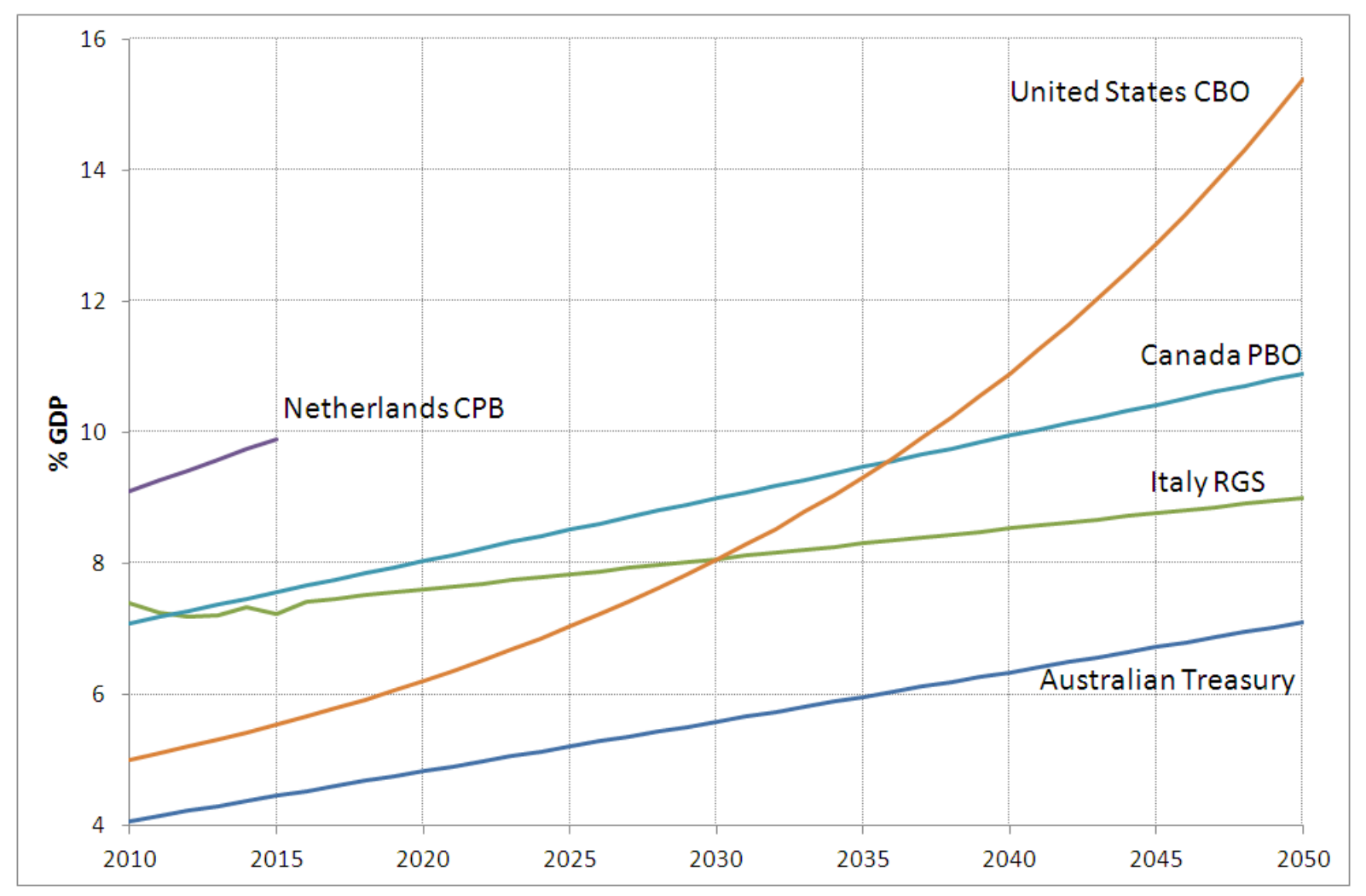

N.B. Model classes, structures and specifications vary and results are not comparable. USA refers to Medicare and Medicaid only.

Sources: Congressional Budget Office, 2008; Besseling, P. et al., 2010; Askari M. et al., 2010; Ministry of Economy and Finance, 2011; Goss, J., 2008

45. A related question then becomes:

\subsection{In which sector of the health care system are costs rising the most?}

46. Whether the interest is in understanding differences in the growth of private and public expenditures; growth among various levels of government; different types of health care providers; 
different types of health care services; or by sources of funding; there are many models which will provide the desired breakdown. For example, the Centres for Medicare and Medicaid Services in the United States have forecast that total health expenditures may reach just under 20 percent of GDP by 2020 . While the largest shares of future health expenditures will continue to go to hospitals and physicians, smaller but faster rising components of health expenditure include government administration, retail sales of prescription medicines, investment in research and development, and private health insurance: all of which may double or more from 2009 amounts (CMS-OACT, 2010).

47. In the context of increases in health expenditures that place undue pressure on public finances, models have addressed a number of key questions, including:

\subsection{What may happen if we put a brake on growth in public health expenditure?}

48. The extent to which health care expenditures are financed by the state is a policy decision and some forecasting models explicitly consider scenarios related to the public/private cost split. For example, the Netherlands Bureau for Economic Policy Analysis forecast public health expenditures to reach 10\% of GDP by 2015 with no policy action. An alternative scenario held public expenditures to match the expected increase in GDP, plus additional costs associated with population aging. Any increase above that level would then be financed by co-payments. Under this scenario, the share of health care funded by copayment would increase from 5\% in 2010 to 30\% in 2015 and public health expenditure would rise a bit more slowly, to exceed 9.5\% of GDP in 2015 (Besseling et al., 2011).

49. In order to see where a brake on spending could be applied, forecasting models attempt to uncover the factors driving the increases.

\subsection{What are the main drivers of rising expenditures?}

50. Virtually all models take into consideration demographic shifts in the population, which is likely the result of assumptions about the impact of population aging on health spending and the availability of credible demographic projections. However, other influences on the upward trend in health expenditures have also been identified, including the introduction of new health technologies; increases in the intensity of treatments provided to patients; inflation in health-care specific prices including labour costs; overall growth in national income (as rising wealth enables health spending); changes in the organisation and delivery of care; the productivity of the health system; trends in key diseases and their treatment costs; and changes in health-seeking behaviours.

51. The Australian Government Treasury forecasted total health expenditure to rise from 2009-10 to 2049-50 (Figure 2). Approximately 60\% of this growth was estimated to be due to the influence of nondemographic factors. These included increasing intensity of treatments through the growing use of physician services, medical tests and pharmaceutical medications; and the introduction of new technologies including new drug therapies. There may also be interactions between an aging population and nondemographic influences on expenditure growth; such as, changing community expectations for levels of care and incentives for further investment in research and development of health-care technologies.

52. Forecasts of the Australian Institute of Health and Welfare point to the importance of an increasing intensity of treatments provided to patients as a leading driver of health expenditure growth (Goss, 2008). Intensity of treatments is influenced by new technologies, changes in use of technologies and delivery of care, and changing views about treatments provided to older patients. Of concern is the linkage between treatment intensification and improvements in health status or "value for money".

53. Forecasts of the Ministry of Social Affairs in Sweden point to a stronger impact on expenditure forecasts of new technologies and treatment practices, compared with the impact of even the most 
pessimistic assumptions about the health status of future populations (Ministry of Health and Social Affairs, 2010).

Figure 2 Total Australian government health expenditure with and without non-demographic growth (in 200910 dollars)

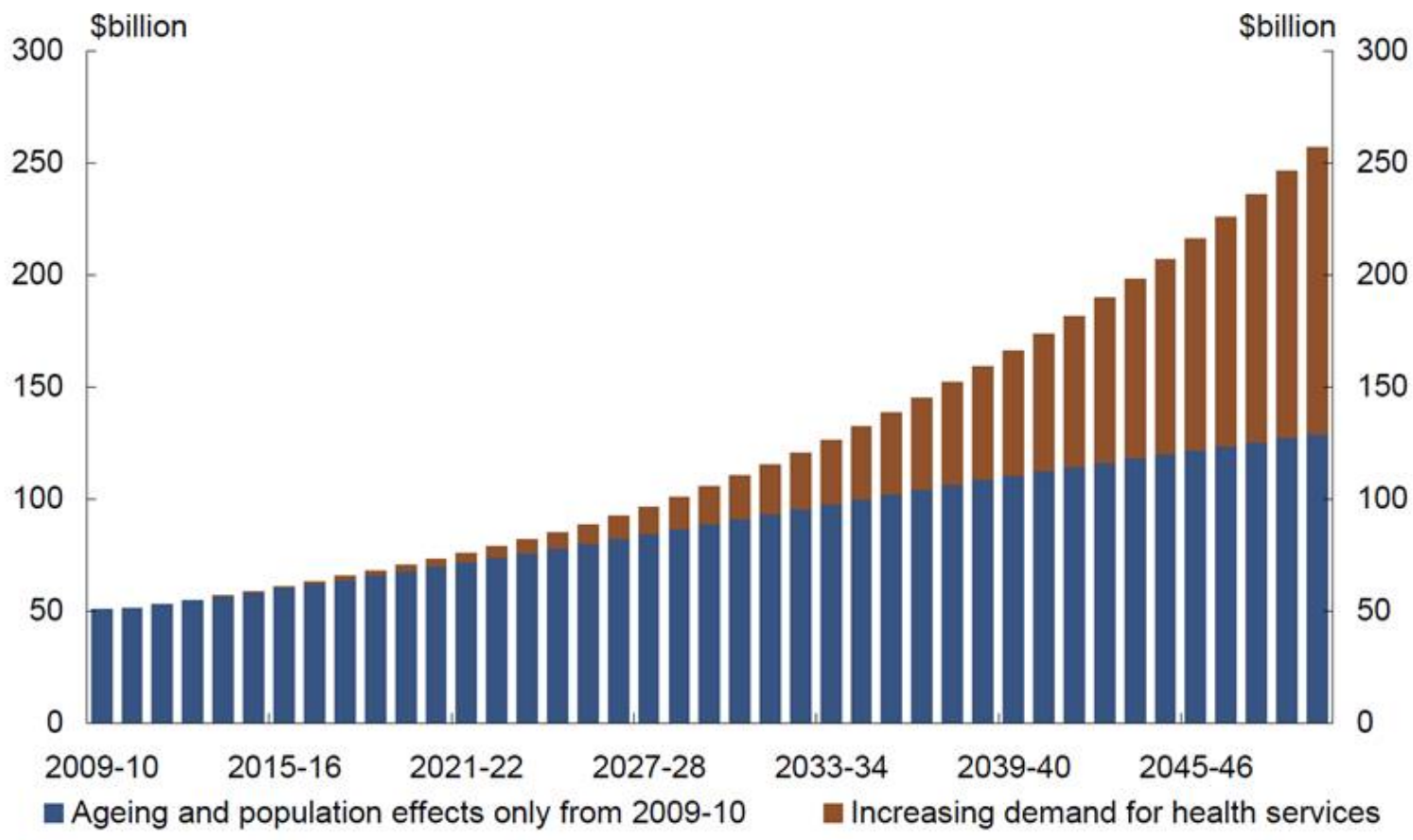

Source: Australian Treasury, 2010

54. A follow-up question then becomes:

3.5 What will be the potential impact on health care expenditures if different medical technologies or innovations which experts view as being on the horizon are actually introduced?

55. Forecasts from the Australian Productivity Commission indicate that while some advancements may have cost savings, on the whole, technological progress in health care is likely to be cost-increasing. This is due to the high cost of research and development, the expansion of treatment possibilities and more on-going treatment (Banks, 2008). The cost impacts of new technologies across four leading disease types (diabetes, cardio-vascular, cancer and neurological) were forecast to increase expenditure over existing treatments because treated prevalence and unit costs would likely rise, more than offsetting any cost savings elsewhere in the health system (Productivity Commission, 2005).

56. The RAND Corporation in the United States developed a forecasting model that simulated the population of the United States at the level of individual people. RAND examined 10 technologies (drugs, devices and vaccines) that a consensus panel of experts deemed to be the most likely to become widely adopted. Assuming the full adoption of these technologies back in 2002, by 2030, some new technologies were simulated to have a large impact on health expenditures. Effective new technologies, even those that are inexpensive on their own (such as cancer vaccines), tend to increase health spending. This is particularly true when a large share of the population will be treated. Treated people will go on to live longer, and thus incur further costs related to new health-care needs (Goldman, 2005). Other technologies are expensive and do not yield strong improvements in population health. 
57. Given the upward pressure on health expenditures related to the intensity of treatment, including the influence of the introduction and use of medical technologies, further questions arise:

\subsection{Are rising health expenditures good for the economy? And, conversely, will economic forces ever constrain the growth in health expenditures?}

58. Researchers from the Office of the Actuary, Centers for Medicare and Medicaid Services in the United States, estimated the opportunity cost of higher levels of medical spending, taking into consideration the introduction of new medical treatments (Borger et al., 2008). This approach models the future demand for, and supply of, medical care including consumer preferences. In this framework, a point is reached where the marginal utility of consuming additional health services drops below that derived from consuming other goods and services as spending on health increases. At that point, consumer preferences shift to limit the degree to which new technologies are adopted. Cost pressure can also affect the health technology industry, pushing innovation to favour new less-expensive therapies. Forecasts of health expenditure growth as a share of GDP range widely under different assumptions about how sensitive consumers may be to rising medical care prices. Nonetheless, forecasts from this model point to a slowdown in expenditure growth in the future. This model can be further extended to directly study the impact of health expenditure growth on economic growth (Borger et al., 2008).

59. Researchers from the University of Canberra and Monash University were the first to create a framework where detailed forecasts of the health status of the population and resulting health expenditures were combined with models of the economy. Through this approach, they estimated the economic impact of a diabetes prevention programme from its introduction in 2005-08 to 2023-26. Forecasting the financial impact of the programme resulted in an overall increase in health expenditures. The initial impact of the programme on the economy is a drop in GDP, as consumption is affected by the tax imposed on the population to finance the programme. Over time, however, real consumption and investment and GDP are all projected to grow more than they would have done if the programme was not introduced, resulting in a net benefit to the country (Brown et al., 2009). 


\section{CLASSES OF FORECASTING MODELS}

60. Our review has identified distinct classes of health care expenditure forecasting models, with each class best suited to address specific policy questions. For instance, if the policymakers need a shortto-medium term expenditure forecast, models accounting for the influence of key demographic variables may be appropriate. But, if the policy question to be addressed is a longer-term strategic issue, where there is a strong need to understand interactions among individuals; to assess dynamic risks; or to evaluate the epidemiological transition of a population; in this case, microsimulation may be a preferred method (Anderson et al. 2007). Finally, if the policy question refers to the impact of health expenditure in a very short run (e.g. up to two years), then macro-level models would probably be the first choice. The remainder of this section presents the main features of each class of health forecasting models.

61. Forecasting models typically project health expenditure at the level of individuals, groups of individuals or the community as a whole (Hollenbeck, 1995). At the same time, models can focus on specific sections of health expenditure, such as public expenditure, social security, private insurance, or household out-of-pocket payments. By considering both the level of aggregation of the units analysed and the level of detail of health expenditure to be projected, it is useful to identify three broad categories of health expenditure forecasting models (see Figure 3). Models focusing on individuals as the unit of analysis for the projection are referred to as micro models. All examples of micro models in this review use microsimulation techniques. Those stratifying sections of health expenditure into groups, or stratifying individuals into groups, or combinations of these two dimensions, are identified here as component-based models. Finally, macro-level models focus on total health expenditure as the unit of analysis. Within this group, some macro-level models (called computable general equilibrium models) project future health expenditure trends within the context of the whole economy.

62. In the remainder of this section, we discuss the extent to which the various models can address the policy questions of interest; the main features of each class of models; their existing applications and their data requirements. We conclude that no model can be considered as superior to the others and that the choice of approach to use depends on the policy questions to be addressed. 
Figure 3 Families of health forecasting models

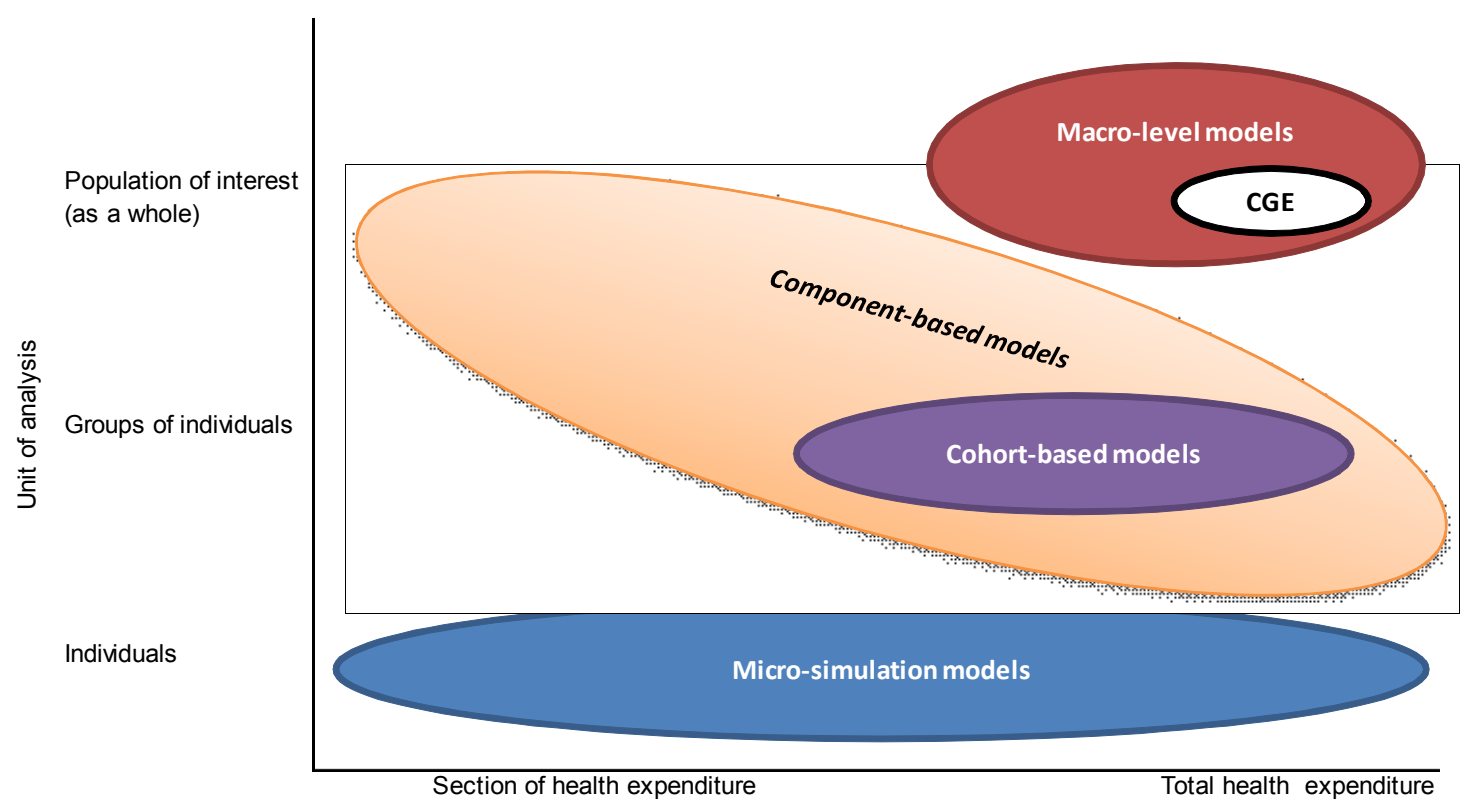

Source: Roberto Astolfi, Luca Lorenzoni and Jillian Oderkirk for the OECD.

\subsection{Microsimulation models}

63. Microsimulation models are powerful tools which allow analysis and testing of relatively detailed "what-if" scenarios resulting from a variety of policy options. The scenarios can be very informative for policy makers as they may provide information beyond what is available from retrospective population studies. For example, the US Future Elderly Model is a dynamic microsimulation model that investigates the impact of different interventions aimed at influencing the body weight mass index (BMI) of individuals on the potential health and health care expenditure of the future elderly population. BMI interventions explored included a universal strategy that reduces BMI across the population and a targeted strategy aimed at overweight or obese people. The Population Health Model (POHEM), a dynamic microsimulation model developed by Statistics Canada, projects the potential future health, health care utilisation and health expenditure outcomes of leading chronic diseases. It has been used to evaluate the possible impact on acute-care and home-care costs of an out-patient/early discharge strategy for breast cancer surgery patients; as well as the prospective impacts of new drugs and cancer screening.

64. The units of analysis of the microsimulation models are individuals. These individuals can be aggregated into policy-relevant groups and analysed using relevant indicators such as inequality and poverty indices (Zucchelli et al., 2010). For example, outputs of the Future Elderly Model can be expressed as total health expenditures, expenditures by disease category, expenditures by age group, or expenditures by smoking status.

\section{How do microsimulation models work?}

65. Microsimulation models reproduce the characteristics and behaviour of a large sample of individuals representing the whole population of interest. Major life-course events can be represented in the lives of the simulated individuals and, in the case of dynamic models, certain characteristics and behaviours can evolve over the life course. Events like pregnancy and birth; exposure to risk factors like hypertension, cholesterol, smoking (initiation and cessation); and changes in weight; as well as the 
incidence and progression of diseases such as cancer, diabetes or heart disease; can all be associated to simulated individuals with attributions based on risks or probabilities. Events compete to occur in each simulated life and a random component embedded in the models ensures that not all individuals at risk of an event may experience it. Individual life trajectories are simulated until death. Costs can be assigned to interventions associated with the life events that have been simulated to project a future trend in health spending.

66. To test the potential impact of a new policy, the microsimulation model is run twice - once with the base case or status quo scenario and then again with a policy change or variant scenario perturbing the environment in which the individuals operate. These scenarios produce a chain reaction where individuals react to the policy changes first and then, depending on the design of the model, may also react to the reaction of other individuals. The results are the potential future outcome of the reform and are often compared with the base case to evaluate the potential impact of the reform.

\section{Data requirement}

67. Microsimulation models require large amounts of data to effectively assemble a sample that adequately represents the whole population of interest and includes all of the characteristics of interest. Data are often gathered from a variety of sources, and sophisticated statistical techniques are often required to standardize the various databases so that they can be used to populate all of the desired attributes of individuals included in the sample. In addition to characterizing the state of the population, For instance, when performing the economic evaluations of cancer control interventions, POHEM typically uses a simulation sample size of one million individuals and draws together information on risk factors; disease incidence by age, gender and cell-type; stage distribution at the time of diagnosis; and the 'standard' or typical diagnostic and therapeutic approaches used. Moreover, data on disease progression after initial diagnosis (depending upon age, gender and stage at diagnosis) are required, in addition to follow-up patterns of practice, treatment at relapse, and terminal care. Therefore 23 different datasets are used which include various cancer registries and hospital registries, data from pharmaceutical associations, population health surveys, screening studies and clinical trials, etc. (Will et al., 2001).

68. For dynamic microsimulation, a second data requirement concerns the design of realistic behaviours for all of the individuals. Degrees of response that individuals may have to changes in an external variable (elasticities) may be estimated through econometric regressions based on the individual's past experiences and choices or may be taken from a review of the health and economic literature (Ringel et al., 2010).

\subsection{Component-based-models}

69. The most widely used class of models is component-based-models. This class includes a large variety of forecasting models that analyse expenditure by financing agents, by providers, by goods and services consumed, by groups of individuals or by some combination of these groups. When expenditures are grouped by financing agents, for example public expenditure, private insurance or out-of-pocket payments, the models often consist of different layers, each of which may use a different technique to project a sub-component of health expenditure. For example, the Actuarial office of the Centers for Medicare \& Medicaid Services (CMS/OACT) in the United States models the public and private component separately, where the former is further divided into Medicare and Medicaid.

70. An important sub-class of component-based models is represented by cohort-based models. In cohort-based models, individuals are grouped into cells according to several key attributes. Typically age is the principal criteria used to stratify the population of interest (generally into five-year age cohorts). Further refinements are obtained by sub-dividing the cohorts according to other commonly-used attributes, 
such as gender, health status, and proximity to death. These models are often referred to as actuarial models or cell-based models, where the term cell identifies the sub-categories into which each cohort is divided.

\section{How do component-based models work?}

71. Each cell in the model is associated with an average cost of health goods and services (usually expressed in real terms). Actuarial projections allow predicting the likely evolution of the population and therefore the future number of individuals included in each cell of the model. Future health expenditure is determined by multiplying the average costs by the projected number of individuals included in each cell. More advanced cohort-based models take into account trends in disabilities as well as factors influencing epidemiologic trends such as, individual behaviour and exposure to risks factors (e.g. smoking, obesity, hypertension and cholesterol). Wherever possible, the introduction of medical innovations is considered. To evaluate the impact of policy options, exogenous shocks are introduced. Each cell typically reacts to exogenous shocks by having a number of individuals migrate to another cell.

72. Cohort-based models have been very common over the years, probably because they offer a number of advantages. First, their implementation and maintenance tends to be simple and relatively inexpensive. This is because this class of models can be developed in an interactive spreadsheet, requiring a limited amount of data and generally including only a few parameters. Many of these parameters can be found in the literature, rather than being estimated. Secondly, the impact of policy changes can be assessed easily by simply modifying the policy parameters (Ringel et al., 2010).

\section{Data requirement}

73. Component-based models are typically less data demanding then microsimulation models which partially explains their popularity. Basic version of the component-based models typically use health expenditure estimates broken down into major spending categories and age classes. All of these data requirements are generally recorded in databases in OECD countries and often cover a relatively long time span. Similarly, demographic projections are often regularly produced and updated. However, the development of more sophisticated versions of the component-based models could require additional information, such as health spending broken down by gender and disease categories, by descendent and survivor status or by end-of-life costs. The absence of national data for some models in this review was overcome by using partial information or information from another country and assuming that the same trends could apply to the country analysed. For example, Wanless uses Scottish data that link records of hospitals use with death records and assumes the results would be representative of all of the UK (Wanless, 2002).

\subsection{Macro-level models}

74. Macro-level models restrict the analysis to aggregate health expenditures. They are most appropriate for short-term projections in the presence of clear and undisturbed trends and in the absence of structural breaks (Bartosz, 2010). Therefore, these extrapolation methods can benefit from the inertia in the health systems in the short-run (Getzen et al., 1992).

\section{How do macro-models work?}

75. Econometric regression analysis is used to fit time-series data. Projections can be based on pure extrapolation of the statistical models fitting the data or they can be based on the projected values of the critical explanatory variables, whenever included. For example, Getzen and Poullier (1992) proposed a simple econometric approach to forecast aggregate health expenditures as a function of past GDP growth and inflation rates. The accuracy of forecasts was then compared to the results obtained from three 
different pure extrapolation methods (exponential smoothing, moving average and ARIMA methods). The authors concluded that a combination of all four forecasts was more accurate than any one of them in isolation.

76. Within the class of macro-level models are "computable general equilibrium (CGE)" models. These are models that allow for the measurement of broader consequences to the economy resulting from medical spending growth and for feedback or reaction from consumers and producers. They allow assessing the implications of higher levels of medical-care spending and higher governmental health expenditures on economic growth; and identify what are the long-run determinants of medical spending growth. For example, a CGE model could be used to estimate the extent to which increases in medical spending are driven by capital investment in health technologies. The CMS Dynamic Computable General Equilibrium Model represents the U.S. economy as being composed of two markets, health and non-health products, for which aggregate demand and supply are modelled (see annex 1.21). From the demand side, individuals are assumed to maximize their welfare through consumption of both products, subject to their income and savings. The supply side of this CGE model assumes that both medical and non-medical firms maximize profits and that their profits depend on capital and labour costs and tax rates. The model allows for feedback from consumers and producers to rising levels of medical care expenditures and therefore a response to levels of expenditure that negatively affect consumer welfare. These models depend on assumptions of equilibrium that may not account for observed trends and rely on strong simplifying assumptions about the behaviour of individuals, firms and governments.

\section{Data requirements}

77. Macro-level models are typically the least demanding in terms of data requirements (Bartosz, 2010). This is particularly the case for pure extrapolation methods which use a single time series and for regression-based models which very often include just a few explanatory variables. The computational and data requirements for Dynamic Computable General Equilibrium Models, on the other hand, are generally much higher and depend on the specification of the equations included in the model.

78. Overall, it appears that no class of model can be considered as superior to the others and that there is great flexibility within and between models to design platforms to support addressing a variety of policy questions. The choice of platform depends on the policy questions that are the most pressing.

\subsection{Combined-models}

79. While many approaches to forecasting health-care expenditures have been around for a very long time, new approaches are appearing on the horizon that take advantage of advancements in data development and computer technology to bring a fresh look to the issue of rising health expenditures. Recent decision-support models offer enhanced opportunity to test policy scenarios and to understand the broader social and economic implications of policy changes.

80. Of note, are the efforts made by some institutes to combine the various approaches mentioned above in order to develop a more flexible modelling platform. For example, the U.S. CBO is combining microsimulation and component-based approaches within a platform for health expenditure projections (see Annex 1.22). In Australia, a microsimulation approach has been combined with a computable general equilibrium approach to project the impact of chronic disease prevention efforts (see Annex 1.2 Australia National Centre for Social and Economic Modelling (NATSEM) Micro-Macro).

81. Table 1 reports the list of the models reviewed and their main features. 
Table 1. Health expenditure forecasting models reviewed

\begin{tabular}{|c|c|c|c|c|}
\hline Country & Models reviewed & Class of models & Year & Annex \\
\hline Australia & Australian Institute of Health and Welfare (AlHW) & Component-based & 2008 & 1.1 \\
\hline Australia & National Centre for Social and Economic Modelling (NATSEM) Micro-Macro & Combined component-based \& macro-level CGE & $2002 / 2009$ & 1.2 \\
\hline Australia & Australian Government, Productivity Commission & Macro-level & 2005 & 1.3 \\
\hline Australia & Australian Government, The Treasury & Component-based & 2010 & 1.4 \\
\hline Canada & Canadian Institute for Health Information (CIHI) & Macro-level & 2006 & 1.5 \\
\hline Canada & Parliamentary Budget Officer (PBO) & Component-based & 2007 & 1.6 \\
\hline Canada & Statistics Canada /Population Health Model (POHEM) & Microsimulation & 1994 onwards & 1.7 \\
\hline European Union & European Union/Ageing Working Group & Component-based & 2012 & 1.8 \\
\hline France & Direction de la recherche, des études de l'évaluation et des stat. (DRESS) & Component-based & 2007 & 1.9 \\
\hline France & Sénat & Macro-level & 2004 & 1.10 \\
\hline Italy & Ministry of Health/Università di Roma Tor Vergata & Macro-level & 2011 & 1.11 \\
\hline Italy & Ragioneria Generale dello Stato & Component-based & 2011 & 1.12 \\
\hline Netherlands & Bureau for Economic Policy Analysis (CPB) & Component-based & 2010 & 1.13 \\
\hline New Zealand & Ministry of Health and Treasury & Component-based & 2004 & 1.14 \\
\hline OECD & Economics Department & Component-based & 2006 & 1.16 \\
\hline Sweden & Ministry of Health and Social Affairs & Microsimulation & $2010 / 2011$ & 1.17 \\
\hline UK & HM Treasury/ Office for Budgetary Responsibility (OBR) & Component-based & 2002 & 1.18 \\
\hline UK & National Heart Forum Microsimulation Model (Foresight) & Microsimulation & $2007 / 2011$ & 1.19 \\
\hline USA & Centers for Medicare \& Medicaid Services (Component) & Combined component-based \& macro-level & annual & 1.20 \\
\hline USA & Centers for Medicare \& Medicaid Services (GE) & Macro-level CGE & 2008 & 1.21 \\
\hline USA & Congressional Budget Office (CBOLT) & $\begin{array}{l}\text { Combined component-based and } \\
\text { microsimulation }\end{array}$ & annual & 1.22 \\
\hline USA & The Future Elderly Model (CMS/RAND) & Microsimulation & $2004 / 2011$ & 1.23 \\
\hline USA & U.S. Department of Veterans Affairs & Component-based & 2008 & 1.24 \\
\hline USA & $\begin{array}{lllll}\begin{array}{l}\text { Comprehensive Assessment } \\
\text { (RAND/USDL/USDHHS) }\end{array} & \text { of } & \text { Reform } & \text { Efforts } & \text { (COMPARE) } \\
\end{array}$ & Microsimulation & 2010 & 1.25 \\
\hline
\end{tabular}




\section{PROJECTED VARIABLES AND MEASUREMENT UNITS}

82. Forecasts may include only spending on personal care (see Annex A1.20), public spending (A1.4), or total spending (A1.13). The variable of interest may be projected per se or as an aggregation of different components (component-based models); as part of the overall economy (macro-level models); or as an aggregation of individual expenditure profiles (microsimulation models).

83. The area of policy interest also influences the specific components included in the forecasting models. Those components may include the public-private payment split (see Annex A1.20) or the cost of specific functions, such as long-term care (A1.16) or administration. There are models where forecasts are developed to project expenditure on specific health conditions (e.g. expenditure for prevention of chronic diseases, cancer or diabetes), for certain groups of beneficiaries (e.g. children, elderly or veterans) (A1.24), by payers (A1.20), or types of services (A1.4).

84. Some models enable both projections of aggregate expenditures and components of health expenditure, such as expenditures by age groups, diseases, ethnicities, or socio-economic classes. Microsimulation models enable any desired aggregation included within the modelling framework and enable recalculation of potential future expenditure estimates in response to "what if" scenarios of new policies, such as risk-factor prevention or health-care organisation and treatment strategies (see Annex A1.7, A1.17, and A1.23). Expenditure estimates can, thus, be expressed as a distribution and pockets of higher or lower expenditure can be identified.

85. Health expenditure forecasts can have different time horizons depending on the policy question they intend to address. The range can vary from a very short period, to provide timely information for managing current budgets, to up to a century, to estimate what expenditures would be when a country has gone through its demographic (Rannan-Eliya, 2007) or epidemiological transition. Fiscal sustainability - that is the examination of the potential impact of future public sector spending and revenues - is a concern over the medium term (Di Matteo, 2010) or the long term (see Annex A1.20, Office for Budget Responsibility, 2011). Most of the models that we reviewed use a long-term horizon, ranging from 30 years (A1.1) to 75 years (A1.22). Only a few use a medium-term time horizon (A1.13 and A1.20).

86. As the time window expands, many drivers that influence the trend in health expenditures can change and are difficult to forecast. The degree of uncertainty increases over time in long-run forecasts and only a good estimate of the uncertainty surrounding those long-run projections could confirm the value of the information provided (Lee, 2002).

87. Models project different variables depending on the time horizon. As an example, the Commonwealth of Australia (see Annex A1.4) projects the main components of health spending separately for ten years, to allow for different growth rates of medical benefits, pharmaceutical benefits, private health insurance, hospitals and other health spending over this period. Afterward, the approach uses a model of total Australian government health spending instead. A similar approach is followed by $\mathrm{CBO}$ (A1.23).

88. Measurement units include current price and constant price figures, measured in per-capita terms or as a share of GDP. When short-term projections are developed, estimations expressed at 
current prices for aggregate categories are often regarded as the most suitable. As the time horizon extends over the medium-term period, health expenditure is more appropriately forecasted in real terms (i.e. at constant prices) (see Annex A1.4, A1.10, A1.14, and A1.20). This is because the decomposition of price and volume growth using health-specific indices, where possible, could help to identify which elements underlie health spending growth. Finally, in the long run, the health spending to GDP ratio is often considered the most appropriate measure for the projections, as the relevant question relates to how much society has to give up to pay for health care (A1.11, A1.12, A1.13, and A1.16) (Getzen, 2000a). 


\section{DRIVERS OF HEALTH EXPENDITURE}

89. Many medium- to long-term forecasting models attempt to clarify the factors that are driving health expenditures and thus make clearer the policy options available. Our review of what drives health care expenditure shows that the factors that are important to explaining the growth of health spending vary according to the time horizon of the projection. In the short run, expenditure growth is very much linked to government budget decisions. In the medium term, technological changes play a more important role in explaining growth. In the long run, risk factors, such as obesity, and changes in the prevalence of chronic diseases also enter the picture (Thorpe et al., 2004). Factors influencing the future trajectory of health spending include demand-side factors, such as ageing and the health status of a population, income growth, and consumers' behaviour; supply-side drivers, such as technological progress and changes in treatment practices, productivity, and health prices ${ }^{2}$; and regulatory factors, such as institutional characteristics of health systems and their financing ${ }^{3}$.

\subsection{Demographic factors and health status}

90. Health care expenditures depend - among other factors - on the structure of the population and its health status ${ }^{4}$. It is a popular notion that an ageing population is a major driver of health care costs (see Annex A1.6, A1.11, A1.12, A1.13, A1.14, and A1.16) as the increase in life expectancy is assumed to be associated with a decline of the health status of the population. However, empirical evidence suggests that the age structure of the population has only a modest impact on the growth of health expenditures. Population aging in British Columbia contributed less than 1\% per year to total growth in expenditures on hospital, medical and pharmaceutical care from 1996 to 2006 (Morgan, 2011). Demographic changes in the US accounted for an annual growth of $0.4 \%$ in health spending from 1963 through 2007, about 7 percent of growth in real per capita health spending (Smith et al., 2009). As a consequence, future effects of population aging on healthcare spending are considered as a minor factor in the expected rise in the burden of health services (Fogel, 2008).

91. The influence of population ageing on health expenditure growth has generated an animated debate (the "red-herring" debate). Empirical evidence (Seshamani et al., 2004; Batljan et al., 2004) suggests that health expenditures tend to concentrate in the period immediately preceding death (also referred to as "time-to-death") to the extent that around 25 percent of life time health expenditures are concentrated in the last year of life (McGrail et al., 2000, Spillman et al., 2000, Yang et al., 2003, Miller, 2001). Therefore, the red-herring argument considers that traditional projection methods overestimate the influence of population ageing because longevity gains would progressively postpone health expenditure from one age class to the next, rather than raise it (Zweifel et al., 1999).

2 It should be noted that supply and demand are not independent. One additional driver is supplierinduced demand (Gerdtham et al., 2000). This variable was not included as a specific driver in the models that we reviewed; however, it may be embedded within the treatment practices driver.

3 Health prices may also influence demand or regulation.

$4 \quad$ It should be noted that health expenditure growth could lead to gains in overall population health status through prevention and treatment innovations that promote healthy life years. None of the models we reviewed accounted for this feedback effect. The RAND Future Elderly Model [9] came the closest, by testing the potential future impact of the introduction of new technologies on both population health status and direct health care expenditures. 
Other authors (see OFS, 2007 for a review) have pointed out that increases in health expenditure in the period immediately preceding death apply specifically to acute care, whereas expenditure on longterm care could potentially follow different paths (see Figure 4). The first is known as the "dynamic equilibrium" or "healthy ageing" hypothesis. It assumes that the morbidity period prior to death remains unchanged as life expectancy increases, so that each year gained in life expectancy corresponds to an equal increase in years of healthy life. The second is a pessimistic view called "expansion of morbidity" where by increases in life expectancy yield a longer-time spent with illhealth and reduced "quality" of life. This theory points to technological advances extending the life of those with diseases and disabilities (Grunenberg, 1977). In addition, living longer would expose an increasing number of people to the non-fatal disabling diseases of old age (Parkinson's disease, dementia, vision hearing and mobility loss). The opposite theory is expressed by the third hypothesis known as "compression of morbidity" (Fries, 1980). According to this theory, longevity gains can be associated with an increase in the healthy-life period.

Figure 4 Relationship between life expectancy and morbidity

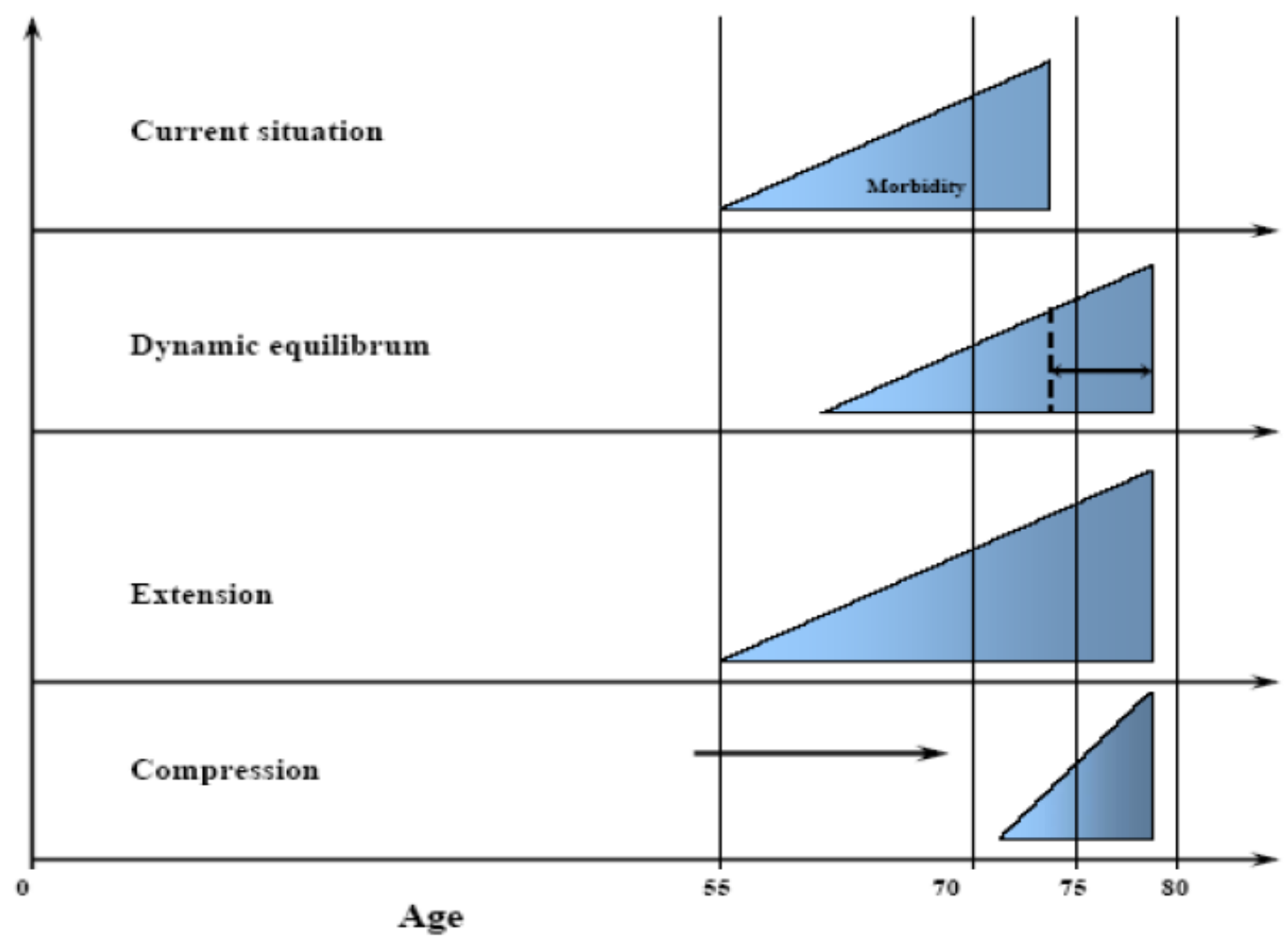


92. Michel and Robine (2004) suggest that each of the three possible scenarios may depend on the relative size of the following four factors:

1. An increase in the survival rate of sick persons which would explain the expansion in morbidity;

2. A control of the progression of chronic diseases, which would explain a subtle equilibrium between the fall in mortality and the increase in disability;

3. An improvement in the health status and health behaviour of the new cohorts of old people, which would explain the compression of morbidity, and eventually;

4. The emergence of very old and frail populations which would explain a new expansion in morbidity.

93. The alternative hypotheses on the expansion, contraction or dynamic equilibrium of morbidity have been included in many of the models reviewed here. For instance, the Dutch model developed by the CPB assumes that, on average, half of the overall life expectancy increase corresponds to a healthier life. The Swiss OFS model, instead, considers two hypotheses (dynamic equilibrium and expansion of morbidity) and the impact of each of these is tested in relation to three demographic scenarios (high, middle and low growth). A further refinement is proposed by the UK HM Treasury model, which distinguishes between the use of acute and long-term care. The "dynamic equilibrium" is assumed in the solid progress scenario; whereas the "expansion of morbidity" hypothesis is assumed for both acute and long-term care in a pessimistic scenario.

94. Some studies have directly modelled the potential future health status of the population. Using a microsimulation approach, individuals' current and future health status can be projected conditional on their background characteristics, such as ethnicity and socio-economic status, as well as their exposure to risk factors, such as obesity and smoking, and their current and past health status and chronic health conditions (see Annex A1.7 and A1.23). As an example, the Ministry of Health and Social Affairs in Sweden (see Annex A1.17) forecasted the potential impact on health and elderly care expenditures under different scenarios of the future health status of the population. Using a microsimulation approach, the project explored whether anticipated gains in life expectancy would increase, reduce, or leave proportionately similar morbidity at older ages. While the assumption of reduced morbidity at older ages is the most optimistic scenario, none of the health status scenarios exerted significant upward pressure on expenditure as a share of GDP. However, expenditure forecasts increased for all health status scenarios, when a new scenario was introduced where there is "excess cost growth" due to technological change and changes in treatment practices. With "excess cost growth" expenditures as a proportion of GDP rose from 13 percent in 2010 to around 16 percent in 2050 (Figure 5). 
Figure 5 Projected growth in health and elderly care expenditures as a share of GDP in Sweden under different scenarios

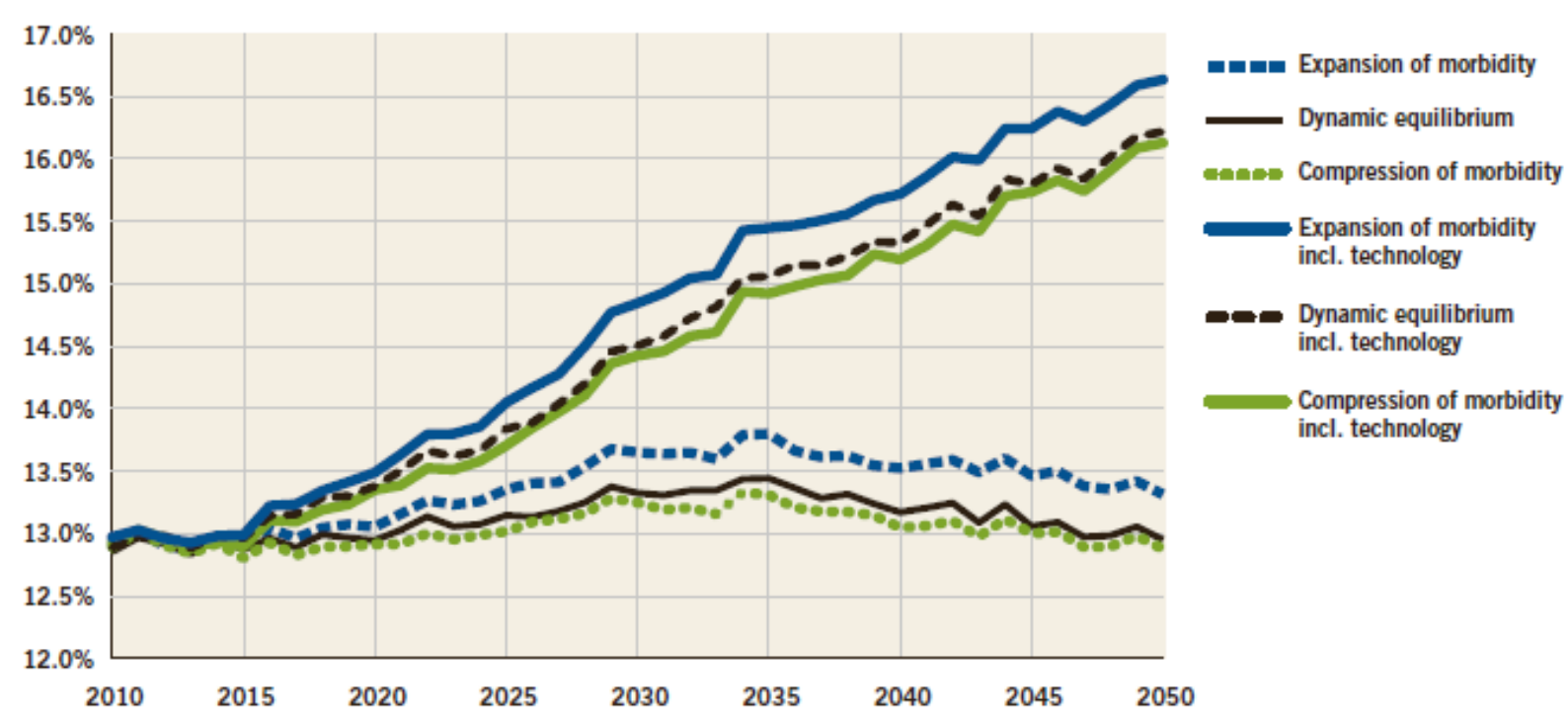

Note: The bottom three lines isolate the impact of the three health status scenarios alone, while the top three lines include estimates with the effect of excess cost growth from increased treatments/technology.

Source: Ministry of Health and Social Affairs, 2010.

95. Another approach to indirectly include health status in the projections is to develop diseasespecific projections (see Annex A1.1). Those include changes in disease incidence and prevalence among the factors that contribute to projected changes in expenditure. The consequences of the increasing prevalence of overweight and obesity for health spending in the medium term have received particular attention in the literature (Thorpe, 2004; Lakdawalla, 2005). Individuals who were overweight or obese at age 65 were found to have 6-17 percent higher lifetime expenditure than the same age cohort within the normal weight range at age 65 in the United States (Yang, 2008).

\subsection{Income}

96. Income has been identified as the most important factor that explains differences across countries in the level and growth of health spending (Newhouse, 1992). It has generally been well accepted that variations in per capita national income are closely correlated with variations in per capita health spending, and higher levels of GDP contribute to higher levels of spending ${ }^{5}$ (see Annex A1.2, A1.6, A1.10, A1.11, and A1.12). One possible explanation for this is that as nations become richer, people place higher value on health and want to spend a larger share of their income on improving their health (Fogel 2008). The "income elasticity" varies a lot in empirical results and whether health care is a luxury good or a necessity is still an unsettled issue. Results for the US and Canadian provinces, as well as national-level data for 16 OECD countries, confirm that estimates of the size of the income elasticity vary by level of analysis, with international income elasticity generally larger than elasticities estimated in national or regional studies (Di Matteo, 2003).

$5 \quad$ It should be noted that better health could also lead to economic growth through gains in human and physical capital that raise productivity and per capita GDP (Swift, 2010). The only model we reviewed that accounted for this feedback effect was developed in Australia by NATSEM (Brown et al 2009). 
97. Getzen (2006) reviewed nearly 40 empirical studies that had estimates of the health income elasticity, with values ranging from 0 to 2.2. Getzen concluded that the variation in those results depends primarily on the level of aggregation of the data, with the elasticity increasing with the unit of analysis. More recent studies, however, have emphasised that the estimation techniques may also explain the variation in empirical results for the income elasticity and that using more advanced techniques (e.g. co-integration analysis) may lead to values below 1 (Di Matteo et al., 1998, Ariste et al., 2003, Di Matteo, 2010). Herwartz and Theilen (2010) suggest that the income elasticity could be directly correlated with age.

98. In practical applications, however, increases in health expenditure are sometimes assumed to exceed GDP growth. Such an assumption is introduced by the Dutch CPB, the Italian RGS model and the USA CBO long-term model, among others. In the CBO case, the assumption is labelled as "Excess Cost Growth (ECG)" and refers specifically to the percentage points by which the growth of various components of health expenditure (e.g. Medicare, Medicaid, or health care generally -per beneficiary or per capita) are assumed to exceed the growth of nominal gross domestic product (per capita). Under the assumption that excess cost growth rates for spending on Medicare, Medicaid, and all other health care continue increasing indefinitely at their average values from 1975 to 2005, federal expenditure on health in the United States could reach 99 percent of GDP by 2082 (Orszag, 2008) (Figure 6). It is obvious that such a long-term forecast is totally implausible and therefore the validity of the GDP $+\mathrm{X}$ growth hypothesis is questionable for long-term projections.

99. In other examples, a unit value is considered. For example, the OECD (2006) argues that this is a reasonable starting assumption for health projections that can be tested through sensitivity analysis. This advice has influenced developers of the Canadian PBO model, who also assumed a unitary income elasticity for health spending; and the EU, whose model assumes a unit value and includes one scenario to test the impact of this assumption. This particular scenario tests the effect of an income elasticity of demand higher than one by assuming the income elasticity at the start of the projection period is 1.1 and then gradually decreasing the estimate to reach one over a fifty-year period. A different approach is taken by CMS, which fixes the income elasticity at 1.54; while the Dutch CPB and French DRESS opt for values slightly below one. The Australian Productivity Commission estimates the effects of a plausible range of values (from 0.2 to 1); and selects an elasticity of 0.6 as the Commission's preferred estimate. That value represented the midpoint between the macro-level estimates (not controlling for technological change); and the micro-level estimates based on individual decision-making.

100. It is worth noting that the subset of models that relies on forecasts of GDP growth as a driver of health expenditure are subject to the potential error within those forecasts (Frankel, 2011). 
Figure 6 CBO Projected Health Expenditure under the Excess Cost Growth Assumption

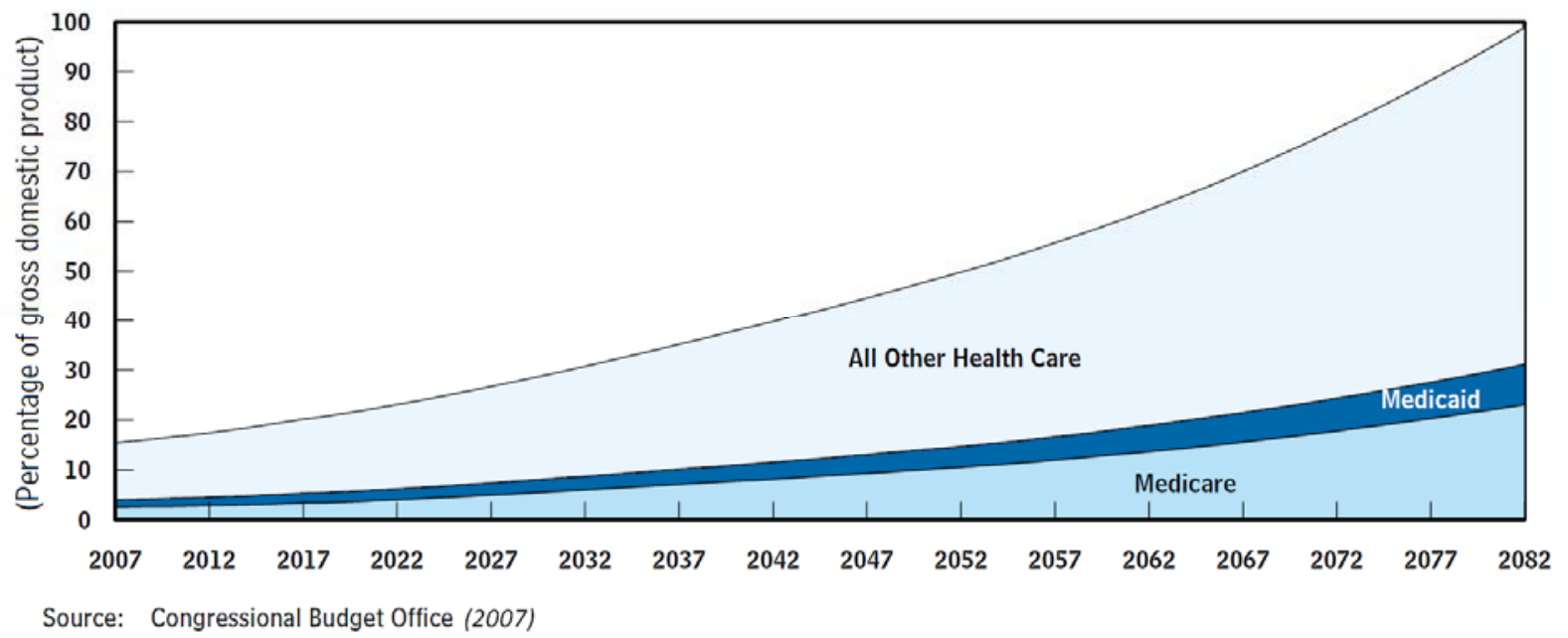

\subsection{Consumers' behaviour}

101. Public health, through health promotion and disease prevention programmes, and healthseeking behaviour could have a significant impact on health status and, ultimately, on the demand for health services and their costs. The population's engagement in healthy lifestyles and behaviour; and their use of preventative health services, could have a positive impact on health services expenditures, both in terms of the volume and the effectiveness of resource use (Wanless, 2002). Changing societal norms and preferences for health care can also influence health-seeking behaviour and consequent demand for health care. These effects are difficult to measure and hence to incorporate into forecasting models.

102. Among the models reviewed, only microsimulation approaches including POHEM, the Future Elderly Model and the model of the U.K. National Heart Forum (see Annex A1.7, 1.18, 1.23) allow testing "what if" scenarios of the impact of changes in lifestyles. Microsimulation approaches enable the modification of population's exposure to risk factors, such as tobacco smoking, unhealthy eating, alcohol consumption and lack of physical activity; and therefore enable the testing of the impact on health expenditures of investments in public health programmes, clinical interventions or medical treatments designed to reduce the population's exposure to risk factors.

\subsection{Treatment practices}

103. Changes in treatment practices might be associated with assumptions about increases in intensity of care, changes in treatment location (Thorpe, 2010) and changes in health expectations and demand. An Australian model (see Annex A1.1) projected that total health and residential aged care expenditures may exceed 12 percent of GDP by 2032-33, up from 9.3 percent in 2012-13. The most important factor driving this increase was change in the intensity of care provided to patients, followed by population aging ${ }^{6}$, population growth and health price inflation (Figure 7). The intensity of care provided to patients is influenced by the emergence of new technologies, the use of existing technologies in new ways; changes in how care is delivered; and changing views about the appropriateness of treatments applied to the oldest patients.

6 Note that when expenditure forecasts include long-term care for the aged, aging will be a more important driver than when forecasts examine health care alone. 
Figure 7 Intensity of care may be the most important driver of projected growth in health expenditures in Australia, 2003-2033

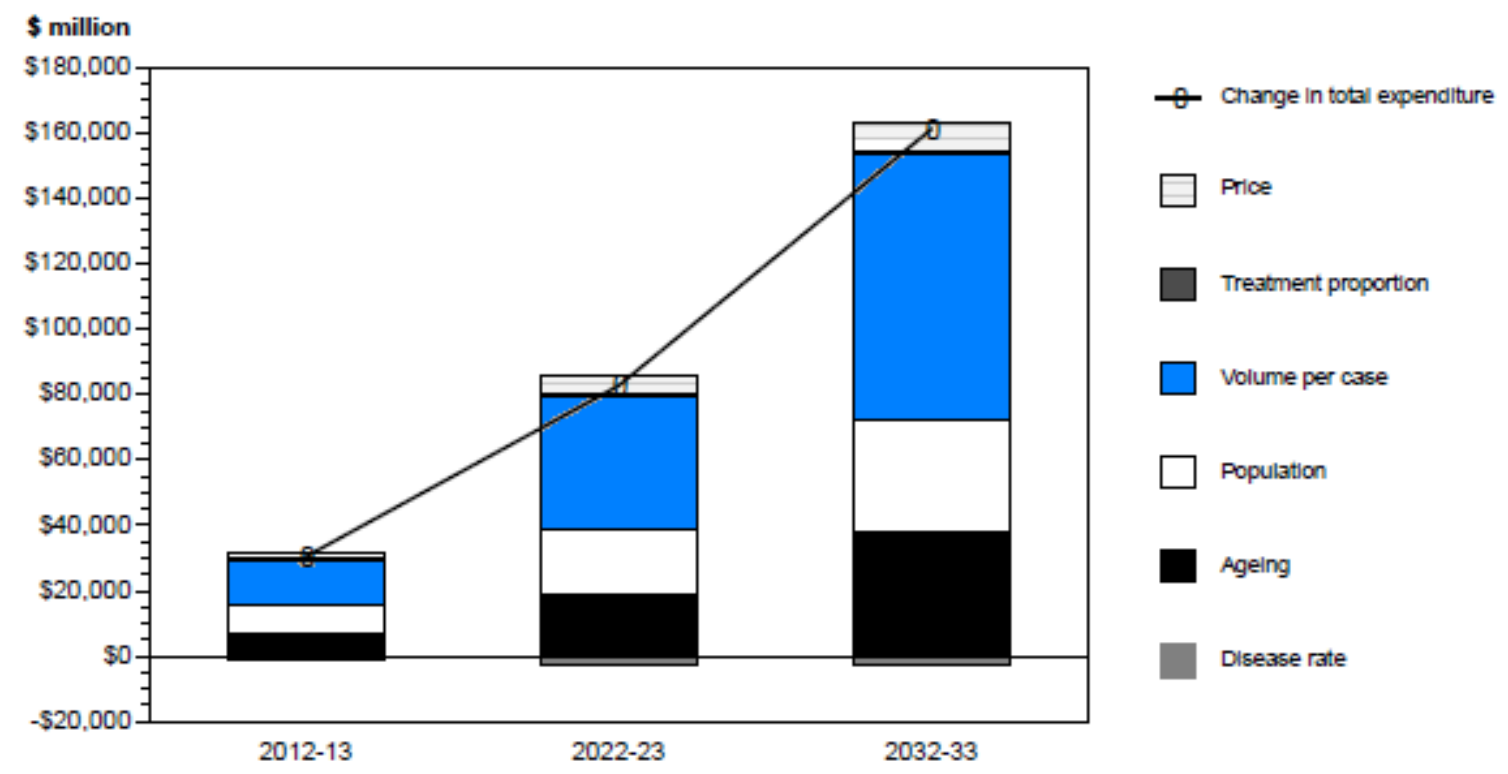

Source: Goss, 2008.

\subsection{Technological progress}

104. The general consensus is that growth in real spending on health care is mainly the result of the emergence of new technologies and services, and their adoption and widespread diffusion. Approximately half of all long-term growth in health care spending has been associated with technological advances (Congressional Budget Office, 2008). However, when it comes to measuring how much this factor accounts for growth in health spending, the effect of technological change is proxied in a number of ways. One way is to ascribe it to the residual after all other factors have been controlled for ("excess growth") (see Annex A1.6; White, 2007). Given that technological change occurs over time, a time index is another logical way to control for the effects of technological change on health expenditures (see Annex A1.10; (Di Matteo, 2005). Two models (A1.3 and 1.24) among those reviewed used a direct measure of specific technologies.

105. As an example, OECD analysis of public health expenditure growth across member countries also concluded that past trends in health expenditures were in excess of demographic changes and increases in GDP and that this residual growth was likely attributable to the introduction of new technologies and health-price inflation. On average across the OECD, demographic effects are projected to have a small impact on expenditure growth of 0.7 percentage points from 2005 to 2050 . Even under a very pessimistic assumption about the health of the future elderly, where gains in life expectancy only add years lived in ill-health, the percentage point increase due to demographics would be 1.5. Residual growth, on the other hand, could contribute as much as 3.2 percentage points, if it is not addressed by policy intervention (OECD, 2006).

106. RAND (see Annex A1.23) developed a forecasting model that simulated the population of the United States at the level of individual people in a framework where "living to die another day", after benefitting from treatment, is accounted for. They examined 10 technologies, including drugs, devices and vaccines that a consensus panel of experts deemed could become widely adopted. Assuming the full adoption of these technologies back in 2002, by 2030, some new technologies have a large impact on health expenditures (Table 2). Effective new technologies, even those that are 
inexpensive on their own (such as cancer vaccines), tend to increase health spending. This is particularly the case when a large share of the population will be treated. This is because treated people will go on to live longer, and incur costs related to new health-care needs. Effective technologies are, conversely, an important mechanism to continue to make progress toward alleviating suffering and enabling gains in both life-expectancy and healthy life years. RAND forecast that the rising prevalence of chronic diseases among the elderly will drive modest increases in health expenditure; however the greatest spending risk is not from demographic or health trends, but from medical technologies.

Table 2 Impact of Selected Medical Technologies on Spending and Life Years in the United States

\begin{tabular}{|c|c|c|c|c|c|}
\hline \multirow[b]{2}{*}{ Technology } & \multicolumn{2}{|c|}{$\begin{array}{l}\text { Annual treatment } \\
\text { cost (\$ billions) }\end{array}$} & \multicolumn{2}{|c|}{$\begin{array}{l}\text { Increase in health care } \\
\text { spending over status quo (\%) }\end{array}$} & \multirow{2}{*}{$\begin{array}{l}\text { Cost per } \\
\text { additional } \\
\text { life year (\$) }\end{array}$} \\
\hline & 2015 & 2030 & 2015 & 2030 & \\
\hline Anti-aging compound (healthy) & 48.6 & 72.8 & 8.7 & 13.8 & 8,790 \\
\hline Cancer vaccines & 0.5 & 0.8 & 0.1 & 0.4 & 18,236 \\
\hline Treatment of acute stroke & 3.1 & 4.4 & 0.4 & 0.4 & 21,905 \\
\hline Anti-aging compound (unhealthy) & 48.8 & 73.3 & 22.7 & 70.4 & 29,785 \\
\hline Telomerase inhibitors & 4.4 & 6.4 & 0.2 & 0.5 & 61,884 \\
\hline Alzheimer's prevention & 33.6 & 49.1 & 7.4 & 8.0 & 80,334 \\
\hline ICDs & 14.0 & 20.7 & 3.6 & 3.7 & 103,095 \\
\hline Diabetes prevention & 13.7 & 20.6 & 2.6 & 3.2 & 147,199 \\
\hline Anti-angiogenesis & 38.8 & 51.9 & 8.8 & 8.0 & 498,809 \\
\hline LVADs & 10.2 & 14.2 & 2.1 & 2.3 & 511,962 \\
\hline Pacemaker for atrial fibrillation & 10.4 & 13.6 & 2.2 & 2.3 & $1,403,740$ \\
\hline
\end{tabular}

SOURCE: Simulations based on data from the Medicare Current Beneficiary Survey and the National Health Interview Study. NOTES: All spending is in constant (1999) dollars. The exhibit shows the treatment costs, additional health care spending, and cost per additional life year associated with ten promising medical innovations. Treatment costs refer to the costs of providing the listed breakthrough technology and are based on comparisons with existing technologies as identified by expert panels. The additional health care spending differs from treatment costs because the technologies can lead to changes in disability, morbidity, and mortality, all of which are accounted for in the simulation model. Costs per additional life year do not include improvements in morbidity and disability during a lifetime and hence should be thought of as upper bounds on a costeffectiveness ratio. ICD is intraventricular cardioverter defibrillator. LVAD is left ventricular assist device.

Source: Goldman, 2005.

\subsection{Health prices and productivity}

107. The price of health care relative to the general price level was reported as a significant driver of health spending growth (Huber 1999; Leung 2007). Excess health care inflation explained - on average - 1.1 percentage points of growth in personal health care spending in the US from 2007-2010 (Martin et al., 2012). Several models reviewed included excess medical prices among the nondemographic drivers when forecasting current health spending growth or if health expenditure are projected as a share of GDP, while others ascribe it to the residual category when no measures of health-sector inflation are available (see Annex 1.1, 1.10 and 1.20).

108. A positive effect of relative prices on health spending would support Baumol's model of unbalanced growth (Baumol, 1967) which states that productivity in the health sector is low relative to other sectors because health services are highly customised and labour-intensive. Hence, prices for health services will tend to rise relative to other prices because wages in low-productivity sectors must keep up with wages in high-productivity sectors (Baltagi, 2010). 
109. There is no consensus on this effect. Some empirical studies using OECD panel data confirm that the "Baumol effect" is an important explanatory variable of health spending growth (Pomp, 2008; Hartwig, 2008); and increasing labour productivity in health care is seen as a realistic and viable option to slow the rate of growth of health care spending (Wanless, 2002; Kocher et al., 2011). On the other hand, some other studies (Gerdtham, 1992) report an insignificant effect or even go so far as to assert that "Baumol's disease has been cured" (Triplett, 2003). The OECD model ${ }^{7}$ included the "Baumol effect" among the factors that drive long-term care spending projections.

110. The "Baumol effect" is included among the factors that drive long-term care spending projections in the OECD model ${ }^{8}$ (see Annex A1.16), although this variable is not crucial in the OECD model of health care spending projections.

\subsection{Health care system organisation}

111. Insurance coverage, and health care financing and delivery systems, might explain part of health expenditure growth (White, 2007; Baltagi, 2010).

112. Insurance coverage influences health spending through three channels: (i) the proportion of population with insurance; (ii) the depth of coverage in insurance contracts; and (iii) the level and structure of reimbursement. The net expansion in insurance coverage accounted for 10.8 percent of the growth in real per capita spending from 1960 to 2007 in the United States (Smith et al., 2009); the willingness of insurance programmes to reimburse for new innovation was considered a key driver to both innovate and diffuse existing technology in the U.S. (Weisbrod, 1991; Chandra et al., 2011).

113. Public-integrated and public-contract models - compared with private insurance/provider models - give a central authority a great deal of leverage over providers. That leverage could be used to constrain health spending (Docteur et al., 2004).

114. An attempt to compare the potential contribution of different ways to organize and pay for care on spending growth is made by Bac (see Annex A1.10), who indicates that the system that manages costs best is an integrated system; followed by a contract system; and then by an activitybased payment system.

115. Figure 8 below reports the relative importance of factors ${ }^{9}$ accounting for growth in personal health care expenditure ${ }^{10}$ for the Medicare programme in the United States. It shows that utilisation and excess health prices account for a large share of projected growth in health spending.

7 The average labour productivity in the economy is used as a proxy for this driver, with an elasticity assumed to be 0.5 (OECD 2006).

8 The average labour productivity in the economy is used as a proxy for this driver, with an elasticity assumed to be 0.5 .

9 The Sustainable Growth Rate (SGR) is used to control the growth in aggregate Medicare expenditures for physicians' services.

Personal health care expenditure measures the total amount spent to treat individuals with specific medical conditions. It excludes government public health activity, government administration, the net cost of private health insurance, and investment. 
Figure 8 Utilisation and excess health prices account for a large share of projected growth for the United States Medicare Programme

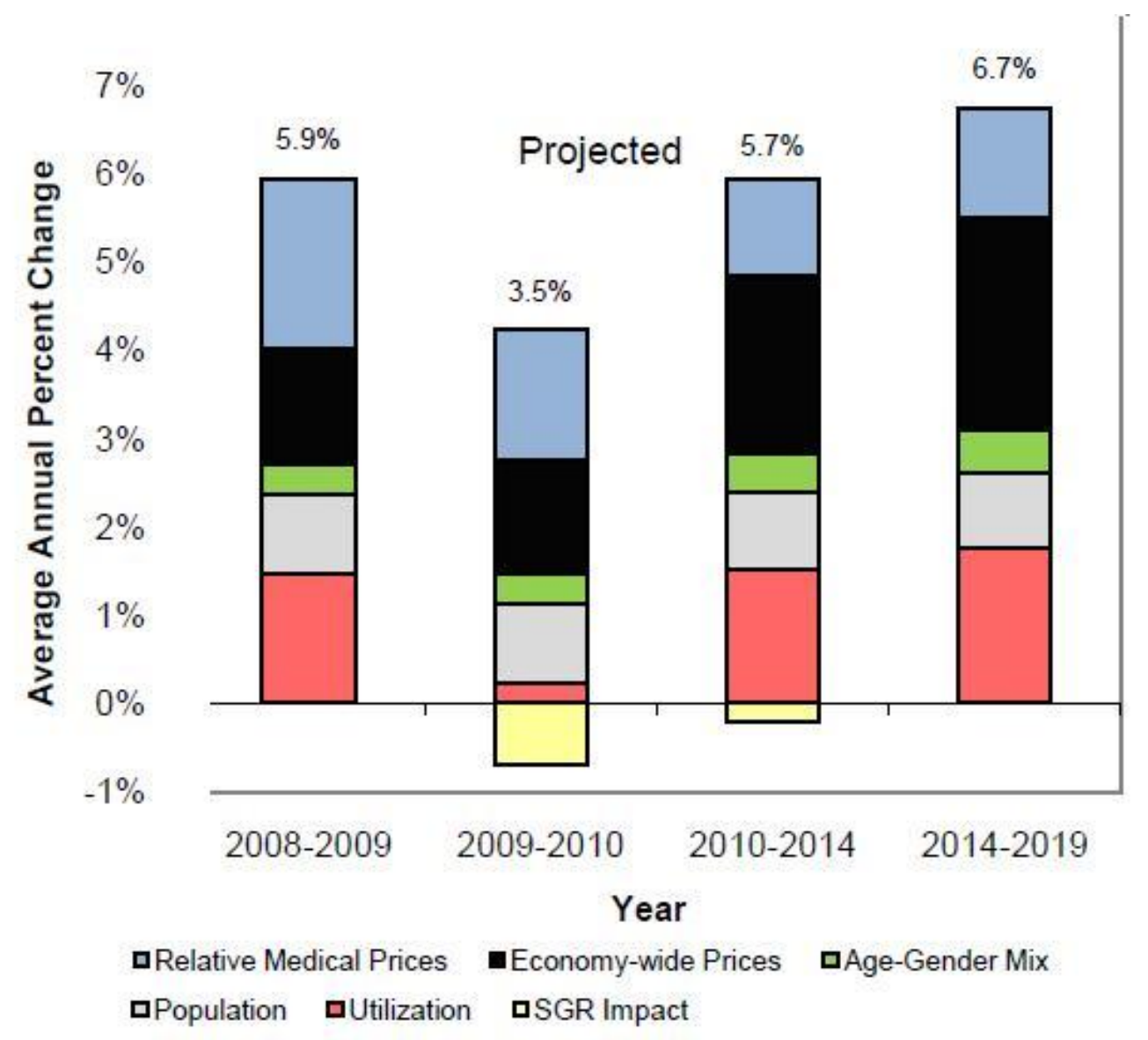

Source: Centers for Medicare and Medicaid Services, Office of the Actuary (www.cms.gov) 


\section{CRITERIA TO ASSESS THE PERFORMANCE OF FORECASTING METHODS}

116. Forecasting models can be predictive or policy-oriented (Kopec, 2010; Weinstein, 2003). For example, weather forecasting models are essentially predictive models in that no policy can be implemented to influence the weather in the very near future. Measures can, however, be taken as a result of the information provided by the forecasts; such as to evacuate a population which is likely to be exposed to a hurricane. In contrast, policy-oriented health expenditure forecasting models aim to inform policy makers about when and how to implement reforms and what effects those reforms are likely to produce. While it is desirable for predictive models, like weather forecasting models, to produce projections that are as accurate as possible; the most important feature of a longer-term health forecasting model should be its ability to influence policy makers. To do that, health expenditure projections not only need to be scientifically sound, but must also be considered credible (Zucchelli et al., 2010) by policy makers. The credibility of health expenditure forecasting models, in turn, relies on their validity, accuracy, tractability and transparency (Harris et al., 2008).

117. The validity of a model refers to its ability to address the request of policy makers. A model is valid if its structure reflects relevant features of the policy environment and avoids nonessential elements. Noteworthy in this context is the inclusion of health expenditure drivers which specifically allow the policy questions of interest to be addressed. For example, when assessing the "Enrolee Health Care Projection Model (EHCPM)", RAND Corporation concluded that the model "is likely to be valid for short-term budget planning but may not be valid for longer-range planning and policy analysis" (House Committee on Veterans' Affairs, April 29, 2009, Statement of Carl Blake). ${ }^{11}$

118. The accuracy of health expenditure forecasting models relies on their ability to reproduce observed data for the past and their ability to adapt to new evidence as it becomes available. In other words, the predictive accuracy of policy-oriented models should be evaluated retrospectively rather than prospectively (Weinstein et al., 2003). Future trends in health expenditure should diverge from projected values as a result of the implementation of policy changes which have been stimulated by the projections themselves.

119. Tractability indicates how easily modellers and users can understand, and potentially replicate, the model's features, particularly its validity and accuracy.

120. Finally, models should be transparent in that they should reveal the conditional relationship between assumptions and outcomes rather than make unconditional claims about the consequences of policy interventions (Weinstein et al., 2003). The remainder of this section focuses on two key elements: the model assumptions and the techniques used to assess their influence on the outcome of the forecasting models. fits the data well or not. Technical details about model validation are not addressed in this paper. 


\subsection{Techniques to assess the influence of assumptions on the outcome of forecasting models.}

121. Transparent models provide policy makers with a measure of the uncertainty associated with a projected value. Three tools are theoretically available to that end: the prediction interval, scenarios, and sensitivity analysis.

122. A prediction interval consists of an upper and a lower bound between which the future value is expected to lie with a prescribed probability. Knowledge of the prediction interval enables users to:

- Assess future uncertainty;

- Plan different strategies for the range of possible outcomes indicated by the prediction interval;

- Compare forecasts from different methods more thoroughly; and

- Explore different scenarios based on different assumptions more carefully.

123. "Scenario analysis" provides information about the range of possible outcomes of the model. Starting from the most likely outcome, the baseline, scenarios analysis sets values for a series of variables which lead to identifying the most favourable outcome (best-case scenario) and the most unfavourable outcome (worst-case scenario). Although possible, the best- and the worst-case scenarios are not necessarily associated with the highest probability to occur. Instead, they fix the extremes of the range of all possible outcomes.

124. Scenario analysis is used by the AIHW disease expenditure projection modelling team to gain insight into the level of uncertainty around the projected volume of services per treated case and excess health-price inflation. Under the low scenario, both the estimated volume of services per treated case and excess health price inflation were reduced by $20 \%$; while in the high scenario, both variables were assumed to be $20 \%$ greater than the baseline assumptions used in the model. The analysis concluded that the uncertainty around the central estimate is about plus or minus $15 \%$ (see Figure 9). 
Figure 9 AlHW Projections of health and residential aged care expenditure under different scenarios, 2002-03 to 2032-33, (\$ billion in 2006-07 dollars)

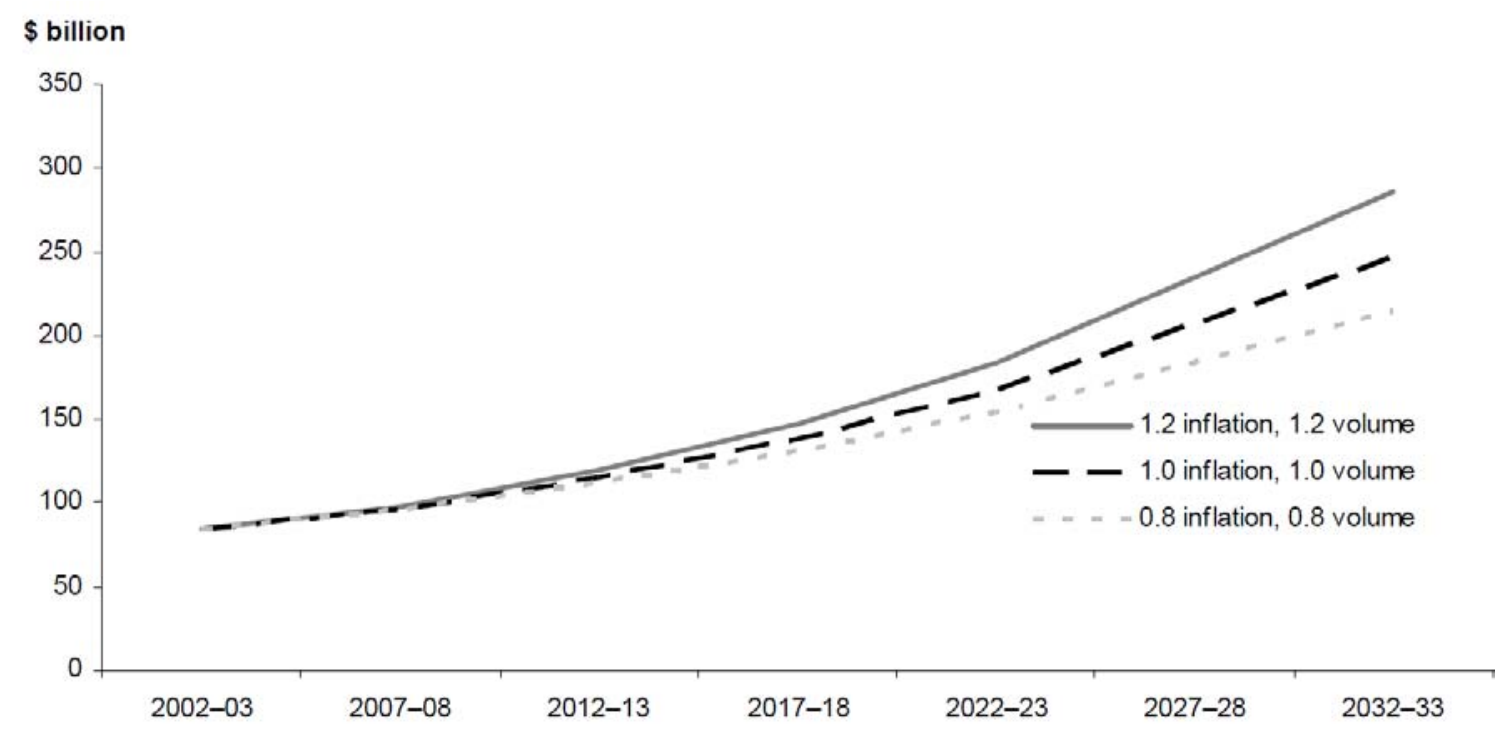

Source: AlHW Disease expenditure projection model.

125. A different valuation approach is given by "sensitivity analysis". Sensitivity analysis is the process of assessing the impact of modifying the value of a single variable on the final outcome of the model. Therefore, sensitivity analysis modifies one variable at the time, while scenarios analysis modifies a series of variables at once. Sensitivity analysis can be seen as a subset of scenario analysis.

\section{CONCLUSIONS}

126. The importance of strategies to mitigate rising health expenditures is likely to remain high, as long as expenditures continue to account for a growing proportion of GDP. As a consequence, the development of helpful tools to support decision makers in assessing the evolution of health expenditures and the potential impact of policy reforms on health expenditure growth is likely to continue to be valuable.

127. Our review has identified distinct classes of health care expenditure forecasting models: microsimulation; component-based; and macro-level. No model can be considered as superior to the others and the choice of which approach to use depends on the policy questions to be addressed. This decision should also take into consideration the constraints of time and resources, including the available data and evidence to build the model and the capacity to gather new evidence.

128. Virtually all models reviewed here account for demographic shifts in the population as they represent steady and modest forces that can be forecasted for a number of decades. Changes in individuals', or groups of individuals', profiles of health care costs, are more difficult to forecast as they can change quickly and are amenable to policy interventions. Two particularly important areas for data development in support of health expenditure forecasts are: better understanding and measuring drivers of expenditure growth, particularly innovation and technological change in health 
care; and the role of changes in health-seeking behaviour on demand for care. In particular, technological advances and the intensity of their use are among the least well measured and modelled drivers (Friedman, 2010).

129. While very short-term forecasts should be valued for their predictive accuracy, similar to a weather forecast; medium-to-longer term forecasts should be valued for their ability to demonstrate the likely future course of events, if past trends continue. In so doing, they are like a map, an abstraction of reality that shows the way to several potential destinations and the various choices of routes that may be taken.

130. The choice of modelling tool should depend, first and foremost, on the policy questions that are the most pressing to be answered. From this starting point, decisions can then be made about the class of forecasting model that would be the most appropriate to address the questions. This decision should also take into consideration the constraints of time and resources, including the available data and evidence to build the model and the capacity to gather new evidence. Two particularly important areas for data development in support of health expenditure forecasts that have emerged from this review are (i) better understanding and measuring drivers of expenditure growth, particularly innovation and technological change in health care; and (ii) the role of changes in health-seeking behaviour on demand for care.

131. Advances in computing technology and in detailed health and economic data enable the development of models that can more accurately disentangle the set of drivers of health expenditure growth; and can better help to test the potential future impact of policy interventions before they are implemented in the "real world". Such models can help to direct efforts to where they may be the most effective. Emerging onto the scene are approaches that enable detailed "what if" questions about the introduction of polices related to prevention, treatment, organisation and financing of care, technological innovation and health-sector productivity. Further, there are new approaches that enable health expenditures to be situated in a broader context: they can take account of factors such as the health, longevity, and productivity of the population; and investment, consumption and economic growth which can help policy makers evaluate "value for money".

132. On the horizon are systems of models, where a set of policy questions drives the development of the modelling platform. In the system, a forecast from one model can provide a needed input parameter for another model. Within the system, each forecasted variable is estimated from a model well-suited to that purpose, with all models in the overall architecture designed to work well together. Such systems enable a broad range of policy questions to be addressed and thus can become an on-going decision support tool capable of adapting to new questions as they arise.

133. Regardless of the choice, all models should be transparent to their users and limitations and assumptions should be well described. Forecasts from the models should always be accompanied by clear and complete notes on the methodology used. In addition, models should be validated and users should be informed about the results, including about how sensitive forecasts may be to assumptions and small changes in key variables.

134. There is tremendous future potential for the development of decision-support tools to help guide policy makers in the management of health systems, resources and expenditures and the landscape is evolving rapidly. There is an opportunity for the OECD to draw from this comparative analysis to develop and implement an international decision-support platform for health expenditure forecasting. Benefiting from the lessons learned from model development in member countries; and building from OECD experience in model development, including the recent CDP model that supported the Fit not Fat report; this platform could be designed to address pressing policy questions and to provide a tool for testing the impact of reforms and comparing results. 
135. Advantages of an internationally comparable forecasting platform include the opportunity to produce comparable forecasts through the standardisation of model specifications, assumptions and data; the opportunity to estimate and compare the relative impacts of potential policy reforms; and the opportunity to begin to examine global issues, including the pressures associated with cross-border movement of patients, personnel, services and capital. 


\section{BIBLIOGRAPHY}

Anderson LH, Martinson BC, Hall KM and Duncan IG (2007). Critical Review of Stochastic Simulation Literature and Applications for Health Actuaries. Society of Actuaries.

Ariste R and Carr J (2003). New Considerations on the Empirical Analysis of Health Expenditures in Canada: 1966-1998. Health Canada Working Paper 02-06.

Askari M. Barnett R, Danforth J, Matier C, Recker B and Tapp S (2010). Fiscal Sustainability Report. Ottawa: Office of the Parliamentary Budget Officer.

Australia Treasury, Commonwealth of Australia (2010). Australia to 2050: future challenges.

Bac C (2004). Les determinants macro-economiques des dépenses de sante : comparaison entre quelques pays développés. Rapport du CIREM pour le Sénat. 2004.

Ballinger G (2006). Improving the Timeliness of Health Expenditure Data by Means of Preliminary Data and Forecasting: the Experience of Canada. Presentation given at the OECD Health Accounts Experts, October. Paris.

Baltagi BA (2010). Health Care Expenditure and Income in the OECD Reconsidered: Evidence from Panel Data. Bonn: Institute for the Study of Labor (IZA).

Banks G (2008). Health Costs and Policy in an Ageing Australia. Health Policy Oration, John Curtin School of Medical Research, ANU, Canberra: Productivity Commission, Australia, www.pc.gov.au/speeches/?a=81758.

Bartosz P (2010). Projecting future health care expenditure at European level: drivers, methodology and main result. European Union.

Batljan I, Lagergren M (2004). Inpatient/Outpatient Health Care Costs and Remaining Years of Life: E_ect of Decreasing Mortality on Future Acute Health Care Demand. Social Science and Medicine 59: 2459-66.

Baumol W (1967). Macroeconomics of unbalanced growth: the anatomy of urban crisis. The American Economic Review 57 (3), 415-426.

Besseling P and Shestalova V (2011). Forecasting public health expenditures in the Netherlands. The Netherlands Bureau for Economic Policy Analysis CPB Background Document .

Borger C, Rutherford TF and Won GY (2008). Projecting long term medical spending growth. Journal of Health Economics 27: 69-88.

Brown L, Harris A, Picton M, Thurecht L, Yap M, Harding A, Dixon P, Richardson J (2009). Linking microsimulation and macro-economic models to estimate the economic impact of chronic disease prevention. In: Zaidi A, Harding A, Williamson P, editors. New Frontiers in Microsimulation Modelling. Ashgate: European Centre Vienna: 527-556. 
Chandra A and Skinner J (2011). Technology Growth and Expenditure Growth in Health Care. Cambridge: National Bureau of Economic Research.

CMS-OACT (2010). National Health Expenditure Projections 2010-2020. U.S. Department of Health and Human Services, ww.www.cms.gov/nationalhealthexpenddata/03_nationalhealthaccountsprojected.asp.

Congressional Budget Office (2008). Growth in Health Care Costs. Washhington: CBO.

Di Matteo L (2003). The income elasticity of health care spending. A comparison of parametric and nonparametric approaches. European Journal of Health Economics 4: 20-29.

Di Matteo L (2005). The Macro Determinants of Health Expenditure in The United States and Canada. Assessing the Impact. Health Policy 71: 23 - 42.

Di Matteo L (2010). The sustainability of public health expenditures: evidence from the Canadian federation. European Journal of Health Economics 11 (6): 569-84.

Di Matteo L and Di Matteo R (1998). Evidence on the determinants of Canadian provincial government health expenditures: 1965-1991. Journal of Health Economics 17: 211-228.

Docteur E and Oxley H (2004). Health-systems Reform: Lessons from Experience. In OECD, Towards High-Performing Health Systems (chapter 1).

European Commission (2009). The 2009 Ageing Report: Economic and Budgetary Projections for the EU-27 Member States (2008-2060).

Fogel R (2008). Forecasting the cost of U.S. health care in 2040. Cambridge, Massachussetts: National Bureau of Economic Research.

Frankel J (2011). Over-optimism on forecasts by offical budget agencies and its implications. Oxford Review of Economic Policy 27(4): 536-562.

Friedman J (2010). Predicting Medicare Cost Growth. In G. Wunderlich, Improving Health Care Cost Projections for the Medicare Population: Summary of A Workshop (pp. 83-106). Washington: The National Academies Press.

Fries J (1980). Aging, Natural Death and the Compression of Morbidity. New England Journal of Medicine 303(3): 130-135.

Gerdtham U-G and Jonsson B (2000). International comparison of health expenditure: theory, data and econometric analysis. In A. Culyer, \& J. Newhouse, Handbook of Health Economics (pp. 11-53). Elsevier Science.

Gerdtham U-G, Sogaard J, Andersson F, Jonsson B (1992). An econometric analysis of health care expenditure: A cross-section study of the OECD countries. Journal of Health Economics 11: 63-84.

Getzen TE and Poullier J-P (1992). International Health Spending Forecasts: Concepts and Evaluation. Social Science and Medicine 34 (9): 1057-1068.

Getzen TE (2000a). Forecasting Health Expenditures: Short, Medium, and Long (Long) Term. Journal of Health Care Financing 26 (3): 56-72. 
Getzen TE (2000b). Health care is an individual necessity and a national luxury: applying multilevel decision models to the analysis of health care expenditure. J Health Econ 19: 259-270.

Getzen TE (2006). Aggregation and the Measurement of Health Care Costs. Health Services Research 41 (5): 1938-1954.

Goldman DE (2005). Consequences of Health Trends and Medical Innovation for the Future Elderly. Health Affairs, www.content.healthaffairs.org accessed May 31, 2011.

Goss J (2008). Projection of Australian Health Care Expenditure by Disease, 2003 to 2033. Canberra: Australian Institute of Health and Welfare.

Grunenberg EM (1997). The failure of success. Milbank Mem Fund Q Health Soc. 55: 3-24.

Harris KM, Galasso JP, Eibner C (2008). Review and evaluation of the VA Enrollee Health Care Projection model. Report prepared for the Department of Veterans Affairs.

Hartwig J (2008). What drives health care expenditure? Baumol's model of "unbalanced growth" revisited. Journal of Health Economics 27, 603-623.

Herwartz H and Theilen B (2010). The Determinants of Health-Care Expenditure: New Results from Semiparametric Estimations. Health Economics 19: 964-978.

Hollenbeck K (1995). A Review of Retirement Income Policy Models. Upjohn Institute Staff Working Paper 95-38. W.E Upjohn Institute for Employement Research.

Huber M (1999). Health Expenditure Trends in OECD Countries, 1970-1997. Health Care Financing Review 21 (2): 99-117.

Kocher R and Sahni N (2011). Rethinking Health Care Labor. The New England Journal of Medicine 365 (15): 1370-1372.

Kopec JA, Finès P, Manuel DG, Buckeridge DL, Flanagan WM, Oderkirk J, Abrahamowicz M, Harper S, Sharif B, Okhmatovskaia A, Sayre EC, Rahman MM and Wolfson MC (2010). Validation of population-based disease simulation models: a review of concepts and methods. BMC Public Health 10:710.

Lakdawalla DN, Goldman DP and Shang B (2005). The Health and Cost Consequences Of Obesity Among The Future Elderly. Health Affairs W5: R30-R41.

Lee R and Miller T (2002). An Approach to Forecasting Health Expenditures, with Application to the U.S. Medicare System. Health Services Research 37 (5): 1365-1386.

Leung GM, Tin KYK and Chan W-S (2007). Hong Kong's health spending projections through 2033. Health Policy, 81: 93-101.

Martin AB, Lassman D, Washington B, Catlin A and the National Health Expenditure Accounts Team (2012). Growth In US Health Spending Remained Slow In 2010; Health Share Of Gross Domestic Product Was Unchanged From 2009. Health Affairs 31 (1): 208-219.

McGrail K, Green B, Barer, M, Evans R, Hertzman C and Normand C (2000). Age, costs of acute and long-term care and proximity to death: Evidence for 1987-88 and 1994-95 in British Columbia. Age Ageing 29:249-53 
Michel JP and Robine J (2004). A "new" general theory of population ageing. Geneva Papers on Risk and Insurance-Issues and Practice 29(4): 667-678.

Miller T (2001). Increasing Longevity and Medicare Expenditures. Demography 38: 215-226.

Ministry of Economy and Finance (2011). Mid-long Term Trends for The Pension, Health and Longterm Care Systems. Available at: www.rgs.mef.gov.it.

Ministry of Health and Social Affairs (2010). The Future Need for Care: Results of the LEV Project. Stockholm: Government Offices of Sweden.

Morgan SC and Cunningham C (2011). Population Aeging and the Determinants of Healthcare Expenditures: The Case of Hospital, Medical and Pharmaceutical Care in British Columbia, 1996 to 2006. Healthcare Policy, 7 (1): 68-79.

Newhouse JP (1992). Medical Care Costs: How Much Welfare Loss? The Journal of Economic Perspective 6 (3): 3-21.

OECD (2011). Health at a Glance. Paris: OECD.

OECD (2006). Projecting OECD Health and Long-Term Care Expenditures: What Are The Main Drivers? Paris: OECD Economics Department Working Paper.

Office fédéral de la statistique (2007). Déterminants et évolution des coûts du système de santé en Suisse. Revue de la littérature et projections à l'horizon 2030. Neuchatel.

Orszag P (2008). Growth in Health Care Costs. CBO Testimony before the Committee on the Budget, United States Senate. Washington: Congressional Budget Office.

Pomp M and Vujic S (2008). Rising health spending, new medical technology and the Baumol effect. The Hague: CPB Netherlands.

Productivity Commission (2005). Impacts of Advances in Medical Technology in Australia. Research Report, Melbourne.

Rannan-Eliya R (2007). Population Ageing and Health Expenditure: Sri Lanka 2001-2101. Colombo, Sri Lanka: Institute for Health Policy.

Ringel JS, Eibner C, Girosi F, Cordova A and McGlynn A (2010). Modeling Health Care Policy Alternatives. Health Services Research 45(5): 1541-1558.

Seshamani M and M.Gray A (2004). A longitudinal study of the effects of age and time to death on hospital costs. Journal of Health Economics 23:217-235.

Smith S, Newhouse JP and Freeland MS (2009). Income, Insurance, And Technology:: Why Does Health Spending Outpace Economic Growth? Health Affairs 28 (5): 1276-1284.

Spillman B and Lubitz J (2000). The effect of longevity on spending for acute and long-term care. New England Journal of Medicine 342(19):1409-15.

Swift R. (2010). The relationship between health and GDP in OECD countries in the very long run. Health Economics, published online. 
Thorpe KE, Florence CS, Howard DH and Joski P (2004). The Impact Of Obesity On Rising Medical Spending. Health Affairs Web Exclusive, W4: 480-486.

Thorpe KE, Ogden LL and Galactionova K (2010). Chronic Conditions Account For Rise In Medicare Spending from 1987 To 2006. Health Affairs 29 (4): 1-7.

Triplett J (2003). Productivity Measurement Issues in Services Industries: "Baumol's Disease" Has Been Cured. FRBNY Economic Policy Review 23-33.

Wanless D (2002). Securing our Future Health: Taking a Long-Term View. London: HM Treasury.

Weinstein MC, O'Brien B, Hornberger J, Jackson J, Johannesson M, McCabe C and Luce BR (2003). Principles of Good Practice for Decision Analytic Modeling in Health-Care Evaluation: Report of the ISPOR Task Force on Good Research Practices-Modeling Studies. Value in Health 6(1): 9-17.

Weisbrod B (1991). The Health Care Quadrilemma: An Essay On Technological Change, Insurance, Quality of Care, and Cost Containment. Journal of Economic Literature 24: 523-552.

White C (2007). Health Care Spending Growth: How Different Is The United States From The Rest Of The OECD? Health Affairs 26 (1): 154-161.

Yang Z, Norton EC and Stearns SC (2003). Longevity and health care expenditures the real reasons older people spend more. Journals of Gerontology Series B: Psychological Sciences and Social Sciences 58: 2-10.

Yang Z and Hall AG (2008). The Financial Burden of Overweight and Obesity among Elderly Americans: The Dynamics of Weight, Longevity, and Health Care Costs. Health Services Research 43 (3): 849-868.

Zucchelli E, Jones AM and Rice N (2010). The evaluation of health policies through microsimulation methods. HEDG Working Paper - University of York (3).

Zweifel P, Felder S and Meiers M (1999). Ageing of population and health care expenditure: a red herring? Health Economics 8: 485-496. 


\section{ANNEX 1 FORECASTING MODELS REVIEWED}

\section{Annex 1.1 Australia - Australian Institute for Health and Welfare (AIHW)}

The Australian Institute of Health and Welfare (AIHW) model provides projections of expenditure for Australia for the period 2003 to 2033. The projections revise and update those in an earlier report prepared for the United Nations (Vos et al. 2007). The AIHW model has the merit of extending the usual cell-based actuarial approach to also include epidemiological projections for a specific set of diseases. Health expenditure projections by age, gender and functions (such as hospitals, out-of-hospital medical services and pharmaceuticals) are therefore enriched by taking into account also the projections on cardiovascular disease, road traffic injuries, dementia, musculoskeletal disorders, lung cancer and diabetes. By forecasting health expenditure at a disease level, the model shows that expenditure for each disease can be determined by different drivers.

\section{Policy questions the model has supported}

The AIHW model aims at assessing the impact on long term health expenditure of:

- different health reform plans,

- changes in external environment,

- modification of health specific prices as compared to general inflation,

- variations in the volume of services per treated cases of disease.

\section{Class of forecasting model}

Component-based model combining an actuarial and epidemiological approach.

\section{Forecasting methods}

The AIHW model projects Australian health expenditure by combining both demographic and non-demographic factors. Demographics include population growth and changes in the age structure, while non-demographic factors refer to the change in disease rates (incidence or prevalence), volume of services per treated case, treatment proportions (the proportion of cases that receive treatment) and excess health price inflation (i.e. the difference between health inflation and general inflation).

Health expenditures by age, gender and functions are projected for a set of diseases. Functions refer to the different areas of expenditure, such as hospitals, out-of-hospital medical services and pharmaceuticals. Diseases include cardiovascular disease, road traffic injuries, dementia, musculoskeletal disorders, lung cancer and diabetes.

The cell-based model potentially includes, for each disease modelled: 16 functions, 20 age-sex profiles, five time periods and four non-demographic factors - giving a total of 6,400 separate cells for each disease. For practical reasons, however, for certain diseases the dimensions have been reduced by aggregating the functions so to limit the actual number of cells to 110 . 
Disease incidence and prevalence for 2003 were used as the baseline for the projections. Expected increases in the cost per case of disease in the future were estimated using trends observed between 1993-94 and 2004-05. More detail is provided below on parameters used in the model.

Demographic projections are those produced by the Australian Bureau of Statistics (ABS), whereas the incidence or prevalence of diseases is projected by using the WHO-DisMod2 Software.

\section{Projected variables and unit of measurement}

Expenditure on personal health care (public + private) at constant prices (2006-07 dollars).

\section{Time horizon}

30 years into the future (from 2003 to 2033). However, not all years are estimated but just a few points in time ( $t$-reference, $t+10, t+20, t+30)$.

\section{Health expenditure drivers}

The AIHW model puts into a single framework a large set of health expenditure drivers. Drivers analysed include: population growth and the changes in its age structure, the impact of technological change, proximity to death expenditures, the difference between health inflation and general inflation and the obesity 'epidemic'.

\section{Assumptions, sensitivity analysis and criteria to assess forecasting method}

The central assumptions used in the AIHW projection model are that the non-demographic drivers of health and residential aged care expenditure will grow at similar rates to previous years, and that no change in the levels of efficiencies and inefficiencies occurs. Moreover, the model assumes that new technologies and changes in treatment practices will have a similar impact on the growth in the volume of services per case of disease as occurred in the last decade

The projection model also assumes that the proportion of health expenditure that the Australian government, state and territory governments and the private sector funds for each type of service remains the same throughout the whole period. The proportion considered is that observed in 2004/05.

Sensitivity analysis is also used to gain additional insight into the levels of uncertainty of the volume of services per treated case and health price inflation. Three assumptions were used for each variable (low, medium and high). The medium assumption refers to the central assumptions used in the model. Under the low assumption scenario, both the estimated volume of services per treated case and health price inflation were reduced by $20 \%$, and under the high assumption scenario, both variables were assumed to be $20 \%$ greater.

\section{References}

Goss J (2008). Projection of Australian Health Care Expenditure by Disease, 2003 to 2033. Canberra: Australian Institute of Health and Welfare.

Vos T, Goss J, Begg S \& Mann N (2007). Projection of health care expenditure by disease: a case study from Australia. Brisbane: School of Population Health, University of Queensland. 


\section{Annex 1.2 Australia - National Centre for Social and Economic Modelling (NATSEM) Micro- Macro}

The Micro-Macro Chronic Disease Prevention Model forecasts the health, health-care costs and macroeconomic impacts associated with population health initiatives. The first version of this model was developed to study the impact of type 2 diabetes on the Australian population including health, health expenditures and broader economic impacts, such as changes in employment and productivity. The model was used to test the potential future impact of various policy interventions to reduce the future burden of diabetes for the purpose of improved decision-making regarding population health investment, work-force participation and productivity.

It represents the first generation of model building where both health expenditures and broader macroeconomic impacts are forecast together in an integrated framework. As a result, it enables estimates of both short term costs of a policy intervention, as well as potential broader and longerterm returns on this expenditure. For example, a diabetes prevention program may produce higher future health expenditures but also produce growth in employment and GDP.

The joint models were developed by the National Centre for Social and Economic Modelling (NATSEM) at the University of Canberra and the Centre for Health Economics (CHE) and the Centre of Policy Studies (CoPS) at Monash University.

\section{Policy questions the model has supported}

What are the relative benefits of investing in primary prevention compared to secondary prevention in terms of health outcomes and health expenditures?

What is the optimal balance of investment across strategies aimed at the whole population versus those targeting high risk groups?

What could be the health, health expenditure and macro economic impacts of the introduction of a program to reduce the incidence and progression of type 2 diabetes?

\section{Classes of forecasting methods}

The framework incorporates together two forecasting classes: component-based and computable general equilibrium.

\section{Technical description}

The Micro-Macro Chronic Disease Prevention Model links a projection model of disease prevalence to a computable general equilibrium model (CGE) of the Australian economy through a labour supply model. ${ }^{1}$

The diabetes model is a cell-based simulation model with 3,456 cells representing eight diabetes risk factors: sex, age, income, waist circumference, blood pressure, abnormal cholesterol, physical activity and smoking history. Data from the Australian Diabetes, Obesity and Lifestyle Study (AusDiab) are used to initialize the model. The prevalence of diabetes and pre-diabetes are determined for each cell depending on the risk factors within that cell. The population base is updated every three years to reflect population ageing according to estimates from the Australian Bureau of Statistics. Assumptions of changes in the prevalence of modifiable risk factors are based on historical trends. Alternative prevention programs are tested by moving records from cells with higher prevalence of certain risk factors to cells with lower risk factor prevalence. The probability of diabetes for a particular cell, multiplied by its population, yields the number of persons expected to develop 
diabetes. The model then estimates the overall prevalence of diabetes, disability-adjusted life years, and total direct health expenditure enabling estimates of cost effectiveness, cost-utility and costbenefit.

The labour supply model is a logistic regression model examining a discrete choice, working or not working. This choice is a function of predicted health status, objective measures of health, and individual characteristics. Predicted health status is a linear combination of past health status and individual characteristics estimated via an Ordinary Least Squares (OLS) model.

The general equilibrium model (Monash CGE) is a computable dynamic model that projects the future economy from baseline and in the presence of shocks, such as the introduction of a new policy. ${ }^{2,3}$ The base case is derived from input/output data in a given year as well as other exogenous variables, such as population size; foreign currency prices of imports; tax and tariff rates; public consumption; and, at the industry and commodity level: outputs, employment, capital, investment, export, import, private consumption, and price deflators. ${ }^{3}$ Monash CGE also includes, as exogenous variables, projections prepared by experts in various dimensions of the economy, such as world commodity markets, international tourism, production technologies and economic policy. Forecasts of the base case are made for 107 industries over time and results reflect general conditions of the economy as well as commodity and industry-specific technological change. ${ }^{2}$

Under different diabetes prevention policies, the shocks imposed on the CGE model result from modifying the base case by the predicted annual percentage change in employment hours (from the labour supply model) and in expenditure on health (from the diabetes model) which acts as the measure of health care demand.

\section{Projected variables, measurement units and time horizons}

The Micro-Macro model projects a broad range of health and economic indicators including:

- Prevalence of risk factors for diabetes,

- Prevalence of diabetes,

- Disability-adjusted life years,

- Mortality associated with diabetes,

- Direct health care costs in 2005 constant dollars in total and by diabetes status,

- Gains or losses in the number of employed persons,

- Percentage change in total employment hours, and

- Percentage change in real GDP, consumption and investment.

Projections were produced from 2006 to 2026. This enables examination of both the short term impact of the intervention on health care expenditures and taxes as well as a longer-term view of the impact on health, health expenditure, employment and GDP.

\section{Determinants of health expenditures}

As this is a set of interconnected models, the drivers of direct health expenditure projections are a sub-set of the drivers of percentage change in GDP. 
Drivers of health expenditures included in the model are:

- Population dynamics

- Risk factors (income, waist circumference, blood pressure, abnormal cholesterol, physical activity and smoking history)

- Prevalence of diabetes

Drivers of percentage change in GDP are:

- Population dynamics

- Socio-demographic factors

- Health expenditures (demand for care)

- Employment hours

- General conditions of the economy as well as commodity and industry-specific technological change

\section{Assumptions, sensitivity analysis and criteria to assess forecasting methods performance}

The diabetes model is a discrete time Markov chain that identifies the states that individuals can occupy and allows them to transition between states at fixed time intervals of three years. Unlike most models we have reviewed, risk factors, disease prevalence and functional health status are explicitly modelled, not assumed.

Estimates of total health care expenditures are allocated based on the following assumptions. A non-diabetic patient has an annual per capital direct cost of health care of 1.00. Individuals with diagnosed diabetes have a ratio of 1.7 (obtained from the literature); individuals with undiagnosed diabetes have a ratio of 1.5 and individuals with pre-diabetes 1.3 . In the prevention scenario, newly diagnosed individuals were assigned a ratio of 1.6.

The diabetes model forecasts health expenditure using constant prices. Details on the financing of health expenditures, the organisation of health care and treatment pathways were not modelled. Implicitly, the impact of technological change or other factors on prices are assumed to be constant. In the Monash CGE model, however, technological change is modelled from historical trends for all industries and for each, price changes are modelled.

The CGE model depends on assumptions of economic equilibrium including that demand(s) equals supply(s); that demand and supply maximise utility and profits; that prices equal unit costs; and that end of year capital stocks equal beginning of the year capital stocks plus investment and minus depreciation. One of the challenges with this approach is that there are often multiple model solutions.

There is no explicit budget constraint in this CGE model; however, all costs of an intervention must be recovered through taxation. Therefore, maximum spending on a diabetes prevention program would occur when all taxable income is exhausted.

No feedbacks between the micro and macro-level were captured. Therefore changes in the broader economy, such as an increase in income taxes, would not change the behaviour of individuals. 


\section{References}

Brown L, Harris A, Picton M, Thurecht L, Yap M, Harding A, Dixon P, Richardson J (2009). Linking microsimulation and macro-economic models to estimate the economic impact of chronic disease prevention. In: Zaidi A, Harding A, Williamson P, editors. New Frontiers in Microsimulation Modelling. Ashgate: European Centre Vienna: 527-556.

Dixon, P.B. and M.T. Rimmer (2002). Dynamic General Equilibrium Modelling for Forecasting and Policy. Amsterdam: Elsevier Science B.V. 


\section{Annex 1.3 Australia - Australian Government Productivity Commission}

The Australian Government asked the Productivity Commission to undertake a research study detailing and explaining the impact of advances in medical technology ${ }^{12}$ on public and private healthcare expenditure, and the associated costs and benefits for the community. The approach used has the merit of being "technology-specific" as it treats technologies at an identifiable, descriptive level, and measurable level. It should be noted that the estimates were illustrative only, and intended to give some insights as to whether the impacts of new technologies were likely to be expenditure increasing or decreasing, rather than to accurately estimate the magnitude of those impacts.

\section{Policy questions the model has supported}

Assess the likely impact of advances in medical technology on healthcare expenditure over the next ten years, and identify the areas of significant potential growth

\section{Class of forecasting model}

It is a macro-level model designed to forecast the expenditure impacts of potential future technologies to treat cardiovascular disease, cancer, diabetes and neurological diseases. If the benefits delivered by technologies were measured, this would have been a cost-effectiveness analysis.

\section{Forecasting methods}

To assist in determining whether a new technology is expenditure increasing or decreasing, a comparison is made between estimates of expenditure in 2015-16 for treatment of a condition within a disease category using a new technology compared to using a current technology

Estimates are derived for the following four advances in medical technology:

- insulin sensitisation drugs for prevention of type 2 diabetes mellitus

- implantable atrial defibrillators for control of atrial fibrillation and stroke prevention

- robotic-assisted surgery for prostate cancer

- a vaccine for treatment of established Alzheimer's Disease

\section{Projected variables, measurement units afnd time horizons}

\section{Projected variables}

Likely future expenditure impacts of new medical technologies for both the government and the private sectors.

Measurement units

Net health expenditure impact of selected technology

Time horizons

Ten years (to 2015-2016)

12 The definition of medical technology is very broad, including diagnostics, pharmaceuticals, medical devices and equipment, as well as knowledge and administrative support systems. 


\section{Drivers of health expenditure}

New technology:

- Volume: number of cases eligible for the new technology

- Unit cost per year

- Cost savings: reduction in prevalence or complications

- Health inflation

Current technology:

- Volume: number of cases eligible for the current technology

- Unit cost per year

- Cost savings: reduction in prevalence or complications

- Health inflation

Assumptions sensitivity analysis and criteria to assess forecasting methods performance

- The potential benefits delivered by the technologies in study have not been evaluated.

- To convert expenditure estimates to 2015-16 dollars, a health inflation rate of 2.7 per cent per annum is assumed. This rate is based on the average health inflation rate between 199293 and 2002-03 and is derived from the total health price index (an implicit price deflator) calculated by the Australian Institute of Health and Welfare

\section{References:}

Productivity Commission (2005). Impacts of Advances in Medical Technology in Australia. Research Report, Melbourne. 


\section{Annex 1.4 Australia - Australian Government, The Treasury}

The Intergenerational Report 2010 provides a comprehensive analysis of the economic and fiscal challenges that Australia will face over the next forty years. The key conclusion is that an ageing population and climate change present significant long-term risks for the economy and the sustainability of government finances, particularly in the health sector. This model has the merit of combining a component approach for the short-to-medium term to an aggregate approach for the long term spending projections.

\section{Policy question the model has supported}

To assess the fiscal and economic challenges of an ageing population, and develop responses that will mitigate these consequences in the most effective way and minimise the size of the adjustment costs in the future.

\section{Class of forecasting model}

Component-based simulation model (actuarial approach).

\section{Forecasting methods}

Over the next 40 years, forecasts are based on trends in the cost of health services per head of population by age and gender, combined with projected population changes. Projections are derived by first applying non-demographic growth to current, age-specific spending rates per person. These estimates are then increased by the projected population and Consumer Price Index (CPI) to derive nominal projections of spending.

The model projects the main components of health spending separately for ten years beyond the end of the forward estimates. This allows different growth rates for medical benefits, pharmaceutical benefits, private health insurance, hospitals and other health spending over this period. From 2023-24 onwards, the approach uses a model of total Australian government health spending that assumes that non-demographic growth trends towards the historical growth rate for health spending by all levels of government over the longer term.

The non-demographic growth rates for each component are derived from trends in the historical data. ${ }^{13}$ This is done by first adjusting historical spending data for CPI growth and changes in the size and age structure of the population to derive a series of real age-adjusted spending per person. The non-demographic growth rates are then determined by fitting trends to these series and, where possible, calculating non-demographic growth by age group ${ }^{14}$.

\section{Projected variables, measurement units and time horizons}

\section{Projected variables}

Central government health spending

\footnotetext{
13 Private Health Insurance trend is drawn from data from 2000-01 to the present; Medical Benefits trend is drawn from data from 1988-89 to the present; Pharmaceutical benefits trend is drawn from data from 2002-03 to the present. Hospital expenditure is based on a growth factor which is updated annually. 
Measurement units

Cost of health services per head of population by age and gender

Time horizons

- $\quad$ short-to-medium term (to 2023-2024): component model

- $\quad$ long term (from 2023-2024 to 2049-2050): aggregate model

\section{Determinants of health expenditure}

\section{Component model}

Five spending components are used:

- Hospitals

- Medical benefits

- Pharmaceutical benefits:

- Private health insurance rebate

- Other health spending ${ }^{15}$

For medical and pharmaceutical benefits, a linear trend fits the historical data more closely, so non-demographic growth is projected forward as a constant real dollar increase in spending. For expenditure on private health insurance, an exponential trend fits the data more closely, so nondemographic growth is projected as a percentage increase in spending each year. For hospitals, a composite index that reflects age-weighted population growth, growth in health prices and a health technology growth factor is used ${ }^{16}$.

\section{Aggregate model}

The aggregate model forecasts health spending per person by age and gender using the same growth rate for all age groups. Non-demographic growth is projected forward using an exponential growth form, starting at the rate implied by the component models at the end of their projections around 1.8 per cent. This is transitioned up to the all-government growth rate of 3.2 per cent using a logistic curve.

\section{Assumptions sensitivity analysis and criteria to assess forecasting methods performance}

CPI is assumed to grow at its trend rate of by $2 \frac{1}{2}$ per annum beyond the forward estimates. The impact on percentage point change in 2049-2050 in health spending of alternative scenarios as to participation - total labour force, older workers, and unemployment - productivity, and population - net migration, fertility, and life expectancy - is assessed.

\section{References}

Commonwealth of Australia (2010). Australia to 2050: future challenges.

15 Other health spending includes population health and safety, workforce initiatives and non-Medical Benefits Scheme payments to GPs (including for infrastructure, training and the Practice Incentive Program), medical research, and veterans' health spending not elsewhere modelled. 


\section{Annex 1.5 Canada - Canadian Institute for Health Information (CIHI)}

In the framework of the ordinary compilation of health expenditure data, the Canadian Institute for Health Information CIHI has implemented the Nowcasting model which allows the release of health expenditure aggregated figures a few months after the end of the accounting year. The model breaks down total health expenditure into several subcomponents, corresponding to a combination of financing agents and functions. Depending on the nature of the subcomponents, CIHI employs various forecasting techniques, ranging from the use of provisional public budgets to pure extrapolation of past trends.

\section{Policy questions the model has supported}

The model is not meant to address any specific policy questions. Its use, however, improves the timely release of health expenditure data for the benefit of policy makers, stakeholders and general public.

\section{Classes of forecasting model}

$$
\text { Macro-level model (nowcasting) }
$$

\section{Forecasting methods}

Total health expenditure is broken down into different subcomponents each representing a combination of function and financing agent such as, for example, dental care services funded by the private sector. Each subcomponent is then separately forecasted. The provincial government sector represents the main subcomponent. To forecast it, it is assumed that the ex-ante growth rate of the Provincial Government Budget entirely determines the ex-post increase in health expenditure funded by the Provincial Government. Hence, the forecasted value is obtained by applying the same growth rate observed for the Public budget to the value of provincial health expenditure recorded in the previous period.

The remaining part of health expenditure is decomposed by financing agent and a selection of functions. Each of them is then forecasted using various pure extrapolative techniques relying solely on a statistical analysis of values observed in the past. Forecasts are based either on an automatic forecasting procedure or on a locally weighted polynomial regression.

\section{Automatic Forecasting Procedures}

For each series, up to 40 different univariate forecasting specifications are evaluated using the module ETS in SAS. The best specification is then automatically selected based on the root mean square error of prediction. Specifications include the exponential smoothing family (simple, double, Holt, Brown, Winters, damped trend, etc.); time trends and ARIMA models. Logarithmic transformations are also sometime used.

\section{LOESS (locally weighted polynomial regression)}

The polynomial is fit using weighted least squares, giving more weight to the values near the year being forecast and less weight to the values farther in the past. 
Projected variables, measurement units and time horizons

Total (public and private) expenditure on health at current prices up until t-1 (for example up until 2010 if data are released in 2011).

\section{Drivers of health expenditure}

Provincial governments budgets

\section{References:}

Ballinger G (2006). Improving the Timeliness of Health Expenditure Data by Means of Preliminary Data and Forecasting: the Experience of Canada. Presentation given at the OECD Health Accounts Experts, October. Paris. 


\section{Annex 1.6 Canada - Parliamentary Budget Office (PBO)}

The Parliament of Canada mandates the Parliamentary Budget Officer to provide independent analysis of the state of Canada's finances and economy. A report on the sustainability of the federal government's fiscal structure was prepared containing projections according to two scenarios related to assumptions about the Canada Health Transfer. The Canada Health Transfer is the federal government's main health-care related expenditure and accounts for one-fifth of total provincialterritorial government spending on health care in Canada. The majority of governmental expenditures on health are funded by provincial and territorial governments. An alternative projection is also estimated for provincial and territorial expenditures using the components of health care.

\section{Policy questions the PBO models have supported}

What may be the proportion of GDP in the future accounted for by provincial-territorial and federal spending on health care?

How have population aging, income and enrichment factors contributed to historical expenditure growth?

How have different components of health care spending (hospitals, medications etc.) contributed to historical expenditure growth?

\section{Classes of forecasting methods}

Component-based model with a cohort framework developed from the methods used by the US Congressional Budget Office.

\section{Forecasting method}

Using a growth-accounting approach, the PBO modelled historical growth in health expenditures per capita by estimating annual expenditure as a sum of growth in an age factor, in nominal GDP per capita and a residual which is considered to represent an enrichment factor. In the work of the CBO, this enrichment factor is labelled "excess cost growth" and represents the impact of technological change and other factors on historical health expenditure growth.

The age factor is an age-weighted index of health expenditure growth and is included to represent the change in health expenditures associated with population growth and aging. Each year, the share of the population represented by each age group is multiplied by the average per-capita health expenditures for that same age group in 1998. The annual age factor is then the sum of the estimated values for all age groups each year. The base year is 1998 as it was the first year that estimates of health expenditure per year by age group were available from the Canadian Institute for Health Information.

A transformation of the same equation is used to project expenditures into the future. To do so, the PBO estimates the future annual ratio of per capita health expenditure to per capital GDP as a function of the ratio in the previous year, the change in the age factor from the previous year, and the enrichment factor. The age factor is estimated separately by PBO using PBO assumptions modifying demographic projections of Statistics Canada. The enrichment factor is assumed to equal, in all future years, the average value estimated from the historical analysis. 


\section{Projected variables, measurement units and time horizons}

Total provincial-territorial government health expenditure as a share of GDP is projected to rise from $6.8 \%$ in 2007 to $10.9 \%$ in $2050-51$ and then to $12.3 \%$ in $2084-85$ using this methodology.

For the Canada Health Transfer, in the baseline projection, the federal share of all governmental health care expenditures is assumed to be maintained at 2013-14 levels (therefore, to grow in proportion with estimated growth in provincial/territorial expenditures) beginning in 2014-15 and continuing to 2084. With these assumptions, its share of GDP is estimated to reach $2.8 \%$ in 2084 . Under an alternative scenario, the CHT is assumed to grow at its current rate of $6 \%$ per year to 2084 and the CHT is estimated to account for $9.5 \%$ of GDP by $2084-85$.

In an alternative approach, provincial-territorial expenditures are decomposed into each of the following components of health care spending: hospitals, other institutions (residential care), physicians, other professionals, drugs, and other (capital, public health, administration, research, home care and transportation).

Each of these components was then also projected separately. This approach indicates that provincial-territorial expenditures as a share of GDP could reach $60 \%$ in 2084-85. The much greater projected growth is driven by growth in medication and other expenditures and shows the potential outcome of allowing components of health care expenditure to rise well above growth in the size of the economy for an extended period of time and also the effect of compounding resulting from the projection method.

\section{Determinants of health expenditures}

Potential drivers of health expenditures as a share of GDP that were included in the model are:

- Income - expressed as previous nominal GDP,

- Aging - expressed as the component of health expenditure attributed to aging, and

- Technological change - estimated residually and identified as an enrichment factor.

\section{Assumptions, sensitivity analysis and criteria to assess forecasting methods performance}

The age factor does not take into account the potential for improvements in life expectancy to lead to improved health status and therefore delay the impact of aging on health care spending.

The PBO model assumes unitary income elasticity. In other words, that nominal-GDP and health care spending will grow at the same rate over time and the relationship between these two variables is, therefore, one.

The enrichment factor is assumed to mainly reflect technological advancements in health care that raise the quality and effectiveness of health care and therefore raise demand for and spending on health care. However, as a residual, it measures all factors not explicitly included in the model. Decomposition of the growth in this factor into four time periods indicates that the estimated average annual growth in this factor varies widely from -0.7 (1990-1999) to $1.2 \%$ (1980-89). To account for periods of low and high growth, the average annual growth in the factor over the period 1975 to 2007 was input into the projection.

To assess plausibility, the authors compared their projection results to those published elsewhere. 


\section{DELSA/HEA/WD/HWP(2012)2}

\section{References}

Askari M. Barnett R, Danforth J, Matier C, Recker B and Tapp S (2010). Fiscal Sustainability Report. Ottawa: Office of the Parliamentary Budget Officer.

Congressional Budget Office (2007). The Long-Term Outlook for Health Care Spending, Congress of the United States. 


\section{Annex 1.7 Canada - Statistics Canada/Population Health Model (POHEM)}

The Population Health Model (POHEM) projects the potential future health and health-care utilisation of particular chronic diseases (lung, breast and colorectal cancer; osteo-arthritis; and cardiovascular disease and diabetes) (Statistics Canada, 2011). POHEM is not developed to generate projections of total health expenditures, but rather provides a platform for the evaluation, through scenarios, of the health and health care system impacts of new prevention or treatment policies targeted to specific risk factors or to particular diseases. For example, the new POHEM Cancer Risk Management Model, projects total public health expenditure and other economic impacts (labourforce participation and taxes and transfer payments) of lung, colo-rectal and cervical cancers at baseline and in response to policy scenarios (Canadian Partnership Against Cancer, 2011).

Statistics Canada leads POHEM development and works in partnership with the Canadian Partnership against Cancer, the Public Health Agency of Canada, and other health organisations and experts.

\section{Policy questions the model has supported}

POHEM supports testing a wide-range of user-defined policy scenarios related to prevention and treatment policies. Example policy questions include:

- What would be the impact on public acute care and home care expenditures of an outpatient/early discharge strategy for breast cancer surgery patients? (Will, B.P. et al. , 2001)

- What may be the potential health and public health-care expenditure impacts of adopting faecal-occult blood testing as a screening technique for colorectal cancer? (Maroun J. et al. , 2003)

- What would be the additional treatment costs if indications were expanded for the use of a more expensive treatment (drug X) compared to current treatment practice? (Canadian Partnership Against Cancer, 2011)

\section{Class of forecasting model}

Microsimulation (dynamic)

\section{Forecasting method}

POHEM focuses on individuals and builds a virtual population that represents Canada (Wolfson, M.C., 1994). Individuals experience health-related events, such as developing risk factors and disease, experiencing treatments, gaining or losing health and eventually dying. Risk factors are explicitly modelled, including changes in smoking behaviour, body mass, hypertension and others.

Recent cancer models include detailed diagnostic and treatment pathways for patients at various stages of disease progression; the costing of treatment pathways from the bottom up including all aspects of care received. This enables projection of total public expenditure on cancer diagnosis and treatment. The models also include the estimation of other economic impacts, such as the individual's capacity to continue working during treatment and impacts of cancer on individual's earnings, income and consumption taxes.

POHEM is a dynamic microsimulation model in continuous time based on a monte-carlo process. Hazards compete to determine the time of the next event in a person's life. The occurrence of an event effects a change in the state of the individual's life. Events compete to be the next to occur. 
The monte-carlo process involves the generation of a random number that influences the occurrence of events and allows outcomes to vary from one individual to another. The dynamic framework ages the individual through their lifecycle and allows for time spent with multiple health conditions.

POHEM integrates data distributions and equations from a wide range of sources including nationally representative health surveys, particularly the Canadian Community Health Survey and the National Population Health Survey; cancer registries; hospitalization databases; vital statistics; censuses of population; health-care costing databases; as well as parameters in the published literature.

\section{Health expenditure drivers}

- Population dynamics

- Distribution of health risk factors (e.g. smoking, obesity, hypertension, cholesterol)

- Disease prevalence and severity

- Utilisation of diagnostic tests and health-care therapies

- Cost of diagnostic tests and health care therapies

\section{Projected variables and measurement units}

Projects the future incidence and prevalence of chronic diseases (breast, lung and colorectal cancers, diabetes, acute myocardial infarction and osteo-arthritis); risk factors associated with these diseases; the prevalence of use of diagnostic tests and treatments (primary care and specialist visits, out-patient care, in-patient hospitalisations and palliative care); and the estimated public expenditure on these diagnostic tests and treatments.

Public expenditures on diagnostic tests and treatments are projected in total and by subcomponents such as sex, age group, region, and organisation of care. Recent cancer models project expenditures in constant 2008 dollars. POHEM also supports projection of cost-effectiveness and cost-utility measures such as cost per life year gained and cost per quality-adjusted life year gained. POHEM incorporates official population projections of Statistics Canada. The time horizon of the projections is usually twenty to twenty-five years with recent projections from 2011 to 2030.

Tests "what-if" scenarios, such as the impact of potential breakthrough technologies as well as changes in lifestyles and in the health care system-by exploring changes in the parameters of the model.

\section{Assumptions, sensitivity analysis and criteria to assess the forecasting method}

POHEM explicitly models the potential future health status and healthy life expectancy of the population at baseline and in response to policy scenarios. This differs from other models where future health status is incorporated as a model assumption. POHEM also enables the testing of scenarios of the potential future impact of a wide variety of technological developments, such as new medications, medical tests and other therapies. This contrasts with other models that do not explicitly include technological change.

POHEM does not consider several drivers of health expenditure observed in other models. Administration and infrastructure costs that may be needed to meet projected health care demand are not included. Impacts of new technologies can be tested as model scenarios, however, the baseline 
model does not explicitly include technological change as a driver of future health care demand and costs are projected in constant prices. Similarly, the model does not consider the impact of national income or health-care budgets on demand for health-care services. The cancer model does consider the impact of developing disease on labour-force participation. It excludes, however, impacts of changes in demand for care and labour-force participation on the overall economy.

Elements of model validation include the development of a conceptual model based on underlying evidence and theories; development of definitions of variables consistent with the scientific literature; and assessment of the appropriateness of parameters through comparison across different sources of parameters and consultation with experts. Once developed, POHEM models undergo calibration, internal and external model validation; uncertainty and sensitivity analyses; and face-validity evaluation. Further, POHEM models generally begin in the recent past to provide a number of years during which forecasted results can be compared with observed values.

\section{References:}

Dixon, P.B. and M.T. Rimmer (2002). Dynamic General Equilibrium Modelling for Forecasting and Policy. Amsterdam: Elsevier Science B.V.

Berthelot J-M et al. (2000). Decision framework for chemotherapeutic interventions for metastatic non-small cell lung cancer. Journal of the National Cancer Institute , 92(16):1321-29.

Canadian Partnership Against Cancer (2011). Example Applications: Cancer Risk Management Model. www.cancerriskmgmt.ca/learn-more/example-applications (accessed April 2011).

Evans, WK et al. (2000). Breast cancer: better care for less cost: is it possible? International Journal of Technology Assessment in Health Care, 16(4):1168-78.

Kopec JA et al. (2010). Development of a population-based microsimulation model of osteoarthritis in Canada. Osteoarthritis Cartilage , 18(3):303-11.

Kopec, JA et al. (2010). Validation of Population-Based Disease Simulation Models: A Review of Concepts and Methods. BMC Public Health, 10:710.

Maroun J et al. (2003). Lifetime costs of colon and rectal cancer management in Canada. Chronic Diseases in Canada , 24(4):91-101.

Statistics Canada (2011). Health Models. www.statcan.gc.ca/microsimulation/health-sante/healthsante-eng.htm (accessed April, 2011).

Will BP et al. (2001). Canada's Population Health Model (POHEM): A tool for performing economic evaluations of cancer control interventions. Eurpean Journal of Cancer , 37: 1797-1804.

Will BP et al. (2001). First do no harm: Extending the debate on the provision of preventive tamoxifen. British Journal of Cancer, 85(9):1280-8.

Wolfson MC (1994). POHEM - A framework for understanding and modelling the health of human populations. World Health Statistics Quarterly, 47:157-76. 


\section{Annex 1.8 European Union - Ageing Working Group}

The long-term projections for EU27 Member States and Norway provide an indication of the timing and scale of economic changes that would result from an ageing population in a "no-policy change" and "no behavioural changes by individuals" scenario. They show where, when, and to what extent, ageing pressures will accelerate as the baby-boom generation retires and the average life-span continues to increase. Hence, the projections are helpful in highlighting the immediate and future policy challenges posed for governments by demographic trends over a period to 2060. Separate budgetary projections were run for five age-related expenditure items: pensions, health care, longterm care (comprises both in-kind and cash benefits), education and unemployment benefits.

\section{Policy questions the model has supported}

Challenges posed to government spending by demographic trends.

\section{Classes of forecasting model}

Component-based model with a cohort framework.

\section{Forecasting method}

The projections rely on a uniform cross-country framework.

\section{Health care}

The age- and gender-specific per capita public expenditure on health care profiles are provided by Member States. They are then combined with the demographic projections provided by Eurostat in order to calculate nominal spending on health care. Adjustments reflecting the effects of different factors on health care spending are applied by changing one of three main inputs: i) the demographic/population projections, ii) age-related expenditure profiles (capturing unit costs) and iii) assumptions regarding the development of unit costs over time, as driven by assumptions about macroeconomic variables or assumptions about the evolution of the population's health status. Nine different scenarios simulate health care spending up to 2060 based on different assumptions about population projections, age-related expenditure profiles, unit cost development and income elasticity of demand. Two additional scenarios - AWG reference and AWG risk - combine assumptions of other scenarios.

\section{Long-term care}

The methodology allows projecting the future need for long-term services in terms of the number of people who are assumed to need long-term care services. This is done by using dependency rates to estimate the fraction of the elderly population which is dependent, i.e. has some disability which requires the provision of a care service. First, a projection is made of the dependent population, on the basis of the baseline population projection and disability rates. Second, the dependent elderly population is split, by age and gender, following the type of care received (informal, formal at home, formal in institutions). Third, average expenditures (i.e. age-gender profiles) are calculated for both types of formal care and informal care, and then multiplied by the projected number of recipients to obtain the projected public expenditure. Seven different scenarios were simulated to project long-term care expenditure based on different assumptions about population projections, age-related expenditure profiles/dependency status, unit cost development and policy setting/care mix. Two additional scenarios - AWG reference and AWG risk - combine assumptions of other scenarios. 


\section{Projected variables, measurement units and time horizons}

Real public per capita expenditure on health care and long-term care as a share of GDP is projected to 2060 .

\section{Drivers of health expenditure}

Health expenditure drivers:

\section{Population}

Demographic structure and life expectancy of the population. One scenario - high life expectancy - tries to measure the impact of an alternative assumption on mortality rates.

\section{Age-related expenditure profiles}

Age-related public health care spending per capita in 2010 is used as a proxy for the health status (i.e. morbidity). It is held constant in real term over the projection period for six scenarios (out of nine). In one scenario, per capita age profiles observed in the base year are shifted outwards, in direct proportion to the projected gains in age- and gender-specific life expectancy. In another scenario, profiles are held constant but split into profiles of descendents and survivors to account for the concentration of a large share of total spending on health care in a person's final years. A different scenario considers the convergence of all EU27 countries that are below the EU27 average of per capita public expenditure relative to GDP per capita to that EU27 relative average.

\section{Unit cost development}

It is driven by growth in national income in most scenarios. In one scenario, unit costs are driven by changes in labour productivity, while another one consider health care sector specific - wages, pharmaceuticals, therapeutic appliances, capital investment, prevention related health care services rather than economy-wide determinants of unit costs.

\section{Elasticity of demand}

It is assumed to be 1 in most scenarios. In one scenario is equal to 1.1 in the base year and converges to 1 by the end of projection horizon in 2060, while in another is equal to 1.3 in the base year and converges to 1 by the end of projection horizon.

\section{Long-term care expenditure drivers:}

\section{Population}

Demographic structure and life expectancy of the population. One scenario - high life expectancy - assumes that life expectancy in 2060 is higher by one year than the "base case" projected life expectancy.

\section{Dependency status}

Trends in age-specific disability rates are assumed to be constant in most scenarios. One scenario assumes that the profile of age-specific disability rates shifts in line with changes in life expectancy (disability rate in the future is equal to that of a younger - by the same number of years as the change in age-specific life expectancy - age cohort today), resulting in a gradual decrease over time in disability prevalence for each age cohort. 
Age-related expenditure profiles

The shares of the dependent population who receive either informal care, formal care at home or institutional care are kept constant over the projection period in most scenarios. One scenario illustrates the impact of a 10 -year progressive shift into the formal service sector of $1 \%$ per year of the dependent population who have so far received only cash benefits or informal care, while another assumes an extension of the formal/public coverage in any form (institutional, home care or cash benefits) toward the EU-average rate. Member States provided public long-term care expenditure per user (patient) disaggregated into spending on services in kind and spending on long-term care-related cash benefits, by sex and five-year cohorts. Those unit cost were kept constant in most scenarios. Only one scenario assumes an upward convergence of the relative age-gender specific per beneficiary expenditure profiles (as percent of GDP per capita) of all countries from below the corresponding EU27 average to the EU27 average. This is done for each type of formal care coverage (i.e. formal care in institutions, formal care at home, cash benefits).

\section{Unit cost}

The projections link unit cost to GDP per hour worked for in-kind benefits (services), while unit cost of cash benefits evolve in line with GDP per capita growth as cash benefits are more related to a form of income support. Only in one scenario did the unit cost grow in line with GDP per capita.

\section{Assumptions sensitivity analysis and criteria to assess forecasting methods performance}

A number of sensitivity tests were carried out to quantify the responsiveness of projection results to changes in key underlying assumptions. The impact of possible policy changes on the following variables was assessed: population (high life expectancy; lower migration); labour force (higher employment rate; higher employment rate for older workers); productivity (higher/lower labour productivity); interest rate (higher/lower interest rate).

\section{References:}

European Commission (2012). The 2012 Ageing report. Economic and budgetary projections for the 27 EU Member States (2010-2060).

European Commission (2011). The 2012 Ageing report. Underlying Assumptions and Projection Methodologies. 
Annex 1.9 France - Direction de la recherché, de l'évaluation et des etudes statistiques (DRESS)

The model compares the growth rate of health expenditures in France under different assumptions about three major drivers of health spending: aging, income, and excess growth (croissance autonome). What is interesting about this model is that it makes an attempt to compare the potential contribution of the different drivers of health expenditure over the long run. Results confirm that aging has a limited impact on health expenditure growth.

\section{Policy questions the model has supported}

Financial sustainability of health expenditures in a context of limited growth in national income.

\section{Class of forecasting model}

Component-based model with a cohort framework.

\section{Forecasting methods}

Extrapolation of past trends in health expenditure by age, under different assumptions about healthy aging, GDP growth, and excess growth.

\section{Projected variables, measurement units, time horizon}

The model projects total, public, and private health spending as a percentage of GDP to 2050.

\section{Drivers of health expenditure}

Aging

Two different scenarios are studied: health expenditure by age unchanged and therefore as life expectancy increases the number of years lived in poor health also increases; and health expenditure by age adjusted so that the number of years lived in poor health remains unchanged as life expectancy increases. The Eurostat profile of public health spending by age is used as a basis to forecast trends. The profile is transformed into total spending by using a stable share of public health spending to total spending.

Income

GDP is assumed to grow at $2 \%$ per year, with a health spending income elasticity of 0.9

Excess growth

Two different scenarios are studied: unchanged growth of 1.7\% per year (as observed from 19712002); and slower excess growth of $0.5 \%$ per year from 2010 onward.

\section{Assumptions, sensitivity analysis and criteria to assess forecasting methods}

Several limitations are worth noting:

- There is no health-sector price effect as health prices and economy-wide prices are assumed to growth at the same rate.

- Health spending income elasticity is assumed to be 0.9 . 
- The share of public spending on total spending is assumed to be constant at $78 \%$ to 2050 .

- There is a descriptive analysis of additional supply- and demand-side drivers, but those drivers were not specifically modelled.

- The results are dependent upon the assumptions made about excess growth in health spending. The projected value of the dependent variable - that is health spending as a percentage of GDP - increases by two-thirds (from 13.8 to $22.9 \%$ in 2050) depending on which of the two excess growth scenario is used.

\section{References :}

Denis $\mathrm{R}$ (2007). Perspective à long terme des dépenses de santé en France. Complément $\mathrm{C}$ au

Rapport du Conseil d'analyse économique, $\mathrm{n}^{\circ} 72$ Les leviers de la croissance française. 
Annex 1.10 France - Sénat

The model compares the health expenditure growth rate in France to other countries. What is interesting about this model is that it makes an attempt to compare the potential contribution to spending growth of different ways to organize and pay for care. Also, the model explicitly includes a broader range of potential drivers of health expenditure (although with limitations - see below) than have many other models.

\section{Policy questions the model has supported}

How do health spending projections for France compare with neighbouring countries?

How do different approaches to organising the health system contribute to health spending growth across countries?

\section{Class of forecasting model}

Macro-level with explanatory variables.

\section{Forecasting methods}

Health spending per capita is deflated by the health sector price index to 1995 , and made equivalent across countries by adjusting for purchasing power parity. For each country, for intermediate models, it is then further adjusted to correct for differences between countries in the age structure of their populations over time. This is done by dividing health spending per capita, in each country and at each time period, by the change in the age structure of the population between that time period and the base year. The change in the age structure adjustment factor is estimated as the proportion of the population in each age class in a given year, times health spending per age class that year, divided by the same ration in the year 2000 .

The final model takes a different approach where population growth and structural change are independent variables in the model.

\section{Projected variables, measurement units, time horizons:}

Panel data from 1972 to 2001 is used to estimate the equations for the projection of the next 5 years for 7 countries (167 observations).

All intermediate models project health spending per capita in constant dollars and adjusted for the change in the age structure of the population over time.

The final model projects total health expenditure in constant dollars

\section{Drivers of health expenditure}

Intermediate models:

- GDP per capita (in 1995 constant dollars) adjusted for the change in the age structure of the population over time.

- The price of care relative to general prices expressed as the ration of the health sector price index and the GDP price index. 
- Time - representing two factors: general technological progress and country specific organisation of the health system - results decomposing the two factors were shown.

- Residual by country representing fixed effect for each country

Alternative models tested model performance with other drivers (listed below) but none were retained for the final projection. They were:

- The share of health expenditure by household,

- The number of generalists and specialists per 1000 population,

- The dominant compensation model for physicians is added as a series of dummy variables: mainly fee for service $(1 / 0)$; or mainly capitation $(1 / 0)$,

- The type of health system is added as a series of dummy variables: public contract system $(1 / 0)$; integrated public/private system $(1 / 0)$; or reimbursement system $(1 / 0)$,

All dummy variables were multiplied by time $(\mathrm{T})$ to create a time trend.

Final model (fixed effects no longer mentioned):

- Growth in the size of the population,

- Ghange in the age structure of the population,

- The price of care relative to general prices expressed as the ration of the health sector price index and the GDP price index,

- Time - representing two factors: general technological progress and country specific organisation of the health system - results decomposing the two factors were shown (But not explained very well), and

- Residual expressed as statistical difference.

\section{Assumptions, sensitivity analysis and criteria to assess forecasting methods}

- Because the log of the dependent and independent variables are modelled, the coefficient for real GDP per capita represents the elasticity of demand for health care. For all models developed this is the case, and therefore elasticity is a result of the model rather than an assumption. Estimated values presented include 0.948 for the first intermediate model, and a range from 0.716 to 1.153 for models that add various other explanatory variables related to the organisation and financing of health. The estimated value for this parameter in the final model is not shown.

- Relative prices and GDP growth are assumed to be the same in all countries. Two GDP growth scenarios are used: $1 \%$ and $3 \%$ growth per year. The $1 \%$ is somewhat near what they estimated, but there is no explanation why these two values were chosen.

- A non-linear fitting technique (Hoddrick-Prescot) is used to estimate relative prices in each country using only data for the past 5 years for each country (1996-2001). Results range from -0.4 in France and Spain to +1.6 in the USA and UK. The small number of years used 
to estimate this parameter is a limitation. It is possible that a longer time series would have yielded a positive value for France and Spain. The Hoddrick-Prescot technique is also questionable for such a short time series as it gives lower weight to more recent years.

- Time is allowed to differ between countries to capture tech change and country-specific health systems.

- The time trend variable would be capturing all other influences, not just technology and differences in the health systems across countries. The authors take the average of the estimate of the effect of the time trend and label it "Technological Change" and the difference between the average and the estimate for each country is assumed to represent the "organisation of the health system" in each country. This is a very strong assumption. It is not clear why the dummy variables included in earlier models to represent the organisation of the health system directly were not retained.

- For the variable reflecting changes in the age structure of the population over time there is an assumption that health consumption by age is fixed as it was in 2000 (that it is stable). Therefore, there would be an expansion of morbidity over time with increasing life expectancy.

- The final model is a transformation of the models presented in a lot of detail in the paper but with two significant changes: variables reflecting a country specific residual, labelled a fixed effect, were not included and variables reflecting growth in the population and change in the age structure of the population were included as independent variables. Regression output, while shown for all prior models, is not shown for this last model. The reasons why this final model was chosen are not discussed.

- Very strong conclusions are drawn from the results of the final model about the contribution of the organisation of the health system to health spending growth, indicating that the system that manages costs best is an integrated system, followed by a contract system and then by a reimbursement system.

Alboury et al. made the following points about this model's results for France:

- Growth in spending per capita may have been over-estimated due to the inclusion of data from the 1970s, which was a period of atypical expansion of the health system.

- Results for France indicate that if GDP grows by $1 \%$ in volume per year, health spending will grow by $2.5 \%$; if GDP grows by $3 \%$, health spending grows by $4.3 \%$. If the model were used for long-term trends, which the authors did not intend, the percentage of GDP consumed by health would reach 17.4 to 19.4 by 2050 .

- The explicit inclusion in the model of relative pricing assumes that trends observed from 1996 to 2001 will continue. During this period, there was a drop of 0.4 percentage points in France. - Most other countries experienced a rise.

Further limitations the authors point out:

- Definitions of variables may have changed over time within countries and have some differences across countries. 
- Data limitations resulted in some models containing a smaller number of countries and therefore fewer observations.

- Macroeconomic impacts resulting from demographic change that might cause the health sector to grow were not specifically modelled.

\section{References :}

Bac C (2004). Les determinants macro-economiques des dépenses de sante : comparaison entre quelques pays développés. Rapport du CIREM pour le Sénat

Albouy V, Bretin E, Carnot N, and Deprez M (2009). Les dépenses de santé en France : déterminants et impact du vieillissement à l'horizon 2050. Documents de travail de la Direction Général du Trésor et de la Politique Économique 


\section{Annex 1.11 Italy - Ministry of Health/Università di Roma Tor Vergata}

In the context of an agreement with the Ministry of Health, the Centre for Economic and International Studies (CEIS) at Tor Vergata University has implemented a forecasting model which allows the estimation of future health expenditure on the basis of past trends (regression analysis) and of future trends (assumptions) for the selected explanatory variables. The CEIS approach has the merit of an accurate functional specification of the econometric model

\section{Policy questions the model has supported}

Will future public expenditure on health be sustainable?

\section{Class of forecasting model}

Macro-level model with explanatory variables

\section{Forecasting method}

The CEIS approach projects Italian total public health expenditure by:

- Selecting statistically significant explanatory variables,

- Estimating the coefficient of those variables on the basis of historical data from 1969-2009, and

- Making assumptions about the changes in the value of those explanatory variables from 2010-2051.

The regression model is based on an Error Correction Mechanism (ECM) model. The function specification is logarithmic. The model assumes long-term equilibrium among health expenditure and income at constant prices, demographic trends, prices, and technology (pharmaceutical research spending is used as a proxy).

\section{Projected variables, measurement units and time horizons}

Public health expenditure is projected as the share of public health expenditure to GDP from 2010-2051.

\section{Drivers of health expenditure}

Determinants:

- Health spending (lagged)

- Income (at constant prices)

- Income deflator

- Population aged $>65$ years

- Expenditure on pharmaceutical research (proxy of expenditure on research)

- Dummy1, which equals 1 in 1974 (and 0 in any other year) 
- Dummy2, which equals 1 in 1989 (and 0 in any other year)

The following assumptions have been made to forecast health spending:

- Income : $1.5 \%$ annual growth rate at constant prices (with alternative scenarios at $2 \%$ and $2.5 \%)$

- Prices: $1.5 \%$ annual growth rate at constant prices

- Research: 3.5\% annual growth rate (with alternative scenarios at $2.5 \%$ and $3 \%$ )

- Demography : based on projections made by the national institute of statistics (ISTAT)

\section{References:}

Atella V, Marini G, and Proietti T (2011). Previsioni di breve e lungo periodo della spesa sanitaria pubblica. Rapporto preparato per il Ministero della Salute

Atella V (2010). Spesa sanitaria e sostenibilità finanziaria: quale futuro? La sanità in Italia. Organizzazione, governo, regolazione, mercato. De Vincenti C, Finocchi Ghersi R, and Tardiola A edt. Il Mulino. 


\section{Annex 1.12 Italy - Ragioneria Generale dello Stato}

The RGS (Ragioneria Generale dello Stato, Department of General Accounts) model provides projections of public expenditures for Italy for the period up to 2060. It is part of an annual exercise carried out by the Ministry of Economy and Finance - Department of General Accounts that uses a cell-based actuarial approach to project public spending on three components: pensions; health; and long-term care (LTC). Underlying assumptions, updating procedures, methodological improvements and results have been regularly analysed in an annual report published by the Department of General Accounts since $2000^{17}$. As far as health and LTC are concerned, the mid-to-long term projection methodology is broadly consistent with the approach used at the European level by the Economic Policy Committee - Ageing Working Group (EPC-AWG). In the short term, projections are aligned to the forecasts reported in the most recent public finance document ${ }^{18}$.The approach has the merit of assessing the impact on public health and LTC expenditure of dynamic age consumption profiles, different income elasticities, as well as alternative demographic and macroeconomic assumptions.

\section{Policy questions the model has supported}

The RGS model aims at assessing the long-term sustainability of public finances

\section{Class of forecasting model}

Component-based model with a cohort framework.

\section{Forecasting method}

The RGS model is devised to project separately the main typologies of provisions which are subsequently grouped in two expenditure items: acute component of health care expenditure, and LTC. The latter includes: home and institutional care (which are part of health care expenditure), attendance allowances (cash benefits), and benefits, largely in kind, provided at a local level by municipalities, singly or in association. Projections are carried out on the basis of two different scenarios: a pure ageing scenario; and a reference scenario. In the pure ageing scenario, forecasted values are obtained by combining both demographic and non demographic factors, keeping unchanged age and sex consumption profiles. Demographic factors include population growth and changes in the age structure of the population, while non-demographic factors refer to just the per capita GDP growth rate to which the unit cost of each type of provision is indexed. In the pure ageing scenario, changes in the expenditure to GDP ratio depend exclusively on demographic structure. In the reference scenario, the forecasted value is obtained by combining both demographic and non demographic factors, including health status improvements (dynamic age consumption profiles), productivity growth (instead of GDP per capita), and income elasticity above one.

\section{Projected variables, measurement units and time horizons}

Public expenditure on acute health care and LTC is projected in total and by age groups as the share of GDP up to 2060.

17 The last Report is the No. 12 and contains projection updated to March-April 2011.

18 As for the latest update, Documento di Economia e Finanza 2011 covering the period 2011-2014. 
DELSA/HEA/WD/HWP(2012)2

\section{Drivers of health expenditure}

Pure ageing scenario drivers are:

- Demographic factors (population growth and changes in the age structure of the population),

- GDP per capita,

- $\quad$ Age and sex consumption profiles (assumed constant over time), and

- Unit cost of each type of provision grow with GDP per capita.

Reference scenario drivers are

For acute health care expenditures:

- Dynamic age consumption profiles: death-related costs approach is used for the hospital component, while dynamic equilibrium is partially ${ }^{19}$ applied to all other components;

- Unit costs of each type of provision linked to GDP per capita growth; and

- Income elasticity of 1.1 at the beginning, then linearly converging to 1 .

For LTC expenditures:

- Dynamic age consumption profiles: dynamic equilibrium is partially (as in the case of acute health care) applied to disability rates;

- Unit costs are are linked to productivity per employee, for in kind provisions, and linked to GDP per capita for cash benefits; and

- $\quad$ Elasticity either to productivity per employee or GDP per capita is always equals 1.

\section{Assumptions sensitivity analysis and criteria to assess forecasting methods performance}

Different assumptions were tested.

Demographic variables:

- High scenario: birth rate: +0.17 in 2060 ; life expectancy: +2.5 years for males +2.3 years for females in 2060; net migration: $+40,000$ from 2020; and

- Low scenario: birth rate: -0.19 in 2060; life expectancy: -2.8 for males and -2.6 for females; net migration: $-40,000$ from 2020 .

Macroeconomic variables:

- Activity rate: +2 percentage points in 2060 ,

- $\quad$ Activity rate: -2 percentage points in 2060 ,

19 The increase in life expectancy is translated into $50 \%$ years in good health 
- Productivity: $+0.25 \%$ per year,

- Productivity: $-0.25 \%$ per year, and

- Unemployment rate: +1.6 percentage points in 2060 .

\section{References:}

Ministero dell'Economia e delle Finanze, Dipartimento della Ragioneria Generale dello Stato (2011). Le tendenze di medio-lungo periodo del sistema pensionistico e socio-sanitario aggiornamento 2011.

Note: An English version of a comprehensive summary of the Report, including tables of results, is also available: http://www.rgs.mef.gov.it/VERSIONE-I/Attivit-i/Spesa-soci/Attivit-d/2011/index.html. 


\section{Annex 1.13 Netherlands - Bureau for Economic Policy Analysis (CPB)}

The Netherlands Bureau for Economic Policy Analysis (CPB) has implemented a medium-term health expenditure forecasting model. The model is used to project health expenditure for the next five years and to assess the potential impact of government health policies on the public budget. For example, CPB has used the health expenditure forecasting model in a recent research ${ }^{20}$ to evaluate the impact that an increase in compulsory co-payments may have on the public finances.

\section{Policy questions the model has supported}

The model offers a tool for the analysis of potential budgetary implications of government policies. Using an approach similar to that of the European Commission ${ }^{21}$, the Dutch model analyses policy interventions by comparing their impact against a "no intervention" scenario. A "no intervention" scenario depicts how health expenditures will affect public finances if left on current trajectories.

\section{Class of forecasting model}

Component-based model with a cohort or actuarial framework corrected to take into account increases in healthy life expectancy for age classes above 40 as well as the macroeconomic costs of policy changes.

\section{Forecasting methods}

Two periods are considered: the historical period (2001-2008) for which the largest and most detailed information set is available; and the current period (2009-2010) for which a reduced data set is available so that now-casting is required. Historical data are used to estimates parameters of interest (back-casting) which are then used to project health expenditures.

The change in the size and structure of the population represent one of the main spending drivers in the CPB model. The population is divided into 20 age groups (each comprising 5 years). Each age group is associated with levels of per capita expenditure for six major spending sectors. Sectors include health care goods and services which align with the health care functions used in SHA. The two main categories are cure and care services (see Figure 1 below). Cure services include hospitals, specialist practices, GPs, dentists, paramedics and psychiatric services together with medicines and appliances. Care services refer to long-term care expenditures, specifically nursing home care and healthcare for handicapped persons.

Therefore, for each age group $(l)$ in each time period $(t)$, the per capita health expenditure is determined by the sum of health goods and services consumed (i.e. $x_{l, t}=\Sigma_{k} x_{k, l, t}$ ). Health expenditure is then corrected to account for the annual increase in life expectancy in good health. This is done by introducing the hypothesis that in each period, a small proportion (around 1\%) of the population included in the age classes over age 40 spend what was spent by the younger cohort the year before; while the largest share $(99 \%)$ of the population in the same each age spending what was spent, in real terms, by the same age cohort the year before. $\mathrm{x}_{1, \mathrm{t}}=\left(h x_{l-1, t-1}+(1-h) x_{l, t-1}\right)$ where $h$ is the share of population benefitting of an increase in life expectancy in good health.

Health spending is also determined by government intervention $\left(b_{l, t}\right)$ together with a residual component $\left(g_{l, t}\right)$ which comprises all factors that cannot be separately identified.

\footnotetext{
$20 \quad$ Besseling, P., \& Shestalova, V. (2010).

$21 \quad$ European Commission (2011)
} 
Figure 1 Structure of the CPB cell based model

\begin{tabular}{|c|c|c|c|c|c|c|c|}
\hline & \multicolumn{7}{|c|}{20 Age groups } \\
\hline Age groups & $0-4$ & $5-9$ & $\cdots$ & I & $\cdots$ & $\begin{array}{c}90- \\
4\end{array}$ & $>95$ \\
\hline Number of individuals for each group in the year $t$ & & & & $n_{\text {It }}$ & & & \\
\hline
\end{tabular}

Per capita real health expenditure at time $t$

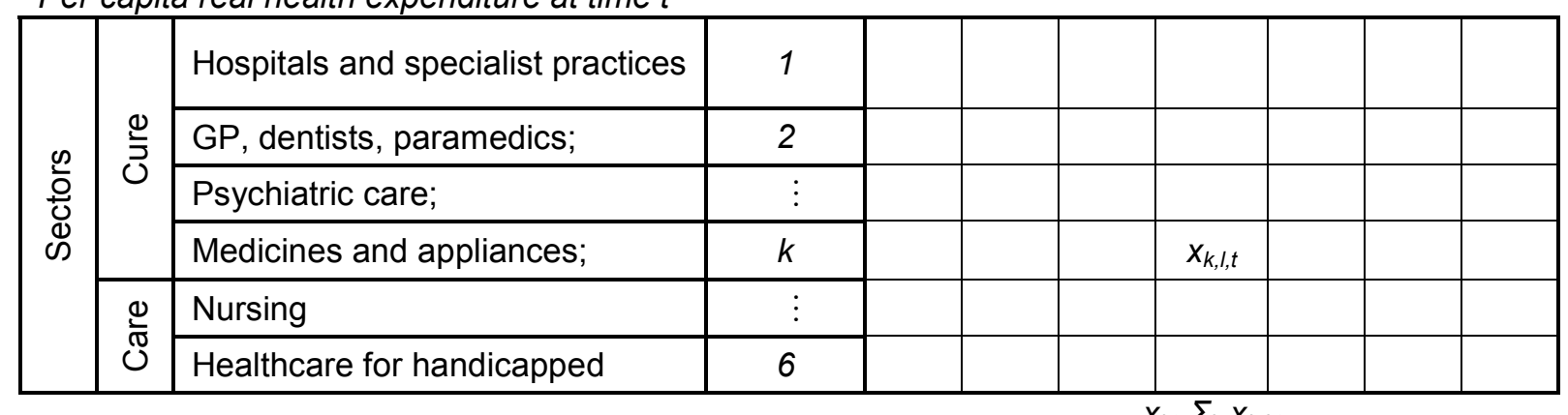

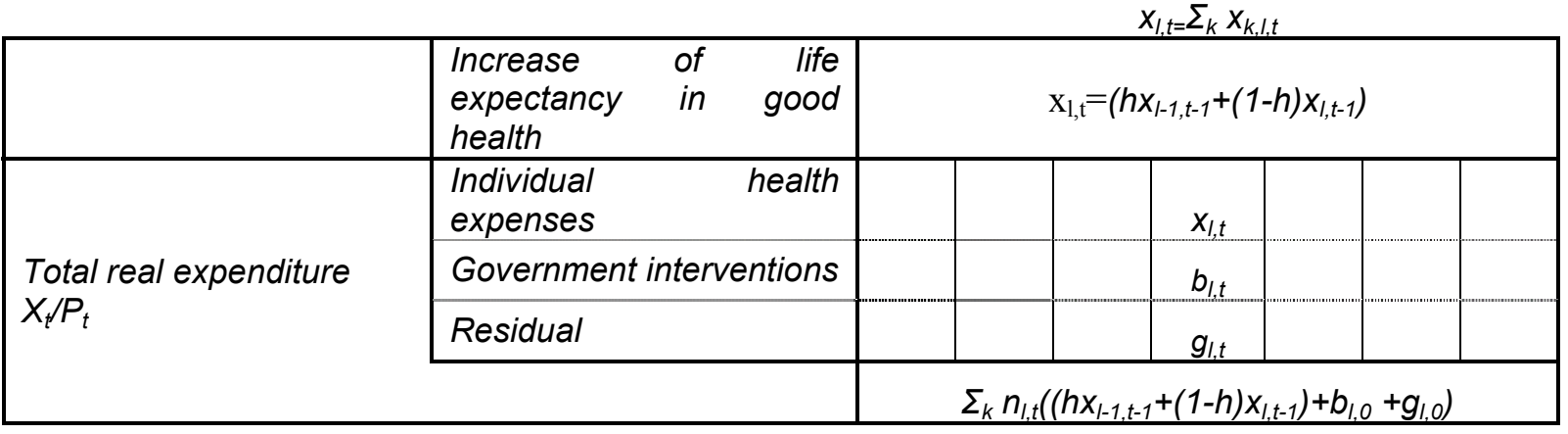

The structure of the $x_{k, l, t}$ matrix is estimated for the reference year (2007) and then used to calculate the corresponding matrixes for all remaining years.

\section{Projected variables, measurement units and time horizons}

Expenditure on personal health care (public and private expenditures) is projected. Health expenditures are considered in real terms, where deflated figures are calculated using the GDP implicit deflator. Also, the share of health expenditures to GDP are analysed.

Forecasts are made for the period five years ahead. However, due to the reduce availability of data, now-casting is used for the two most recent years.

\section{Health expenditure drivers}

Four determinants are considered:

- The change in the size and the age composition of the population;

- Shift in health expenditure profiles due to increased healthy life expectancy;

- The macroeconomic costs of policy changes; and

- A residual component comprising all factors that were not identified separately, such as technological developments, real sector-specific price changes due to the Baumol effect, etc. 


\section{Assumptions, sensitivity analysis and criteria to assess forecasting method}

The model assumes a constant improvement in the health state of each group over time. As a result, the need for healthcare at the individual level is constantly delayed. Due to conflicting empirical evidence, a $1 \%$ increase in life expectancy without limitation is assumed.

\section{References:}

Besseling P \& Shestalova V (2010). Forecasting public health expenditures in the Netherlands. The Netherlands Bureau for Economic Policy Analysis Working Paper .

European Commission (2011). Health care expenditure projections: methodology and main assumption. Note for the attention of the Ageing Working Group attached to the Economic Policy Committee 


\section{Annex 1.14 New Zealand - Ministry of Health and Treasury}

The model is a common effort of the Ministry of Health $(\mathrm{MoH})$ and of the New Zealand Treasury (NZLT). Each institute provides its own report on the same model. The two reports differ in that the $\mathrm{MoH}$ focuses predominately on the demographic variables (e.g. healthy life expectancy) while the NZLT gives more attention to the ratio of health expenditure to GDP.

\section{Policy questions}

Assesses the sustainability of public expenditure on health and provides information on the rate of investment in health technologies.

\section{Class of forecasting model}

Component-based model with a cohort framework.

\section{Projected variables, measurement units and time horizon}

Per capita real government health expenditures are projected. These expenditures are defined as Vote Health, which includes disability support services. The definition appears to be consistent with the SHA definition of current expenditure on personal care. Health expenditure is projected for 20 age groups $\mathrm{x} 2$ genders $\mathrm{x} 4$ health states: non-disabled survivors, disabled survivors, non-disabled decedents, and disabled decedents) yielding a 160 cell matrix.

per capita at time $t$

\begin{tabular}{|c|c|c|c|c|c|c|c|c|c|c|c|c|}
\hline & \multicolumn{12}{|c|}{ Population } \\
\hline & \multicolumn{2}{|c|}{20 Age groups } & \multicolumn{2}{|c|}{$0-4$} & \multicolumn{2}{|c|}{$5-9$} & & & \multicolumn{2}{|c|}{$90-4$} & \multicolumn{2}{|c|}{$>95$} \\
\hline & 2 Gender & & M & $\mathrm{F}$ & M & $\mathrm{F}$ & M & $\mathrm{F}$ & M & $\mathrm{F}$ & $\mathrm{M}$ & $\mathrm{F}$ \\
\hline \multirow{4}{*}{ 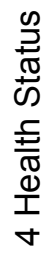 } & Non-disabled survivor & 1 & & & & & & & & & & \\
\hline & Disabled survivor & 2 & & & & & & & & & & \\
\hline & Non-disabled decedent & 3 & & & & & & & & & & \\
\hline & Disabled decedent & 4 & & & & & & & & & & \\
\hline & \multicolumn{2}{|l|}{ Total } & & & & & & & & & & \\
\hline
\end{tabular}

In the NZLT report, the ratio of total health expenditures to GDP is analysed. In that case, GDP is projected on the basis of population size and age structure as well as labour productivity.

The projection horizon is 50 years, from 2002 to 2051 . The back-casting period is 20 years, from 1951 to 2001.

\section{Determinants of health expenditure}

Health expenditures are expressed as a function of the population (both size and aging structure), health status (distance to death and disability), coverage and prices. Prices include technology, expectations, government policies, and inflation of input factors. 


\section{Assumptions, sensitivity analysis and criteria to assess forecasting methods performance}

Mortality trend projections affect the probability of dying at each age in each calendar year, altering distance to death and hence the proportion of decedents to survivors in each age-sex cell.

In the absence of data on the prevalence of chronic diseases, the prevalence of dependent disability, adjusted for severity, is used to index non-fatal health status.

The MoH report projects a range a future mortality trends, each of which influences the size and age structure of the population.

\section{Sensitivity analysis}

Three mortality projections are used to test the sensitivity of projections: a $1 \%, 1.5 \%$ and $2 \%$ annual reduction in mortality rates.

\section{References:}

Bryant et al (2004). Population ageing and government health expenditures in New Zealand, 19512051. New Zealand Treasury Working Paper 04/14.

Ministry of Health (2004). Health expenditure trends in New Zealand. Wellington, Ministry of Health. 


\section{Annex 1.15 OECD - Directorate for Social Affairs, Manpower and Education}

In 1992, OECD undertook the first systematic study of the accuracy of the health expenditure forecasts (Getzen and Poullier, 1992). The authors proposed a series of competing forecasting models which were then implemented by the World Health Organisation to project health expenditure on a regular basis.

\section{Policy questions}

Models were proposed to inform policy makers and governments about the financial needs of the health system, to inform administrators planning future labour force needs, and to inform ancillary supply industries (medical equipment, pharmaceuticals) whose production and inventories must be adjusted to accommodate future demand.

\section{Class of forecasting model}

Six different macro-level models were proposed in this study including:

1) Employing the most recently observed growth rate in health expenditures as a constant rate applied to the projection period.

2) Estimating a growth rate in health expenditures using a series of univariate time series techniques (moving average, exponential smoothing, regression and ARIMA) and applying the estimated growth rate to the projection period.

3) Estimating growth rates for individual countries using one of the first two methods and then creating an international average growth rate to be applied to each country's projection.

4) Estimating an equation to be used to forecast expenditure growth over the projection period using an econometric model with GDP, inflation and expectations variables included as independent variables.

5) A model combining econometric model (4), exponential smoothing (3) and computing an international average (3).

The accuracy of each model was assessed using the mean absolute error (MAE) of each forecasting method.

\section{Projected variables, measurement units and time horizons}

All models focus on public expenditure on health at constant prices. Models were calibrated over a 15 years period and then used to forecast eight years ahead.

Determinants of health expenditure, assumptions, sensitivity analysis and criteria to assess forecasting methods performance

\section{Assumptions, sensitivity analysis and criteria to assess the forecasting method}

The first model assumes that the last observed growth rate of health expenditures (in constant prices) remains constant over the whole projection period. The second proposal, instead, uses the full history of past health expenditure to estimate a growth rate. The third proposal assumes that health systems are exposed to common drivers and should move together. Finally the two econometric models take into account the potential influence of income and inflation on expenditure growth. 
Moreover, they also assume that the health sector tends to lag the rest of the economy, so that its growth in any particular year can be considered as a function of income and inflation in past years.

All proposed models rely on past trends to project future expenditures. They require long-term time series of aggregate data with clear and undisturbed trends. They assume that there will be no changes in policy, the society or the economy in future that would weaken the ability of past trends to forecast future spending. Thus, they are more appropriate for short-term forecasts.

\section{Reference}

Getzen TE \& Poullier JP (1992). International health spending forecasts: concepts and evaluation. Social Science and Medicine; 34(9):1057-68. 


\section{Annex 1.16 OECD - Economics Department}

Rising expenditure on health and long-term care puts pressure on government budgets in most OECD countries. This model attempts to respond to these concerns by considering a number of factors likely to drive public spending on health and long-term care over the period to 2050 . Expenditures on long-term care and on health care are examined separately. For both health and longterm care expenditures, the impacts of demographic and non-demographic factors are brought separately into the analysis. The work has the merit - among others - to carry out sensitivity tests to assess the robustness of the results to key assumptions.

\section{Policy questions the model has supported}

How much could health and long-term care spending increase in the future, and what policy changes could reduce spending increases?

\section{Class of forecasting model}

Component-based model with a cohort framework.

\section{Forecasting method}

The projections rely on a uniform cross-country framework. To project public health expenditure, per-capita expenditure profiles by age are estimated in the base year for two components: health care (for survivors and non-survivors); and long-term care (LTC). The per-capita expenditure is projected according to specific assumptions, and then multiplied by the group-specific population in the projection year.

The principle forces driving health expenditure projections are as follows.

- Demographic factors: A rising share of older age groups in the population will put upward pressure on costs because health costs rise with age. However, the average cost per individual in older age groups should fall over time for two reasons: longevity gains are assumed to translate into additional years of good health ("healthy ageing"); and major health costs come at the end of life.

- Non-demographic factors: Health care costs have typically grown faster than income. This is generally due to the effect of technology and relative-price movements in the supply of health services.

The principle forces driving long-term care projections are as follows:

- Demographic factors: Dependency on LTC will tend to rise as the share of old people in the population increases. This effect is mitigated somewhat by declines in the share of dependents per older age group as longevity increases due to "healthy ageing".

- Non-demographic factors: Expenditures are likely to be pushed up by a possible "Baumol effect", i.e. the relative price of long-term care vis-à-vis other goods and services tends to rise reflecting a negative productivity differential and equalization of wages across sectors. Another determinant is the substitution of informal care by more expensive formal care.

Two main scenarios were simulated, one in which no policy action is assumed, the "cost pressures" scenario, and a "cost-containment scenario" that embodies the assumed effects of policies curbing expenditure growth. 
DELSA/HEA/WD/HWP(2012)2

\section{Projected variables, measurement units and time horizons}

Real public health care expenditures are projected per capita and as a share of GDP to 2050.

\section{Drivers of health expenditure}

\section{Health care demographic drivers}

Each age group is divided between survivors and non-survivors. Under the "healthy ageing" scenario, the cost curve for survivors is allowed to shift rightwards, progressively postponing agerelated increases in expenditures. For non-survivors, two different demographic effects are considered. The number of deaths rises due to the transitory effect of the post-war baby-boom and also, mortality falls over time, due to increases in longevity.

\section{Health care non-demographic drivers}

In projecting public health care expenditures, two alternative scenarios were envisaged for the future: one in which the residual effect ${ }^{22}$ continues to rise at the historical rate, and another in which this rate declines over time due to cost containment policies. The former is the "cost pressures" scenario, where it is assumed that expenditures grow $1 \%$ per annum faster than income. The latter is the "cost-containment" scenario, where policy action is assumed to curb the "extra" $1 \%$ expenditure growth such that it is eliminated by the end of the projection period

\section{LTC. Demographic drivers}

Dependants by age group where the "healthy ageing" hypothesis for LTC was implemented as only one-half of longevity gains translate into a reduction in dependency.

\section{LTC non-demographic drivers}

The main non-demographic driver of LTC expenditure is the relative share of informal and formal care and its evolution over time. This effect is related to the labour-force participation rate of people aged 50-64, which is assumed to proxy the supply of informal caregivers. In addition, the cost curve per dependant is assumed to shift upwards due to increases in the average labour productivity in the economy, thus embodying an implicit "Baumol effect".

In projecting public LTC expenditures, two alternative scenarios were envisaged. In the "cost pressures" scenario, a 'full Baumol' effect is assumed implying that LTC costs per dependant will increase in line with overall labour productivity. In the "cost-containment" scenario, policy action is able to contain the cost pressures associated with the Baumol effect. In the latter scenario, governments would deploy a continuous effort to generate productivity gains and/or contain upward pressures on wages of staff providing long-term care.

\section{Assumptions sensitivity analysis and criteria to assess forecasting methods performance}

In the sensitivity analysis, a number of parameters were changed both for health care and LTC. For health care: the size of the income elasticity, the magnitude of the residual, as well as factors underlying health status scenarios and demographic projections were tested. For LTC, alternative specifications of the assumptions on income elasticity, health status and longevity, dependency and provision of informal care were also tested.

22 After controlling for demographic and income effects, a residual expenditure growth can be derived. The factors underlying this residual expenditure growth are technology and relative prices. 
DELSA/HEA/WD/HWP(2012)2

\section{References:}

OECD (2006). Projecting OECD health and long-term care expenditures: what are the main drivers? OECD Economics Dept Working Paper 477.

Oliveira Martins J \& de la Maisonneuve C (2006). The Drivers of Public Expenditure on Health and Long-Term Care: an Integrated Approach. OECD Economic Studies No. 43/2, OECD, Paris. 


\title{
Annex 1.17 Sweden - Ministry of Health and Social Affairs
}

The Swedish Microsimulation Model - Long-Term Demand for Welfare Services (SESIM-LEV) projects the future utilisation of and public expenditure on health and social care in Sweden, given current demographic, health status, disease and disability trends (Government Offices of Sweden, 2010).

SESIM was originally developed by the Ministry of Finance in Sweden and has been used to study educational financing and aging and pension policies. The health and social care utilisation dimensions of the model were developed by the Ministry of Health and Social Affairs.

\section{Policy questions the model has supported}

What will be the future health status and health expenditure utilisation of the population and what will then be the future cost of care?

How would utilisation and costs change under different assumptions of expansion or compression of morbidity?

How sensitive are forecasted health and social care expenditures as a share of GDP to assumptions about the future health status of the population, the cost pressure of technological advancement and the productivity of the health sector?

\section{Class of forecasting model}

\author{
Microsimulation (dynamic)
}

\section{Forecasting method}

SESIM-LEV is a dynamic microsimulation model that estimates and projects the life course of the population of Sweden including key life events related to family formation, education, employment, retirement and health and aging (Brouwers, L., A. Ekholm, N. Janlöv et al., 2011). The model evolves in discrete time intervals of one year. The model is initialised with a representative sample of 300,000 individuals from a longitudinal register (LINDA). LINDA brings together data from Censuses, Income tax and other registries to examine education, employment, income and pension information for individuals and families longitudinally over time. From analysis of LINDA, SESIM is able to include models of behavioural change over time, such as family formation, births of children, educational pathways, employment pathways, and transitions to retirement. ${ }^{3}$ Other datasets key to the LEV project included surveys of income and employment, living conditions, and patient registries. As the base population for SESIM did not contain information on health or utilisation of health and social care services, initial values were imputed conditioned on background characteristics of the individuals. Health status is a key variable in the model, both influencing the life course, such as participation in education and employment, and consumption of health and elderly care, while also, in turn, being influenced by social and demographic factors. Health status is an index from 1 (severe illness) to 4 (full health) derived from sets of responses to the ULF survey of living conditions.

Consumption of primary care, specialised or outpatient care, and inpatient care were measured in number of visits or days. As zeros are very frequent, negative binomial regression models were used to estimate the risk of health care events occurring. Prescription medicines were modelled as a binary variable using a logit model. To estimate probabilities of health care consumption, these regression models included variables such as age, health status, and consumption of the same type of care in the previous period, consumption of other types of care in the current and previous period, education, sex, and region. Risk of mortality was also estimated with a logit model influenced by a similar suite of 
variables. The presence of dementia and dependence in activities of daily living were also explicitly included and both influenced demand for elder care assistance which was captured as having two levels: home services and special housing with 24 hour care. In turn, these factors were significant predictors of mortality for those receiving elder care.

Sub modules were developed for focus diseases known to result in a high consumption of care: cancer, AMI, stroke and diabetes. Data on incidence, prevalence and health care use of patients were obtained from patient registers providing longitudinal histories for a six-year period. Age and diseasespecific risks of mortality were used. Individuals surviving beyond the six year period were considered disease free and were returned to face the same risks of health care consumption and death as the disease-free population in the model. The exception was diabetes, which was assumed to be a life-long condition.

The model projects public expenditures for outpatient, in-patient and primary care. The exclusion of private payments has only a minor impact on the model, as patients cover only $2-3 \%$ of expenditures on these items. The model projects expenditures for pharmaceuticals including both public and private expenditures. For this item, private payments represent about $25 \%$ of total expenditure. Costs were estimated in 2010 prices for the average health care and elderly care expenditure by age for primary care, specialised or outpatient care, inpatient care, prescription medicines, home care and special housing. These average prices were then multiplied by the number of persons in each age group in receipt of these care elements forecasted by the simulation model.

\section{Projected variables, measurement units and time horizon}

The projected variables include

- Population dynamics

- Health status (from levels 1 to 4 )

- Prevalence of key diseases (cancer, AMI, stroke, diabetes, dementia)

- Prevalence of difficulties with activities of daily living

- Utilisation of health-care services (primary care, specialised or outpatient care, and inpatient care visits or days; use of prescribed medicines)

- Life expectancy

- QALY (quality-adjusted life years)

- Health and social care costs in total and per-capita in 2010 fixed prices

- Health and social care total costs as a percentage of GDP in 2010 fixed prices

All of these variables are projected from 2010 to 2050.

\section{Assumptions, sensitivity analysis and criteria to assess the forecasting method}

The impacts of three different assumptions about the health status of the future population on projected health-care utilisation were tested. An expansion of morbidity assumption, where additional years of life expectancy in the population over time are accompanied by almost as much of an increase in life lived in poor health; a dynamic equilibrium assumption, where care needed is 
postponed by an amount equal to increases in life expectancy; and a compression of morbidity assumption, where the number of years lived in good health increases even more than the growth in life expectancy. These first estimates, which forecast health care demand based on demographic trends alone, show the highest future health care costs under the expansion of morbidity assumption. Nonetheless, annual growth in costs from 2010 to 2050 averages narrowly across all of these assumptions from 0.6 to $0.7 \%$ for health care and 1.3 to $1.4 \%$ for elderly care.

In the baseline projection, SESIM-LEV makes no assumption of what future technological changes may be. Thus the baseline projections consider future health and health care cost trends using current technology. GDP is assumed two grow by $2.16 \%$ per year, according to forecasts of the Ministry of Finance. Under this assumption, projected health care costs as a proportion of GDP fall over time and elderly care costs plateau after 2030. The forecasts change greatly, however, after the introduction of an assumption about technological development. Drawing from the literature, an assumption of $0.8 \%$ annual growth in health care expenditures as a result of medical technologies and other related factors is assumed. This assumption causes health expenditures to take an increasing share of GDP each year, reaching about $12 \%$ by 2050 .

Assumptions about the productivity of the health sector also influence results. If productivity increases match technological progress, the cost growth pressure associated with technological advancement could be neutralised.

The model enables projections of the number and type of health care treatments that may result from different policy scenarios, however, further costs that may result, such as the need to purchase additional equipment, to train new health-care providers or to build new health-care facilities are not part of the model. Projected volumes are translated into costs in a separate calculation. Administrative costs are not included. There is an assumption of constant prices using 2005 as the index year.

SESIM-LEV is developed in discrete time with most decisions occurring in order once per year. This is a limiting structure, as real-world events occur in continuous time, and more importantly, some decisions/transitions are joint, or occur together.

The model focuses on the demand for health care services and implicitly assumes no change in policies that may affect demand, such as health-care financing, as well as an assumption that the supply of health care services would be increased to meet future demand. The model also has no labour-supply dimension. There are models for labour-force participation, unemployment and retirement but no model of hours worked and the variables that influence those hours, including the family budget, tax rates, and health.

SESIM-LEV does not account for feedback loops between the health status and health-care utilisation of the population and market prices or the overall economy. Changes in the macro economy can be entered into the model as a scenario; however, there is no general equilibrium mechanism within the model itself. The Ministry of Finance in Sweden has, however, used a macro model of the public sector in parallel with SESIM for the household sector. ${ }^{3}$

Results of SISEM-LEV were verified during implementation of the model (de-bugging) by comparing model results for a sub-set of individuals with independent calculations for these same individuals using excel workbooks. Simulated output from SISEM-LEV for the years 2000-2008 were compared with observed values from empirical data to validate results. This included comparisons with observed values for health status and health-care consumption by age, sex and key sociodemographic characteristics. The stability of the model outputs were also tested to ensure that differences between model runs for the same scenario were not greater than differences between scenarios. Initially, ten simulations of the same scenario were estimated. Differences between simulation runs for the same scenario were found to be small and the number of simulations was 
reduced to three for each scenario, with the average of the runs used for publication. Calibration of death risks were undertaken to align the SESIM-LEV population projections to those of Statistics Sweden. Thus results replicated official estimates of increases in life expectancy. The demographic composition of the projected population was also examined over time at points in time in the future for 10-year age groups (including sex, age, income, education, health status, and level of dependency). This examination was to assure that projected results were reasonable.

\section{References:}

Government Offices of Sweden (2010). The Future Need for Care: Results from the LEV Project. Stockholm, September.

Brouwers L, Ekholm A, Janlöv N et al. (2011). Simulating the Need for Health- and Elderly Care in Sweden - A Model Description of Sesim-LEV. Paper presented at the International Microsimulation Association Conference, Stockholm, June.

Klevmarken A (2011). Microsimulation for Public Policy: Experiences from the Swedish Model SESIM. ESRI Discussion Paper Series, Economic and Social Research Institute, Tokyo, Japan, No. 242. 


\section{Annex 1.18 UK - HM Treasury/Office for Budgetary Responsibility (OBR)}

In 2001, Chancellor Gordon Brown commissioned Sir Derek Wanless to review health care funding needs for the next 20 years. The team led by Sir Derek Wanless produced an interim report entitled "Securing our Future Health: Taking a Long-Term View" in 2002, followed by a final report in 2004, "Securing Good Health for the Whole Population: Final Report". The final report explored public health interventions in more depth. This summary briefly presents the model used to estimate future health and social care expenditure in the 2002 report.

\section{Policy questions}

Estimates resource requirements over the next 20 years "to ensure that the NHS can provide a publicly funded, comprehensive, high quality service available on the basis of clinical need and not ability to pay".

\section{Class of forecasting model}

Component-based model with a cohort framework.

\section{Forecasting method}

Health and social care expenditures are divided into two main components:

A first component (covering over 80 percent of total NHS spending) is estimated as the product of activity (quantities of services) and their unit costs. Essentially a price times quantities approach. Wherever possible, activities were further broken down by age, sex and disease (between 10 and 13 disease areas depending on the type of care). Inpatients and day-case services were further broken down by decedents (people who would die during the year) and survivors (people who would survive to the next year) in order to account for "proximity to death"،23.

The second component (covering the remaining 20 percent of NHS and PSS expenditure) could not be broke down by quantities of services and unit costs. Therefore, total expenditure for each of those items was considered.

\section{Projected variables, measurement units and time horizons}

The model projects public expenditure on health and social care in England (National Health Service, NHS, and Personal Social Services, PSS) as well as total expenditure . The results obtained for England are then extended to the whole of the UK by applying a simple population factor adjustment.

Public health and social care expenditure is projected in constant prices for the next 20 years. Both total health and social expenditures (public and private) and these expenditures as a share to GDP are projected.

\section{Determinants of health expenditure}

Health and social care expenditure is first estimated at a detailed level for a reference year (called the baseline in the report). Each component is then projected ahead. Wherever possible, future evolution of the volume of services and their relative costs were estimated separately. Future volume

23 In the absence of specific data for England, Scottish data linking records of hospital use with death records were used instead. 
of activities depends on the size, age structure and health status of the population, particularly the extent to which improvements in life expectancy are associated with improvements in healthy life expectancy. It is worth noting that population aging is expected to have a much greater cost pressure on social care expenditures than on health care expenditures. The increase in the volume of activities is then adjusted for changes in activity rates which accounts for quality improvements (e.g. reducing waiting times and guaranteeing specific treatments); the availability of new medical technologies; and productivity improvements (in particular the use of information and communication technology to increase effectiveness). Future unit costs were obtained by multiplying the reference year costs by a cost adjustment factor which accounts for variation in health specific prices.

\section{Assumptions, sensitivity analysis and criteria to assess forecasting methods performance}

The model relies of a series of assumptions. Some refer to the overall architecture of the model, while others are specifically related to various scenarios. Of note in the first group are:

- The extension of the projections made for England to the whole of the UK. This is based on the implicit assumption that existing levels of provision or health status do not vary across the UK; and

- Private health expenditure in terms of GDP is assumed to remain constant.

As for the scenarios, three different hypotheses are made:

\section{Solid progress}

- Demand side: A considerable increase in life expectancy (assuming life expectancy at birth rising from 75.8 to 80.0 years for males and from 80.6 to 83.8 years for females) is associated with an improvement in health status where approximately half of a healthy year is gained for each additional year of life expectancy. This assumption is based on the elderly experiencing around 5 per cent fewer acute health problems (although the probability of using long-term care is kept constant) and that people have confidence in the primary care system and use it more appropriately.

- Supply side: The health service responds to demand with high rates of technology uptake and a more efficient use of resources. This and a more appropriate workforce skill mix contribute towards productivity gains increasing to 3 per cent a year over the second half of the period.

Slow uptake

○ Demand side: Life expectancy rises by the lowest amount in all three scenarios (78.7 years for men and 83.0 years for women) with no gain in healthy life expectancy. Long-term chronic illness is assumed to increase for the elderly and severe, acute ill health also rises. There is a 10 percent increase in health problems requiring GP visits and hospital admissions.

○ Supply side: The health service is relatively unresponsive with low rates of technology uptake and low productivity. 
Fully engaged

○ Demand side: People live longer (life expectancy at birth is 81.6 years for males and 85.5 years for females) and stay in better health (healthy life expectancy rises broadly in line with total life expectancy). People are confident in the health system and demand high-quality care.

- Supply side: The health service is responsive with high rates of technology uptake, particularly in relation to disease prevention. Use of resources is more efficient.

\section{References:}

Wanless D (2002). Securing our Future Health: Taking a Long-Term View Final Report. London: HM Treasury. 
DELSA/HEA/WD/HWP(2012)2

\begin{tabular}{|c|c|c|c|c|c|c|}
\hline \multirow{22}{*}{$\begin{array}{l}\text { Activities } \mathrm{x} \text { unit } \\
\text { costs of delivery }\end{array}$} & \multirow{12}{*}{ Health Care } & \multicolumn{2}{|l|}{$\begin{array}{l}\text { NHS Direct } \\
\text { Dental services } \\
\end{array}$} & & & \\
\hline & & \multicolumn{2}{|l|}{ General optical services } & & & \\
\hline & & \multirow{4}{*}{ Hospital care } & Accident and emergency attendances & & \multirow{4}{*}{ Disease $^{2}$} & \multirow{3}{*}{$\begin{array}{l}\text { Decedent and } \\
\text { Survivor Status }^{3}\end{array}$} \\
\hline & & & Inpatients (Elective and Non-Elective) ${ }^{4}$ & \multirow{3}{*}{$\mathrm{Age}^{3}$ and $\mathrm{Sex}^{1}$} & & \\
\hline & & & Elective day cases & & & \\
\hline & & & Outpatients & & & \\
\hline & & \multirow{2}{*}{ General medical services } & GP visits & \multirow{6}{*}{ Age and Sex } & \multirow[b]{2}{*}{ Disease } & \\
\hline & & & Prescribed items & & & \\
\hline & & \multirow{4}{*}{ Care in the community } & District nursing visits & & & \\
\hline & & & Learning disability nursing & & & \\
\hline & & & Psychiatric nursing & & & \\
\hline & & & Chiropodist visits (65+ only) & & & \\
\hline & \multirow{10}{*}{ Social Care } & \multirow{6}{*}{ Long term for $65 s^{+}$} & Meals on wheels & \multirow{10}{*}{ Age and Sex } & & \\
\hline & & & Home help & & & \\
\hline & & & Day centre attendances & & & \\
\hline & & & Residential care & & & \\
\hline & & & Nursing home care & & & \\
\hline & & & Respite care & & & \\
\hline & & \multirow{4}{*}{$\begin{array}{l}\text { Care for } 18-64 \mathrm{~s} \text { with physical disabilities, learning } \\
\text { disabilities or mental health problems }\end{array}$} & Day centre placements & & & \\
\hline & & & Home help & & & \\
\hline & & & Meals & & & \\
\hline & & & Residential and nursing home care & & & \\
\hline \multirow{16}{*}{$\begin{array}{lr}\text { Other } & \\
\text { (not } & \text { broken } \\
\text { down } & \text { by } \\
\text { activities } & \text { and } \\
\text { unit costs) } & \end{array}$} & & \multirow{16}{*}{ Hospital, community and family health services } & Ambulances & & & \\
\hline & & & Community maternity & & & \\
\hline & & & Family planning & & & \\
\hline & & & Health promotion & & & \\
\hline & & & $\mathrm{HQ}$ administration & & & \\
\hline & & & Immunisation and surveillance & & & \\
\hline & & & Obstetric outpatients & & & \\
\hline & & & Other care in the community & & & \\
\hline & & & Other hospital services & & & \\
\hline & & & Other learning disability related care & & & \\
\hline & & & Other mental health related care & & & \\
\hline & & & Professional advice and support & & & \\
\hline & & & Personal dental services & & & \\
\hline & & & Screening & & & \\
\hline & & & Services to GPs (open access) & & & \\
\hline & & & Personal medical services & & & \\
\hline
\end{tabular}




\section{Annex 1.19 UK - National Heart Forum Microsimulation Model (Foresight)}

The National Heart Forum microsimulation model projects public health expenditures associated with leading diseases where obesity is a significant risk factor. ${ }^{1}$ The model simulates and evaluates how future trends may change in response to policies to reduce the prevalence of obesity. New work has extended the model to focus on smoking and smoking-related diseases and the model is extensible to a broader range of risk factors and diseases. ${ }^{2}$

The NHS model for the projection of obesity disease burden, the Foresight Model, was developed for the UK Government Foresight Programme of the Government Office for Science.

\section{Policy questions}

What may be the future disease and public health-care cost burden associated with obesity in the future?

What would be the impact on obesity-related disease prevalence and public health care costs if we were to successfully constrain population BMI growth in some way?

\section{Class of forecasting model}

\section{Microsimulation (dynamic)}

\section{Forecasting method}

The NHS model focuses on individuals and builds a virtual population representative of England. Individuals are born into the simulation; experience health-related events, such as developing risk factors and disease; and eventually die. Based on current knowledge of the cost of disease treatment, future costs to the government National Health Service are projected. The model is developed in three steps: a regression analysis to project the future distribution of risk factors in the population; a microsimulation model to project the future disease burden associated with these risk factors; and an ex-post calculation to estimate public expenditures in current dollars associated with the projected future disease burden.

For published obesity projections ${ }^{1}$, the model used 15 waves of data from the Health Survey of England, a cross-sectional survey (1993 to 2007), to develop multivariate categorical regression models where age group, sex and calendar year were independent predictors of body mass index (BMI) category. The equations were then used to predict the future distribution of BMI categories from 2008 to 2050. A dynamic microsimulation model probabilistically assigned a BMI category to each individual in a synthetic and representative population over the period 2008 to 2050. Population dynamics (births and deaths) were estimated using national census, vital statistics and official population projections. The assignment of BMI values was based on age, sex and calendar year.

Every year, each simulated individual faces the probability of getting a specific disease, if free of this disease at the beginning of the year. Probabilities depend on the individual's age, sex, and the presence of risk factors and were determined from the published literature. Disease pathways (recovery, continuance, death) were developed to match survival and case fatality statistics via a randomized or Monte Carlo process. The Monte Carlo process involves the generation of a random number that influences the occurrence of events and allows outcomes to vary from one individual to another. Survival probabilities are determined by the survival experience of individuals with a given disease, moderated by age and sex, and were obtained from the published literature. 
The average NHS expenditure per patient for diseases associated with obesity is then used to calculate the future costs associated with these same diseases in constant dollars.

\section{Health Expenditure Drivers}

- Population dynamics

- Distribution of the body mass index

- Prevalence of diseases related to obesity

- Annual public costs of each incident disease (obtained from the literature and national data)

\section{Projected variables, measurement units and time horizon}

The model projects the future prevalence of obesity, chronic diseases associated with obesity (diabetes, coronary heart disease, stroke, colorectal cancer and breast cancer) and the public medical expenditures that may be associated with the future burden by disease type and total. Forecasts future public costs (NHS costs) in constant dollars attributed to increasing obesity rates. The time horizon of the projection is over forty years, with recent published projections from 2008 to 2050 .

The model enables the testing of "what-if" policy scenarios, such as the potential future effects of different risk-factor interventions. Recent published work compared the potential impact of a universal strategy that reduces BMI across the population to a targeted strategy among overweight or obese people.

The model enables generation of projections at various levels of disaggregation, such as by country, age, sex, region, year, disease type, and risk factor status.

\section{Assumptions, sensitivity analysis and criteria to assess the forecasting method}

Once a BMI value has been assigned to the individual in the simulation, it is assumed that the individual's BMI ranking (percentile), in the same age cohort, remains constant over time. Population dynamics in the model do not include immigration and emigration. There is no estimation of the potential impact of technological change on health care expenditures and, unlike other microsimulation models reviewed, no scenarios can be tested that relate to health-care treatments. Thus, all projections assume current technology and treatments are maintained in the future. Other drivers of health care expenditure seen in other models are not included, such as administration, infrastructure and human resource costs associated with a growing burden of disease. There is an assumption of constant prices.

Elements of model validation include comparing simulated results for current years with known population statistics and ensuring that projected population dynamics match official population projections from the Office for National Statistics.

\section{References:}

McPherson K, Marsh T \& Brown M (2007). Tackling Obesities: Future Choices - Modelling Future Trends in Obesity \& Their Impact on Health 2nd Edition. London: Government Office for Science.

National Heart Forum (2011). National Heart Forum Microsimulation Project, www.heartforum.org.uk/our-work/modelling/microsimulation-project accessed August 9, 2011. 


\section{Annex 1.20 USA - Centers for Medicare \& Medicaid Services (Component)}

The Office of the Actuary (OACT) at CMS annually produces eleven-year projections of national health expenditures (NHE). This exercise contributes to its technical support to the Trustees in the preparation of their annual report to the Congress about the financial solvency of the Medicare programme. In addition, CMS prepares a report on the past financial trends and projected outlook for Medicaid, which provides an insight into the nature of Medicaid cost trends and is a useful source of information for policy makers and budget analysts.

The CMS approach has the merit of providing a short-term outlook on total national health expenditure by combining actuarial and econometric techniques.

\section{Policy question the model has supported}

No specific policy question is addressed. The CMS projections do, however, represent the official health care projection of the U.S. government. These projections are intended, in part, to provide a broader context for the actuarial projections of Medicare and Medicaid. In addition, the projections analyze probable sectoral trends, and relationships among private and public sources of funds.

\section{Class of forecasting model}

A combined approach is used. The CMS combines a component-based cohort or actuarial approach for Medicare and Medicaid spending with a macro-level model for private health spending.

\section{Forecasting methods}

To produce projections for total national health expenditures, OACT combines projections for Medicare and Medicaid spending (based on actuarial techniques) with projections for private health spending (based on a multi-equation structural econometric model).

The structure of the Medicare projection model combines projections for the Hospital Insurance (HI) and the Supplementary Medicare Insurance (SMI) trust funds.

To project future HI costs, the present cost of services provided to beneficiaries, by type of service, is established to serve as a projection base. Type of services include: inpatient hospital services, skilled nursing, home health, hospice services, private health plans, and administrative costs. For each type of service, a combination of the following factors is used to project future costs: labour; non-labour; price index; volume of services; and workloads (for administrative costs).

To project future SMI part B costs, estimates of current costs are calculated separately for each category of enrolee - aged; disabled; and persons with end-stage renal disease - and for each type of service. Types of services include - among others - physician services, durable medical equipment, laboratory tests, and outpatient hospital services. Each expenditure category is projected on the basis of recent past trends in growth per enrolee, along with applicable legislated limits on payment updates. To project future SMI part $\mathrm{D}^{24}$ costs, historical per capita spending for beneficiaries in private prescription drug plans, low-income beneficiaries, and beneficiaries in employer-sponsored retiree health plans is used as a projection base. Future drug costs are based on the projected increases in per capita drug expenses for the total U.S. population from the NHE accounts. 
For Medicaid, the projection algorithm begins with development of data on the current level of Medicaid expenditures by eligibility category (that is children, adults, blind/disabled, and aged) and by type of medical service (e.g. inpatient hospital services, home health services), to serve as a projection base. Changes in the three determinants of expenditures - that is the number of people enrolled in the programme, the quantity and intensity of services each person uses, and the price for each unit of service are then projected for future years.

The NHE Projection Model for private health spending attempts to capture the causal relationships between major macroeconomic variables and private health spending, as well as interactions among major causal variables within the health sector. The structure of the NHE Projection Model is a multi-equation structural econometric model that is estimated based on the historical NHE data. The projected growth is primarily determined at the aggregate level on the basis of exogenous projections of macroeconomic variables, actuarial projections of spending for the Medicare and Medicaid programmes, and health sector assumptions.

\section{Projected variables, measurement unit, and time horizon}

Total real national per capita health expenditures public and private personal health care (PHC) spending are projected for 11 years.

\section{Determinants of health expenditures}

For Medicare and Medicaid, health care cost increases are affected by the following factors:

- Growth in the number of beneficiaries;

- Increases in the prices paid per service, which reflect both higher wages for health care workers and higher prices for the goods and services purchased by health care providers;

- Increases in the average number of services per beneficiary ("utilisation");

- Increases in the average complexity of services ("intensity");

- Applicable legislated limits on payment updates; and

- Workloads (for administrative services).

The core of the aggregate model of PHC spending consists of two behavioural equations:

- $\quad$ Private personal health care spending (real per capita); and

- Medical price inflation.

The independent variables in the aggregate model of private personal health care spending are:

- Disposable personal income growth (less Medicare and Medicaid, real per capita) (Exogenous);

- $\quad$ Relative medical price inflation (PHC);

- Public spending growth (PHC, real per capita) (Endogenous); and 
- $\quad$ Time trend.

The independent variables in the aggregate model of medical price inflation are:

- Weighted index of input prices for health providers, and

- Index of physician compensation rates.

The model is estimated with all variables expressed in log differences (a measure of growth rate). The relationship between health spending and the causal variables in the model is assumed to be linear.

The personal health care price inflation index is a chain-weighted deflator based on the indexes from different industries/commodity or services (e.g. hospitals, nursing homes), with the weight for each index set equal to the share of personal health care expenditures accounted for by that type of service.

\section{Assumptions, sensitivity analysis, and criteria to assess forecasting methods performance}

The linear relationship between health spending and the causal variables in the National Health Expenditure Projection Model implies that the relationship between growth in health spending and growth in each of the independent variables is constant over time.

Constant coefficients on growth imply that the elasticities of demand for health care with respect to income, relative price, and public spending are constant over time.

\section{Incorporating the Impact of the Affordable Care Act (ACA)}

Using the methods described above, CMS constructs a pre-Affordable Care Act projection of health spending. That projection is then run through the Office of the Actuary's Health Reform Model, which takes into account all of the provisions of the ACA. A methods paper associated with that model is forthcoming.

\section{References:}

Boards of Trustees (2011). 2011 Annual Report of the Boards of Trustees of the Federal Hospital Insurance Trust Fund and the Federal Supplementary Medical Insurance Trust Fund. Washington.

Centers for Medicare and Medicaid Services (2010). Projections of National Health Expenditures: Methodology and Model Specification, http://www.cms.gov/Research-Statistics-Data-andSystems/Statistics-Trends-and-Reports/NationalHealthExpendData/downloads/projectionsmethodology.pdf accessed 17 October 2012.

CMS-OACT (2010). 2010 Actuarial Report on the Financial Outlook for Medicaid. U.S. Department of Health and Human Services. http://www.cms.gov/Research-Statistics-Data-andSystems/Research/ActuarialStudies/downloads/MedicaidReport2010.pdf accessed 17 October 2012. 


\section{Annex 1.21 USA - Centers for Medicare \& Medicaid Services (GE)}

This dynamic general equilibrium (GE) model generates projections of medical care expenditures within a macroeconomic accounting framework that allows for the measurement of broader consequences to the economy resulting from medical spending growth (Borger, C., T. F. Rutherford and G.Y. Won, 2008). Compared with other techniques, it gives greater scope to investigating the underlying economic drivers of expenditure growth and it enables exploration of "what if" scenarios, regarding the introduction of new policies or other shocks.

The model was developed by researchers within the Office of the Actuary, Centres for Medicare and Medicaid Services, in the U.S. Department of Health and Human Services in collaboration with Thomas Rutherford, an external expert in general equilibrium modelling.

\section{Policy questions the model has supported}

The dynamic GE model framework supports testing a wide range of user-defined scenarios related to the health sector and the economy overall, such as changes in the rate of medical technological innovation, savings rates, and productivity growth. Example policy questions include:

What are the implications of higher levels of medical-care spending and higher governmental health expenditures on economic growth?

What are the long-run determinants of medical spending growth? To what degree is medical spending growth driven by the diffusion of health technologies and the productivity of the health sector relative to the rest of the economy?

\section{Class of forecasting method}

Computable general equilibrium

\section{Forecasting Method}

The U.S. economy is modelled as a market, producing both medical goods and services and nonmedical goods and services. To provide a framework for the relationship between technological innovation and demand for medical care, health is modelled as produced from a combination of medical-care input and the state of medical knowledge. The demand side of the model assumes that individuals maximize their welfare through consumption of health and non-health related goods and services, constrained by their income and savings. The demand for medical care is then conditioned on societal preferences for health and is represented by a health technology share parameter. The greater the preference for health; the stronger the demand for medical care. The health technology share parameter is the share of health output attributed to medical technology. As this parameter approaches zero, new medical technologies do not contribute to health expenditure growth.

The supply side of the model assumes that both medical and non-medical firms maximize profits and that their profits depend on capital and labour costs and tax rates. The model allows for projections that assume different rates of productivity growth between the medical and non-medical sectors. The model also incorporates process-innovative (cost-saving) and product-innovative (cost-increasing) technological change, represented by the elasticity of substitution parameter. This parameter governs the degree to which medical innovations can substitute for medical care inputs. As the parameter approaches zero, new medical technologies do not substitute for medical care inputs. Thus, new medical technologies are never costsaving. 
The technology share and the elasticity of substitution parameters cannot be directly measured. Three methods were used to estimate them. First, the parameters were inferred from what they must have been in order to replicate historical estimates of medical-care consumption. Second, the range of values was then further narrowed to those that would produce existing estimates of the price elasticity of demand for medical care in the published literature. Potential values for the elasticity of substitution then ranged between 0.6 and 1.0 and for the technology share parameter from 0 to 0.4 . Without any other constraints on these parameter values, however, the model generates a wide range of forecasts of medical expenditure as a share of GDP.

Finally, an unobserved components model, a time series regression technique using historical data, was also used to empirically estimate the parameters. The model is estimated using historical data from 1960 to 20004 and the 10-year forecast (2005 to 2015) from the Centres for Medicare and Medicaid Services. The robustness of the results were evaluated by developing the models from two different measures of income, real per-capita GDP and real per-capita disposable income. Both approaches yielded similar estimates of the elasticity of substitution $(0.39$ and 0.41$)$, while the technology share parameter value varied ( 0.89 and 0.52 ). Final values for the baseline scenario were set at 0.4 for the elasticity of substitution and 0.9 for health technology share and assumed to remain constant over time. Given these parameter values, the rate of medical innovation necessary to generate the historical pattern of health expenditure growth was estimated and was also assumed to remain constant over time.

The model is made dynamic by the application of time to all variables in the model and developing the demand equation as a choice of consumption paths over time, subject to an intertemporal budget constraint. Prices are discounted to represent present values. Capital stock evolves through depreciation and investment and markets for labour and capital and production output clear in each period. Long-term projections of medical care spending can then be generated. All projections account for population dynamics through an age-gender adjustment based on official population projections.

\section{Projected variables, measurement units and time horizon}

Two main indicators are projected.

- Public and Private medical care expenditures as a proportion of GDP. Medical care includes goods and services to treat illness and excludes other elements of governmental health expenditure, such as administration and research.

- Rates of annual medical expenditure cost growth.

In the baseline model, and in variants to this model, the trend for the projection of medical care as a share of GDP always has a concave shape. That is, in the long run, the growth of medical care expenditures relative to GDP slows. This is because the model accounts for a reaction from consumers and firms to the impact of rising health expenditures, such as reduced medical care consumption, if it threatens individual's welfare, and reduced capital investment in new technologies, if that investment becomes less profitable. Thus results have, arguably, greater face validity than the traditional GDP $+\mathrm{X}$ forecasts from models that are unconstrained by the adding-up requirement of a rigorous economic model and, therefore grow in a straight line until virtually all of GDP is exhausted on health.

The time horizon for projections with the CGE model is 75 years and the model projects that medical care expenditure as a share of GDP will reach just over $35 \%$ by $2080 .{ }^{1}$ This estimate is lower than the estimate of $41 \%$ for the same year from the methodology used by the Centre for Medicare and Medicaid Services for published projections (a component-based model with the GDP +1 health expenditure growth assumption). 


\section{Assumptions, sensitivity analysis and criteria to assess the forecasting method}

All CGE models depend on assumptions of economic equilibrium including that demand for goods and services must equal their supply; that demand and supply maximize consumers' welfare and firms' profits; and that market prices for labour, capital and goods and services are determined at levels that clear markets. Through these assumptions, in principle, it is possible to iterate to find plausible values for otherwise unknown parameters and to investigate the key economic incentives that underlie medical care cost growth.

In addition to the complexity of the model and the number of assumptions required for the model, there are two significant challenges. First, assumptions of equilibrium may be violated, particularly as health is not a standard good. Second, such models tend to yield multiple plausible solutions.

As discussed earlier, parameters for technology share, elasticity of substitution, and the growth rate for medical innovation have been estimated and are assumed to remain constant over time. Parameters representing the discount rate, the rate of economic growth, intertemporal elasticities of substitution and the capital depreciation rate are also assumed. Further, the baseline model assumes that, in equilibrium, medical expenditures rise in proportion with income, i.e. the income elasticity of demand equals one. Values for other parameters were obtained from the 1977 and 1992 U.S. input-output data.

All model parameters are economic and the model does not account for factors influencing the production of health that are outside of health care, such as healthy lifestyles and risky behaviours, nor those influencing demand for health care, such as trends in diseases. The model does not consider marketdriven innovations in the non-medical sector that influence medical consumption, such as innovations in foods that lower calories and reduce obesity. Household decisions to purchase health insurance, which would influence demand for care, are also excluded.

The model assumes that total government consumption is approximately $20 \%$ of GDP, a figure drawn from current data. Transfer payments are not modelled, nor does it model health insurance, so the model does inform about health care financing issues.

The model assumes efficiency in the production of health, when many studies have revealed significant inefficiencies and deviations from what would be expected from perfectly competitive markets. The model does not identify the mechanism though which the market would constrain growth in medical expenditure, however, it necessitates that long-term spending growth must be consistent with consumer preferences to purchase non-medical goods and services.

The values for the technology share and elasticity of substitution parameters largely determine the value of the price elasticity of demand for medical care. A sensitivity analysis allows these values to vary. In the base case, the price elasticity of demand is -0.45 . A low scenario reduces the value to -0.7 (greater rationing) and a high scenario raises the value to -0.2. This sets a lower and upper boundary for the projection that is quite large, particularly due to the long time horizon of 75 years. The projected ratio of medical expenditure to GDP in 2080 ranged from under $25 \%$ to over $45 \%$ in this sensitivity analysis.

\section{References:}

Borger C, Rutherford TF and Won GY (2008). Projecting Long-term Medical Spending Growth. Journal of Health Economics , 27(1): 69-88.

Friedman JN (2010). Predicting Medicare Cost Growth. In Improving Health Care Cost Projections for the Medicare Population, Summary of a Workshop (G. Wunderlich ed.). Washington D.C.: The National Academies Press, pp. 83-106. 


\section{Annex 1.22 USA - Congressional Budget Office (CBOLT)}

Over the past decade the Congressional Budget Office (CBO) has developed a sophisticated long-term model known as CBOLT to analyse the budgetary effects of social security programs in the United States. CBO focuses on the first 25 years of the projection in its annual Long-Term Budget Outlook, but appendices contain figures showing projections over 75 years.

\section{Policy questions}

CBOLT provides information about future pressures on US federal budgets of federal health care expenditures as well as other social security spending under two scenarios. The extended baseline scenario reflects the assumption that current laws generally remain unchanged. ${ }^{25}$ The extended alternative fiscal scenario incorporates the assumptions that certain policies that have been in place for a number of years will be continued and that some provisions of law that might be difficult to sustain for a long period will be modified, thus maintaining what some analysts might consider "current policies" as opposed to current laws. The framework also enables assessment of policy options. Projections represent an indication of potential long-term trends rather than precise estimates of the future magnitude of health spending.

\section{Class of forecasting methods}

CBOLT is a forecasting platform that amalgamates both component-based or actuarial methods and dynamic microsimulation ${ }^{26}$ methods. The full platform projects the U.S. population, labour force, production and output, earnings and capital income, payroll taxes, social security beneficiaries, social security benefit amounts, other taxes, private savings and capital stock (CBO, 2009).

A component-based cohort model (actuarial model) with explanatory variables is used to project health expenditures (CBO, 2009). The CBO is currently working on a microsimulation module to improve health expenditure forecasts. The microsimulation model currently projects health status and health status transitions at the individual level, and CBO is developing a methodology to project eligibility for Medicare and Medicaid at the individual level. Health status is linked to mortality, and further development will link health status to work, marital status, fertility, and federal health care expenditures (Topoleski and Manchester, 2009).

\section{Forecasting method}

The first step in CBOLT is to project the population. The population changes through births, deaths and immigration. A cell-based approach is used where the population is estimated annually by single year of age (0-119) and sex resulting in a population matrix with 238 cells. For Medicare only, the population matrix is further extended by three "time until death" categories (within twelve months of death, within 24

\footnotetext{
25 $\quad$ BO operates under a long-standing statutory requirement (section 257 of the Balanced Budget and Emergency Deficit Control Act of 1985, Public Law 99-177, as amended; 2 U.S.C. 907). It requires that $\mathrm{CBO}$ assume in its baseline projections that laws are implemented as specified and that funding for entitlement programs is adequate to make all payments.

"A micro-simulation model starts with individual-level data from a representative sample of the population and projects demographic and economic outcomes for that sample through time. For each individual in the sample, CBOLT simulates birth, death, immigration and emigration, marital pairings and transitions, fertility, labour force participation, hours worked, earnings, payroll taxes, Social Security benefit claiming, and Social Security benefit levels. A complex actuarial framework wraps around the micro-simulation model to provide totals for demographic and economic variables as well as additional information in areas where the micro-simulation model has not yet been developed" (CBO, 2009).
} 
months of death, and survivor) and the population matrix grows to 714 cells. Projections of the Social Security actuaries are used to set mortality rates and fertility rates. CBO projects immigration levels.

The second step is to estimate the number of Medicare and Medicaid beneficiaries each year. From Medicare data, the ratio of beneficiaries to the population for each age, sex and time-until-death group is estimated for a current year. These ratios are fixed and applied to the population matrix for the entire projection period. For the first 10 years of the projection, beneficiaries are scaled to match the official CBO baseline budget projections. The same process is used to estimate Medicaid beneficiaries with the exception that time until death is not included.

In the third step, $\mathrm{CBO}$ uses detailed projections of Medicare and Medicaid spending for the first 10 years based on detailed analysis of the programs and enrollees. Beyond the 10-year horizon, CBO assumes Medicare and Medicaid expenditures grow as a result of changes in the number of beneficiaries in each age, sex and time-until-death (Medicare only) group multiplied by growth in GDP per capita and excess cost growth (ECG) relative to potential GDP. ${ }^{27}$ The agency also projects spending on CHIP, a program that provides health insurance coverage for uninsured children living in low-income families, and for federal subsidies that will be provided to low-income people to help them buy health insurance in the future under current law. All other health spending grows with the change in the population in each age and sex group multiplied by GDP per capita and ECG. Estimates of growth in GDP per capita each year over the projection period come from CBOLT in a separate macroeconomic framework (CBO, 2009).

In CBO's judgment, the rate of excess cost growth in overall health care spending since 1985 best reflects features of the health care and health insurance systems that are likely to endure for a number of years. The projection of ECG begins with estimation of historical ECG for the three main components of health spending (Medicare, Medicaid and "all other" health expenditures) and for overall spending on health care. CBO calculated historical rates of ECG as a weighted average of annual rates relative to potential GDP, placing twice as much weight on the latest year as on the earliest year. The resulting growth rate-1.6 percentage points per year-serves as an anchor for CBO's long-term projections of health care costs.

In the long term, however, $\mathrm{CBO}$ expects that the rate of ECG in health care will decrease in response to the pressures created by rising costs. ${ }^{28} \mathrm{CBO}$ assumes that the underlying rate of ECG will decline from 1.6 percentage points in the first year to zero in the final year of the 75 -year projection period for both Medicaid and private insurance premiums. ECG for Medicare declines to 1.0 percentage point. In addition, $\mathrm{CBO}$ assumes the underlying rate of excess cost growth in each sector will decline linearly - that is, by the same fractional number of percentage points - between years 1 and 75. However, under current law prior to 2030 for Medicare and prior to 2023 for Medicaid and other spending, CBO's projected rates of ECG incorporate certain adjustments that are described below. Under current policies, rates of ECG for Medicare and Medicaid follow the underlying paths starting in 2023.

For Medicare under current law during the years from 2023 through 2029, CBO uses a rate of ECG of 0.6 percentage point - equal to the average rate for 2020 through 2022 with certain adjustments. ${ }^{29}$ That rate reflects the projected effects of the recent health care legislation as well as other provisions of current law. After 2029, three policies that will restrain spending growth-provider payment updates, physician payment rates, and a board that will rein in spending growth - are assumed not to be in effect in CBO's

\footnotetext{
27 Potential GDP is CBO's estimate of the output the economy would produce with a high rate of use of its capital and labor resources.

See CBO (2012), p. 56, footnote 34.
} 
extended baseline scenario. As a result, for 2030 and beyond, CBO uses the underlying rates of ECG for Medicare as described above. Under CBO's extended alternative fiscal scenario, CBO assumes that those three policies of current law will not continue after the first 10 years. Without those policies in place, CBO uses the underlying rates of ECG for Medicare for 2023 and beyond.

Under both current law and current policies, CBO estimates Medicaid spending beyond the initial 10year span by using the underlying rates of ECG for Medicaid described above. Spending on CHIP is currently subject to a statutory cap. CBO projects that spending on the program under both scenarios will be constant as a share of GDP after 2022.

Under current law, for federal subsidies of premiums in health insurance exchanges during 20232029, CBO uses a growth rate consistent with its estimates for the latter part of the initial 10-year projection period. In 2030 and beyond, CBO uses the underlying rates of ECG described above. Under current policies, $\mathrm{CBO}$ uses ECG from the underlying path but assumes that the number of people receiving different amounts of subsidies will be altered. As a result, more people will be eligible for exchange subsidies over time, and the subsidies will cover a higher share of the premiums than would be the case under current law.

\section{Projected variables, measurement units and time horizon}

CBOLT projects annual federal spending on major health care programs over a 75 -year time horizon, expressed as a percentage of GDP. Separate projections are developed for two categories: federal spending on Medicare; and federal spending on Medicaid, CHIP, and subsidies to purchase health insurance through exchanges.

\section{Determinants of health care expenditures}

Growth in real annual health care spending is affected by the following factors:

- Growth in the number of beneficiaries or recipients (Medicare, Medicaid, CHIP, and exchange subsidies)

- $\quad$ Population aging (Medicare and Medicaid)

- Population in proximity of death (Medicare)

- Growth in real GDP per capita

- Excess cost growth (ECG) relative to potential GDP

\section{Assumptions, sensitivity analysis and criteria to assess the forecasting method}

CBO assumptions regarding ECG, as discussed above, pose a variety of challenges. Although all long-term economic and demographic developments are uncertain, excess cost growth in health care may be particularly so. The current systems of health care and health care financing have existed for only a few decades, and medical procedures and technology continue to evolve rapidly. Even without policy changes, actual spending for health care could be much lower or much higher than the figures contained in CBO's and other analysts' projections. Compared with the health expenditure methodology of CMS-Office of the Actuary, projections of Medicare expenditures are similar over the 25-year horizon. For the longer term, however, CBOLT relies more heavily on an extrapolation of historical growth rates in costs and assumes that several cost-cutting provisions of recent health legislation will not be in effect after 2029. As a result, 
CBOLT projects Medicare costs to grow more quickly in the long term than does the CMS-Office of the Actuary model. Under current law for the last 50 years of the projection, the 2012 trustees report assumes that all of Medicare spending will grow at an average growth rate of GDP per capita plus 0.2 percentage point (Board of Trustees, 2012). This path lowers ECG from historical averages and, unlike CBO, assumes that the cost-cutting provisions of recent health legislation will remain in effect in the long term.

ECG is also challenging as a concept for policy decisions regarding how to control rising health expenditures as it includes all factors driving future health expenditure that do not relate to growth in GDP or demographics (Friedman, 2009). It is sometimes referred to as representing technological change; but it represents a variety of factors that have driven health care expenditures in the past such as intensification of health care use, preferences for health care, and administrative changes.

The inclusion of time until death is a refinement of the Medicare projections that avoids the assumption that future gains in life expectancy will all correspond to an increase in time spent in ill health (with high health expenditures). The inclusion of time until death ensures costs are shifted to the period when they typically occur, which is preceding death.

In the current model, shifts in economics, demographics, or policy affect only average values, such as the average Medicare expenditure of men at age 75. Recent efforts within CBO to model the future health status of the population within the existing microsimulation model are promising (Topoleski et al, 2009). Including health status within this microsimulation model will increase its utility for both pension policy planning and for health policy planning. In this revised framework, health status and mortality outcomes could be projected conditional on education, earnings, labour-force status, disability status, fertility and marital status and could also be conditional on whether or not the individual participates in Medicare and Medicaid. The forecasts could be both refined to project rather than assume the health status and health care use of the future population and could also be disaggregated for various key population sub-groups (low educated, low earners, unemployed, etc.). In so doing, the framework can be used to project distributional impacts of potential policy changes.

\section{References:}

CBO. (2009). CBO’s Long-Term Model: An Overview. CBO Background Paper.

CBO. (2012). The 2012 Long-Term Budget Outlook.

Friedman, J. N. (2009). Predicting Medicare Cost Growth. Harvard Kennedy School Working Paper.

National Research Council. (2010). Improving Health Care Cost Projections for the Medicare Population: Summary of a Workshop. In G. S. Wunderlich (Ed.), Committee on National Statistics, Division of Behavioral and Social Sciences and Education. Washington, DC: The National Academies Press.

Topoleski, J. \& Manchester, J. (2009). Modeling Health Status for Microsimulation. $2^{\text {nd }}$ General Conference of the International Microsimulation Association, Ottawa, June 8-10. 


\section{Annex 1.23 USA - The Future Elderly Model (CMS/RAND)}

The Future Elderly Model (FEM) projects the potential future Medicare, Medicaid, and total medical and drug expenditures of the population aged 51 and older in the United States, given current demographic, health status and disability trends (RAND, 2011). FEM simulates and evaluates how future trends may change in response to potential changes in the health care environment including health status trends, medical innovations, reduction in chronic diseases and reduction in the number of elderly who are obese or who have other risk factors (Goldman, D.P, B. Shang, J. Bhattacharya et al., 2005).

The Future Elderly Model was developed jointly by the RAND Corporation and the University of Southern California, with collaborators from Harvard University and Stanford University. FEM development has been sponsored by the Centers for Medicare and Medicaid Services (CMS), the National Institutes of Health (NIH), Pfizer, the McArthur Foundation and the US Department of Labor (RAND, 2011).

\section{Policy questions the model has supported}

FEM supports testing a wide range of user-defined scenarios. Example policy questions include:

What may be the future health status and health care expenditures related to an aging population? How would these forecasts change if the health status of the elderly were to improve? (Chernew, M.E., D.P. Goldman, F. Pan and B. Shang, 2005)

What will be the potential impact on health and health care expenditures for the future elderly if different medical technologies or innovations are introduced? (Shekelle, P.G., E. Ortiz, S.J. Newberry et al., 2005)

What will be the potential health and health care expenditure impact for the future elderly given current obesity trends? (Lakdawalla, D.N., D.P. Goldman, and B. Shang, 2005)

Issues analysed with FEM include obesity, disability, technological advances, cancer, the burden of chronic diseases, global pharmaceutical policy and health in the United States and Europe, age versus life expectancy as a predictor of health-care spending, and the fiscal implications of healthier aging.

\section{Class of forecasting model}

Microsimulation (dynamic)

\section{Forecasting method}

The initial population for the model is drawn from the Medicare Current Beneficiary Survey. The model has three main components: a model for health status transitions, a rejuvenation model that predicts health characteristics of new Medicare enrolees introduced into the simulation each year, and a model for health care costs.

The model of health status transitions includes transitions into mortality, cancers, cardiovascular disease, stroke, neurological disorders, diabetes, hypertension, ADL, and facility residence (entry to a nursing home) using piecewise Gompertz proportional hazard models.

The rejuvenation model ensures that the simulation remains representative of the population aged 51+ into the future. FEM incorporates population projections of the U.S. Census Bureau. Health status of future cohorts are estimated by obtaining age-specific prevalence rates for each chronic disease of interest and 
disability status from the National Health Interview Survey. Age-incidence trajectories are completed by combining information on age-specific prevalences with disease-specific death rates from US Vital Statistics. Age-specific prevalence rates and disease-specific trajectories are then used to predict the health status of the incoming Medicare sample.

The models of health care costs estimate Medicare, Medicaid and total medical and drug expenditures based on the demographic and health characteristics of the population using OLS regression equations. Independent variables include activities of daily living, chronic diseases, and interactions of ADL categories and disease conditions. Ever having smoked, residing in the Northeast, mortality, obesity, and physical health status (measured by number of ADLs and admission to nursing home) have considerable effects on expenditures. Further, individuals who die during the year have substantially higher medical expenses than survivors. Results of the health care cost models are used to forecast future health expenditures based on the characteristics and health status of the projected future elderly population from the other two FEM model components.

\section{Projected variables, measurement units and time horizon}

Projects the future prevalence of risk factors such as obesity and smoking; major chronic diseases (cancer, heart disease, hypertension, stroke, arthritis, lung disease, Alzheimer's disease, and diabetes); disability; facility residence; and public Medicare and Medicaid expenditures and total drug and medical expenditures that may be associated with the future burden by disease type and overall.

Projects total expenditures for the population aged 51+ for Part A, Part B, total Medicare, total Medicaid and the total from all sources. Per capita expenditures are also calculated for each of these four payment categories. All projected expenditures are in real terms that correspond to 1998 dollars. Projections are presented for a thirty year period from 2000 to 2030.

Tests "what-if" scenarios, such as the impact of potential breakthrough technologies as well as changes in lifestyle and in the health care system - by exploring changes in the parameters of the model.

\section{Health expenditure drivers}

- $\quad$ Population dynamics

- Distribution of risk factors

- Prevalence of chronic diseases

- Annual costs of disease treatment

\section{Assumptions, sensitivity analysis and criteria to assess the forecasting method}

The model enables projections of the number and type of health care treatments that may result from different policy scenarios, however, further costs that may result, such as the need to purchase additional equipment, to train new health-care providers or to build new health-care facilities are not part of the model. Administrative costs are not included. There is an assumption of constant prices. Extensive sensitivity analysis were conducted based on back-testing the model, that is running the model using the 2000 cohort and comparing model projections to observed data from the Health and Retirement Survey through to 2010 . 
In the baseline projection, FEM makes no assumption of what future technological changes may be. Thus the baseline projections consider future health and health care cost trends using current technology. In FEM, it is through the introduction of scenarios that the impact of new technologies on costs and health in the future can be evaluated. In contrast, other models include implicit or explicit assumptions of a growth in the adoption of new medical technologies. In these models, it is usually impossible to deduce what these technologies may be.

A feedback loop between policy scenarios and potential changes in the behaviour of people is not modelled.

The model also excludes impacts of changes in labour-force participation of those experiencing disease and treatments on the total demand and supply of labour or any broad impacts on the productivity of the whole economy (such as changes to GDP, consumption and investment).

\section{References:}

Bhattacharya J et al. (2004). Disability Forecasts and Future Medicare Costs, in Frontiers in Health Policy Research . Cambridge: MIT Press.

Bhattacharya J et al. (2005). Technological Advances in Cancer and Future Spending by the Elderly. Health Affairs 24 Supp 2, W5R18-29.

Chernew ME, Goldman DP, Pan F and Shang B (2005). Disability and Health Care spending Among Medicare Beneficiaries. Health Affairs 24 Suppl2, W5R42-52.

Goldman, D. et al. (2006). The Value of Elderly Disease Prevention. Forum for Health Economics and Policy, 9(2).

Goldman D et al. (2010). The Fiscal Consequences of Trends in Population Health. National Tax Journal , 63(2): 307-330.

Goldman DP, Shang B, Bhattacharya J et al. (2005). Consequences of Health Trends and Medical Innovation for the Future Elderly. Health Affairs 24 Suppl 2, W5R5-17.

Goldman DP et al. (2009). The Benefits of Risk Factor Prevention in Americans Aged 51 and Older. American Journal of Public Health, 99(11): 2096-101.

Goldman DP Shekelle PG, Bhattacharya J et al. (2004). Health Status and Medical Treatment of the Future Elderly Final Report. Santa Monica: RAND Corporation.

Lakdawalla DN et al. (2009). U.S. Pharmaceutical Policy in a Global Marketplace. Health Affairs, 28(1):W138-50.

Lakdawalla DN, Goldman DP, and Shang B (2005). The Health and Cost Consequences of Obesity among the Future Elderly. Health Affairs 24 Suppl 2, W5R30-41.

Michaud PC et al. (2011). Differences in Health Between Americans and Western Europeans: Effects on Longevity and Public Finance. Social Science and Medicine, 73(2): 254-63.

Michaud, PC et al. (2008). Understanding the Economic Consequences of Trends in Public Health. RAND, in mimeo. 
RAND (2011). Roybal Centre for Health Simulation: About the Future Elderly Model. www.rand.org/labor/roybalhp/about/fem.html (accessed on July 4, 2011).

Shang B and Goldman DP (2008). Does Age or Life Expectancy Better Predict Health-Care Expenditures. Health Economics , 17(4):487-501.

Shekelle PG, Ortiz E, Newberry SJ et al. (2005). Identifying Potential Health Care Innovations for the Future Elderly. Health Affairs 24 Suppl 2, W5-R67-W5-R76. 


\section{Annex 1.24 USA - U.S. Department of Veterans Affairs}

The U.S. Department of Veterans Affairs (VA) engaged a contractor, Milliman, Inc., to develop the Enrolee Health Care Projection Model (EHCPM) (Harris K.M. et al., 2008).

The original mission of the VA was to provide care for disabled Veterans. A reform in 1996, however, expanded the types of services available to patients and extended coverage to all veterans on a priority-based enrolment system. The VA operates a large integrated health care system that serves over 5 million patients annually. Projections are needed for planning and budgeting.

\section{Policy questions the model has supported}

What is the projected veteran enrolment in VA health care?

What may be enrolled veteran's use of health care services?

What are the projected costs of health care services used?

What should be the VA's appropriations request?

\section{Class of forecasting method}

\section{Component based}

\section{Forecasting method}

EHCPM models 58 medical services by age category $(<45,45-64,65+)$, by whether enrolment occurred before or after eligibility reforms, by priority level and by geographic sector resulting in about 40,000 cells representing different enrolee types. These cells are then used in three sub-models.

The first is the enrolment projection model (EPM). Projected monthly enrolment is equal to current enrolment plus new enrolees minus deaths. The VA projects the size of the veteran population by five-year age groups, gender, disability status and county of residence. Projected veteran populations are further disaggregated by priority level using data from historical VA trends as well as from the Census and national surveys. Projections are adjusted for anticipated changes in the priority level of enrolees and geographic migration of enrolees.

The second is the utilisation projection model (UPM). In the base year, utilisation rates for 37 of the 58 health services are estimated from Milliman Inc.'s proprietary database of utilisation-rate benchmarks calculated from commercial sources. These utilisation rates are adjusted to account for differences between the enrolees and private-sector patients in terms of health status, reliance on services, and the relative efficiency of facilities in different areas. The base year estimates are then further adjusted for the difference between modelled utilisation rates and actual utilisation measured from VA workload data. There are no private sector benchmarks for the remaining 19 services and VA workload data is used to estimate utilisation rates. In each projected year, utilisation rates may be adjusted to account for anticipated changes in service utilisation and the efficiency of VA facilities. Adjusted projected utilisation rates are multiplied by projected enrolees in each of the cells to obtain projected units of service.

The third is the Unit Cost Projections Model (UCPM). Base year average unit costs for each service are estimated by dividing the VA budget allocation for that year according to the VA workload for each service. These estimates are often at a level that is too high to be input into the model directly. In these cases, aggregate Medicare Program allowable charges or private-sector billed charges by community are 
used to disaggregate VA estimates. For the few services purchased by the VA, the actual billing for the service by community is used. In each projected year, assumptions about inflation and service intensity are multiplied to base year estimates to project future unit costs.

\title{
Projected variables
}

Enrolment

Service utilisation

Operational expenditures

\section{Measurement units}

Annual Counts

Annual nominal expenditure

\section{Time horizon}

Twenty years

\section{Drivers of health expenditures}

\author{
Enrolment \\ Enrolee reliance on VA services \\ Utilisation rates \\ Unit costs
}

\section{Assumptions, sensitivity analysis and criteria to assess the model's performance}

The VA projection model was evaluated by an independent organisation (Harris K.M. et al., 2008). Key findings from this evaluation are summarised here.

For both the UPM and the UCPM, assumptions about future values of key parameters, such as service utilisation, efficiency of VA facilities, unit costs, and service intensity, are developed by a consensus panel of experts. Decisions taken by the panel are informed by other data and analysis, such as the projections generated by the Centres for Medicare and Medicaid Services, the Medical Consumer Price Index and VA data.

The specifications of the model are such that no geographic area is allowed to have a projected enrolment that exceeds its authorized maximum. Utilisation projections are restricted to the limits of existing VA service capacities and the model specification does not allow for estimates of potential demand that exceeds those limits. The model doesn't allow unit cost measures that are independent from the VA budget allocation. The method of deriving unit costs does not relate to the marginal cost of adding an additional unit of service to existing treatment capacity. The model specifies the VA's cost structure as similar to a fee-for-service payer, i.e. having a high proportion of costs that are variable. If a substantial proportion of the VA's costs are fixed, projected expenditures will be unrealistic. The model does consider the impact of changing offerings of private health insurance that may alter enrolee's preferences for/use of VA services. 
The RAND evaluation concluded that the model is likely to be valid for short-term budget planning but less appropriate for longer-term policy planning. It is a detailed model that does enable examination of expenditure growth for different services and patient groups. In the longer-term, however, assumptions will be needed about factors driving enrolment; how rapidly the VA can expand capacity to meet demand; comparability of health care use patterns between the VA and commercial sectors; and relationships among enrolee health status, VA treatment capacity and enrolee's preferences for treatment in VA facilities. Implementing the capacity to account for longer term expenditure drivers would require additional data and revision to the sub-components of the model. Alternatively, a less complex model may be equally appropriate for short-term projections, while being more transparent.

\section{Reference:}

Harris KM, Galasso JP, \& Eibner C (2008). Review and Evaluation of the VA Enrolee Health Care Projection Model. Santa Monica: RAND Corporation.

\section{Annex 1.25 USA - Comprehensive Assessment of Reform Efforts (COMPARE) (RAND/USDL/USDHHS)}

The Comprehensive Assessment of Reform Efforts (COMPARE) model projects how individuals, families and firms in the United States may respond to potential health care policy changes and has been used to estimate the potential future impact of the Patient Protection and Affordable Care Act (PPACA) (RAND, 2011). The model enables projection of the change in government spending following reforms related to health-care insurance.

The COMPARE model was developed by the RAND Corporation. COMPARE development has been sponsored by the US Departments of Labor and Health and Human Services (Ebiner, C. et al., 2010).

\section{Policy questions the model has supported}

What may be the future impact of policy reforms related to health insurance coverage on the behaviour of individuals, households and firms?

Consequently, how will changes in behaviour impact on insurance coverage of individuals and their dependents and on expenditures of individuals, employers and the government?

\section{Class of forecasting model}

Microsimulation (static)

\section{Forecasting method}

COMPARE projects the effects of health reforms on health insurance coverage and costs, focussing on impacts on businesses of different sizes, workers and their dependents. The microsimulation model develops a synthetic population representative of the U.S. that is composed of individuals of working age and their dependents and firms. The model projects how individuals and their dependents and firms might respond to a policy reform by changing their decisions and considers interactions among these agents, with the decision of one agent potentially influencing the decision of another. For individuals, decision rules may include eligibility for different insurance options; the cost of employer-sponsored insurance; individual characteristics including family income and health; and whether the government offers an incentive to enrol in insurance, such as a tax credit or penalty. Similarly, firms in the model also follow decision rules and may make new decisions in light of changes introduced to health-care policy. These 
rules may include the contribution of health insurance to worker recruitment and retention; the expected cost of offering a policy; and any government regulations, incentives or penalties.

The initial population for the model is drawn from the 2001 Survey of Income and Program Participation (SIPP), a longitudinal study of U.S. households that contain data on demographics, household composition, health insurance status, income, assets, and labour-force participation. COMPARE incorporates estimates and demographic projections from the U.S. Census Bureau. Data from the SIPP are used to establish family units where members may be eligible for employer-sponsored health insurance (spouses and dependent children). Medical expenditures of individuals and families are provided by the Medical Expenditure Panel Survey, adjusted through calibration for known underestimation of expenditures to match published estimates. Statistical matching is used to assign health expenditures to SIPP family units. Firms in the model are based on data from the 2006 Kaiser/HRET Employer Health Benefits Annual Survey. These firms were matched to workers within the SIPP data based on census region, firm size, industry and whether the firm offered health insurance.

Baseline insurance premiums offered to workers and their families consist of an average plan adjusted for the size of the firm. Family premiums are 2.7 times individual premiums. To estimate employer premium contributions, a regression model developed from the Kaiser/HRET data was used to predict each employer's rank within the distribution of employer insurance contribution rates. Employers were then matched to Kaiser/HRET data based on their rank order within the distribution of contribution rates. Alternative insurance schemes, such as the introduction of health insurance exchanges were also modelled for use in policy reform scenarios.

A utility-maximization framework is used to decide how family units and firms make choices. Family unit's utility is a function of out-of-pocket health expenditures, a coefficient for risk aversion and the utility of consuming health services. The demand curve from the RAND Health Insurance Experiment (HIE) was used to model utilisation of health care services and health care expenditures of individuals related to different insurance plans. Plans are characterised by a deductible, co-insurance and a maximum out-ofpocket payment. Plans with co-pays were not considered, however, tests were done to determine that the inclusion of co-pays would not have made a statistically significant impact on results. A family unit selects the insurance options that maximize its utility. Given family units can make sub-optimal decisions; the predicted utilities are adjusted through calibration to produce observed insurance distributions.

The model evaluates the various insurance options that are available to firms of different sizes to maximize the firm's utility. In the base case, there are only two options: to offer or to not offer employer sponsored health insurance. A firm's decision to offer insurance is modelled as a group-choice utility maximization model which is a function of aggregate worker utility, the cost of insurance to the firm and the weight a firm places on worker's utility. There are three unknown parameters within this model: the fraction of the savings from not offering insurance that would be returned to workers as wages; the trade off between the cost of insurance and worker utility; and the administrative costs to firms resulting from offering health insurance.

Guided by the structural model, a reduced-form equation is estimated using a standard logit model. The reduced form model produces a vector of elacticities of firm demand for health insurance corresponding to different firm sizes, where values of the unknown parameters were restricted to those that best reproduced observed elasticities. For the final base case model, the parameter for the share of savings returned to workers as wages was set to 0.8 , a value above the lower bound in the literature of 0.7 and less than the expected value of 1 . The parameter for the weight a firm places on aggregate worker utility was set equal to 1 . The value of the additional wage costs to a firm to administer health insurance was set to $\$ 12,000$. 


\section{Projected variables, measurement units and time horizon}

COMPARE projects the change in total government spending related to health insurance for the working-age population (including workers and their dependents) following the implementation of a health-care policy reform. Projections of government spending include Medicaid expenditures, premium subsidies offered to individuals and families, cost-sharing subsidies offered to firms, and small business subsidies. The model also estimates government revenue from any penalties levied on firms that have not offered insurance coverage. COMPARE projects the number of employers offering insurance coverage; the proportion of workers employed by firms offering health insurance; the total population under age 65 with insurance; total employer spending on health insurance; premium prices and estimates of changes in insurance offerings of firms and insurance coverage of individuals and families following the introduction of a reform.

The model includes population dynamics that would enable it to generate projections to 2050, however, most analysis of the model are limited to 2010 to 2019. Published projections of the potential impact of the PPACA were for the year 2016 (Ebiner, C. et al., 2010).

\section{Health expenditure drivers}

The drivers of change in government spending relate directly to the impact of health insurance-related reforms. From health insurance decisions made by individuals and firms to maximize their utility (described above), the set of variables influencing the estimate of the change in government spending include:

- Number of workers and their dependents receiving Medicaid;

- Government insurance premium subsidies and cost-sharing subsidies; and

- Revenue from penalties for non-compliance with a reform.

\section{Assumptions, sensitivity analysis and criteria to assess the forecasting method}

COMPARE evolves the health system from one equilibrium, the status quo, to a new equilibrium, after a policy reform. It does not inform about how quickly the new equilibrium would be reached, although some researchers have made a deduction about the dynamics. The model is not intended to generate long-term projections of health expenditures and therefore is not comprehensive of the set of drivers of public health spending growth. The model also does not include the impact of broader macroeconomic effects such as firm births and deaths, changes in firm size, and changes in worker's employment statuses, either due to business cycles effects or to policy reforms. Therefore, it is best suited to short-term projections of the impact of health-care policy options, where other economic, health and social factors remain similar.

The model allows a worker and dependent family members to each have a different health insurance plan or no coverage. However, the model does not allow a single individual to have more than one source of insurance or a family unit to have more than one family insurance plan. The model assumes that firms offering an employer sponsored health insurance plan offer an average plan estimated from survey data.

Household medical expenditures are estimated from the MEPS survey and exclude spending on vision and dental care. All monetary amounts are expressed in 2010 constant dollars. 
The firm utility function was validated by comparing estimated elacticities of firm insurance offerings in relation to the price of insurance premiums with estimates in the literature. Model results were found to be within the ranges reported in the literature and in conformance with the theoretical expectation that small firms would have a more elastic demand for health insurance than would larger firms. Sensitivity analysis, where different combinations of potential covariates were used to estimate firm utility, was undertaken and the base case model specification was determined to be the most appropriate.

The baseline results of the model assume no inertia in firm decision making, that is, firms will change insurance offerings to maximize utility. A sensitivity analysis was undertaken where the probability of offering a new insurance option (one of the options available through the new insurance exchanges) estimated from the model was adjusted downward to match other estimates in the literature.

Uncertainty was also quantified in the model by using results from multiple model iterations to generate standard deviations and confidence bands around the estimated output variables. Because there are many more workers than firms in the data used to estimate the model, results for workers are more stable. Firm offer rates were estimated with an error rate of plus or minus 6 percent and therefore small changes in behaviour following a policy reform were not detectable.

COMPARE model results for the change in coverage and government spending resulting from the introduction of the PPACA, were also compared with results generated by the Congressional Budget Office using a different methodology. Results were found to be similar, with the COMPARE model generating a $4 \%$ higher increase in government spending, driven by a higher estimate of spending on premium and cost-sharing subsidies related to the insurance exchanges.

\section{References:}

Ebiner C et al. (2010). Establishing State Health Insurance Exchanges. RAND Corporation.

RAND (2011). How the RAND COMPARE microsimulation model works. www.rand.org/health/projects/compare/how-it-works.html accessed January 2, 2012. 


\section{OECD HEALTH WORKING PAPERS}

A full list of the papers in this series can be found on the OECD website: www.oecd.org/els/health/workingpapers

No. 58 INCOME-RELATED INEQUALITIES IN HEALTH SERVICE UTILISATION IN 19 OECD COUNTRIES, 2008-09 (2012) Marion Devaux and Michael Delooper

No. 57 THE IMPACT OF PAY INCREASES ON NURSES' LABOUR MARKET: A REVIEW OF EVIDENCE FROM FOUR OECD COUNTRIES (2011) James Buchan and Steven Black

No. 56 DESCRIPTION OF ALTERNATIVE APPROACHES TO MEASURE AND PLACE A VALUE ON HOSPITAL PRODUCTS IN SEVEN OECD COUNTRIES (2011) Luca Lorenzoni and Mark Pearson

No. 55 MORTALITY AMENABLE TO HEALTH CARE IN 31 OECD COUNTRIES:ESTIMATES AND METHODOLOGICAL ISSUES (2011) Juan G. Gay, Valerie Paris, Marion Devaux, Michael de Looper

No. 54 NURSES IN ADVANCED ROLES: A DESCRIPTION AND EVALUATION OF EXPERIENCES IN 12 DEVELOPED COUNTRIES (2010) Marie-Laure Delamaire and Gaetan Lafortune

No. 53 COMPARING PRICE LEVELS OF HOSPITAL SERVICE ACROSS COUNTRIES: RESULTS OF A PILOT STUDY (2010) Luca Lorenzoni

No. 52 GUIDELINES FOR IMPROVING THE COMPARABILITY AND AVAILABILITY OF PRIVATE HEALTH EXPENDITURES UNDER THE SYSTEM OF HEALTH ACCOUNTS FRAMEWORK (2010) Ravi P. Rannan-Eliya and Luca Lorenzoni

No. 51 EFFECTIVE WAYS TO REALISE POLICY REFORMS IN HEALTH SYSTEMS (2010) Jeremy Hurst

No. 50 HEALTH SYSTEMS INSTITUTIONAL CHARACTERISTICS A SURVEY OF 29 OECD COUNTRIES (2010) Valerie Paris, Marion Devaux and Lihan Wei

No. 49 THE CHALLENGE OF FINANCING HEALTH CARE IN THE CURRENT CRISIS (2010) Peter Scherer, Marion Devaux

No. 48 IMPROVING LIFESTYLES, TACKLING OBESITY: THE HEALTH AND ECONOMIC IMPACT OF PREVENTION STRATEGIES (2009) Franco Sassi, Michele Cecchini, Jeremy Lauer and Dan Chisholm

No. 47 HEALTH CARE QUALITY INDICATORS PROJECT: PATIENT SAFETY INDICATORS REPORT 2009 (2009) Saskia Drösler, Patrick Romano, Lihan Wei; and ANNEX Saskia Drösler

No. 46 EDUCATION AND OBESITY IN FOUR OECD COUNTRIES (2009) Franco Sassi, Marion Devaux, Jody Church, Michele Cecchini and Francesca Borgonovi

No. 45 THE OBESITY EPIDEMIC: ANALYSIS OF PAST AND PROJECTED FUTURE TRENDS IN SELECTED OECD COUNTRIES (2009) Franco Sassi, Marion Devaux, Michele Cecchini and Elena Rusticelli 
No. 44 THE LONG-TERM CARE WORKFORCE: OVERVIEW AND STRATEGIES TO ADAPT SUPPLY TO A GROWING DEMAND (2009) Rie Fujisawa and Francesca Colombo

No. 43 MEASURING DISPARITIES IN HEALTH STATUS AND IN ACCESS AND USE OF HEALTH CARE IN OECD COUNTRIES (2009) Michael de Looper and Gaetan Lafortune

No. 42 POLICIES FOR HEALTHY AGEING: AN OVERVIEW (2009) Howard Oxley

No. 41 THE REMUNERATION OF GENERAL PRACTITIONERS AND SPECIALISTS IN 14 OECD COUNTRIES: WHAT ARE THE FACTORS EXPLAINING VARIATIONS ACROSS COUNTRIES? (2008) Rie Fujisawa and Gaetan Lafortune

No. 40 INTERNATIONAL MOBILITY OF HEALTH PROFESSIONALS AND HEALTH WORKFORCE MANAGEMENT IN CANADA: MYTHS AND REALITIES (2008) Jean-Christophe Dumont, Pascal Zurn, Jody Church and Christine Le Thi

No. 39 PHARMACEUTICAL PRICING \& REIMBURSEMENT POLICIES IN GERMANY (2008) Valérie Paris and Elizabeth Docteur

No. 38 MIGRATION OF HEALTH WORKERS: THE UK PERSPECTIVE TO 2006 (2008) James Buchan, Susanna Baldwin and Miranda Munro

No. 37 THE US PHYSICIAN WORKFORCE: WHERE DO WE STAND? (2008) Richard A. Cooper

No. 36 MIGRATION POLICIES OF HEALTH PROFESSIONALS IN FRANCE (2008) Roland Cash and Philippe Ulmann

No. 35 NURSE WORKFORCE CHALLENGES IN THE UNITED STATES: IMPLICATIONS FOR POLICY (2008) Linda H. Aiken and Robyn Cheung

No. 34 MISMATCHES IN THE FORMAL SECTOR, EXPANSION OF THE INFORMAL SECTOR: IMMIGRATION OF HEALTH PROFESSIONALS TO ITALY (2008) Jonathan Chaloff

No. 33 HEALTH WORKFORCE AND INTERNATIONAL MIGRATION: CAN NEW ZEALAND COMPETE? (2008) Pascal Zurn and Jean-Christophe Dumont

No. 32 THE PREVENTION OF LIFESTYLE-RELATED CHRONIC DISEASES: AN ECONOMIC FRAMEWORK (2008) Franco Sassi and Jeremy Hurst

No. 31 PHARMACEUTICAL PRICING AND REIMBURSEMENT POLICIES IN SLOVAKIA (2008) Zoltán Kaló, Elizabeth Docteur and Pierre Moïse

No. 30 IMPROVED HEALTH SYSTEM PERFORMANCE THROUGH BETTER CARE COORDINATION (2007) Maria M. Hofmarcher, Howard Oxley, and Elena Rusticelli

No. 29 HEALTH CARE QUALITY INDICATORS PROJECT 2006 DATA COLLECTION UPDATE REPORT (2007) Sandra Garcia-Armesto, Maria Luisa Gil Lapetra, Lihan Wei, Edward Kelley and the Members of the HCQI Expert Group 
DELSA/HEA/WD/HWP(2012)2

\section{RECENT RELATED OECD PUBLICATIONS}

HEALTH AT A GLANCE: ASIA/PACIFIC (2012) (forthcoming)

HEALTH AT A GLANCE: EUROPE (2012) (forthcoming)

OECD HEALTH DATA 2012 (Database available from http://www.oecd.org/health/healthdata)

OECD REVIEWS OF HEALTH SYSTEMS - RUSSIAN FEDERATION (2012)

OECD REVIEWS OF HEALTH CARE QUALITY - KOREA (2012)

SICK ON THE JOB? MYTHS AND REALITIES ABOUT MENTAL HEALTH AND WORK (2012)

OECD REVIEWS OF HEALTH SYSTEMS - SWITZERLAND (2011)

HEALTH AT A GLANCE 2011: OECD INDICATORS (2011)

See http://www.oecd.org/health/healthataglance for more information

HEALTH REFORM: MEETING THE CHALLENGE OF AGEING AND MULTIPLE MORBIDITIES (2011)

A SYSTEM OF HEALTH ACCOUNTS 2011 EDITION

HELP WANTED? PROVIDING AND PAYING FOR LONG-TERM CARE (2011)

IMPROVING VALUE IN HEALTH CARE: MEASURING QUALITY (2010)

IMPROVING HEALTH SECTOR EFFICIENCY - THE ROLE OF INFORMATION AND COMMUNICATION TECHNOLOGIES (2010)

MAKING REFORM HAPPEN - LESSONS FROM OECD COUNTRIES (2010)

VALUE FOR MONEY IN HEALTH SPENDING (2010)

OBESITY AND THE ECONOMICS OF PREVENTION: FIT NOT FAT(2010)

ACHIEVING BETTER VALUE FOR MONEY IN HEALTH CARE (2009), OECD HEALTH POLICY STUDIES

OECD REVIEWS OF HEALTH SYSTEMS - TURKEY (2009)

For a full list, consult the OECD On-Line Bookstore at www.oecd.org,

or write for a free written catalogue to the following address:

OECD Publications Service

2, rue André-Pascal, 75775 PARIS CEDEX 16

or to the OECD Distributor in your country 